DANIEL PEREZ DUARTE

Automação como Recurso de Planejamento de Redes de Distribuição de Energia Elétrica 
DANIEL PEREZ DUARTE

\title{
Automação como Recurso de Planejamento de Redes de Distribuição de Energia Elétrica
}

\author{
Dissertação apresentada à Escola \\ Politécnica da Universidade de São Paulo \\ para obtenção do título de Mestre em \\ Engenharia \\ Área de Concentração: \\ Sistemas de Potência \\ Orientador: \\ Prof. Dr. Marcos Roberto Gouvêa
}


Este exemplar foi revisado e alterado em relação à versão original, sob responsabilidade única do autor e com a anuência de seu orientador.

São Paulo, 11 de junho de 2008.

Assinatura do autor

Assinatura do orientador

FICHA CATALOGRÁFICA

Duarte, Daniel Perez

Automação como recurso de planejamento de redes de distribuição de energia elétrica / D.P. Duarte. -- ed.rev. -- São Paulo, 2008.

$127 \mathrm{p}$.

Dissertação (Mestrado) - Escola Politécnica da Universidade de São Paulo. Departamento de Engenharia de Energia e Automação Elétricas.

1. Sistemas elétricos de potência 2. Distribuição de energia elétrica 3. Distribuição de energia elétrica (Planejamento; Automação) 4. Custo de interrupção I.Universidade de São Paulo. Escola Politécnica. Departamento de Engenharia de Energia e Automação Elétricas II. t. 


\section{AGRADECIMENTOS}

Agradeço a Deus, pela saúde e força necessárias para a conclusão de mais esta etapa.

$\checkmark$ Ao meu orientador Prof. Dr. Marcos Roberto Gouvêa, pela amizade, paciência, incentivo e por estar sempre disponível e solícito às discussões que fizeram parte da elaboração deste trabalho;

$\checkmark$ Aos amigos eng. ${ }^{\text {os }}$ Antônio Paulo da Cunha, Henrique Kagan, João Carlos Guaraldo, Dr. Alden Uehara Antunes e prof. Dr. Nelson Kagan, pelas valiosas colaborações oferecidas;

$\checkmark$ Aos engenheiros Ivo Teixeira Domingues e Rodrigo Queiroga, da AES Eletropaulo, pelas importantes contribuições oferecidas ao longo do desenvolvimento do trabalho;

Aos professores coordenadores do Centro de Estudos em Regulação e Qualidade de Energia (ENERQ), que sempre acreditaram no meu potencial e à quem devo qualquer valor profissional que eu porventura tenha;

$\checkmark$ À minha família, em especial aos meus pais. Exemplos de dignidade sempre colocando a educação dos filhos em primeiro plano e à quem devo quaisquer virtudes que porventura tenha conquistado;

$\checkmark$ À minha noiva Carol pelo companheirismo, incentivo e compreensão nas horas que tiveram que ser dedicadas à elaboração deste trabalho;

$\checkmark$ À todos meus amigos que, direta ou indiretamente, contribuíram para a realização deste trabalho. 
"Fé inabalável só o é a que pode encarar frente a frente a razão em todas as épocas da Humanidade"

(Hippolyte Léon Denizard Rivail) 


\section{RESUMO}

Como produto de engenharia, os componentes das redes de distribuição de energia elétrica são, pela sua própria natureza, susceptíveis a falhas de funcionamento ou a ações de manutenção que impedem a operação de alguma instalação. No sentido de manter o desempenho adequado, nessas condições, são adotados critérios de planejamento e projeto que prevêem redundâncias de instalações, de forma que haja a continuidade de fornecimento de energia mesmo com componentes fora de operação.

Com alguma freqüência os sistemas de potência, principalmente em seus segmentos de transmissão e de distribuição de energia, adotam critérios de planejamento de suas instalações que consideram reserva de capacidade local ("N-1"local) para garantir a continuidade do serviço quando um de seus componentes está fora de operação.

Esse critério se reveste de um conceito qualitativo na medida que, em geral, não quantifica o prejuízo e o transtorno que uma falha pode provocar, nem os recursos operativos que podem permitir ao sistema suportar ações de manutenção programada, sendo dessa forma, insuficiente para a perfeita avaliação de alternativas de expansão da rede de distribuição.

Por outro lado, cálculo da Energia Não Distribuída - END - de forma probabilística para as falhas e de forma sistemática para eventuais interrupções durante as ações de manutenção preventiva é um recurso mais elaborado, de caráter quantitativo, para o dimensionamento da reserva de capacidade dos sistemas elétricos e portanto, de alternativas de expansão.

Com a introdução de dispositivos automáticos e meios de comunicação na rede de distribuição é possível a realização de manobras e transferências de carga de maneira a garantir a continuidade do fornecimento em níveis aceitáveis, substituindo, muitas vezes a instalação de novas estruturas como alimentadores ou mesmo subestações. Disto resulta uma redução de custo proporcionada pela otimização da 
capacidade instalada, necessária para reserva de contingência, sem prejuízo do desempenho e da qualidade de serviço.

O escopo deste trabalho é propor uma metodologia de planejamento fundamentada no custo da interrupção como uma alternativa ao critério $\mathrm{N}-1$, de forma a permitir a avaliação tanto da aplicação de recursos de automação como também dos recursos convencionais de expansão da rede.

A validação da metodologia proposta está ilustrada numa aplicação apresentada neste texto. 


\begin{abstract}
Concerning the components of an electrical distribution network and their susceptibility to functional failures or need for maintenance actions, planning and project criteria should be adopted to assure continuity of energy supply even though some components may be out of work. Traditionally the power systems, especially in power transmission and distribution, adopt the $\mathrm{N}-1$ criterion in the planning of its installations to keep the service continuity when one of the components is out of work. This criterion is based on a qualitative concept, in general, it does not quantify the loss and the inconvenience that a failure can cause, neither the operative resources that can allow the system to support programmed maintenance actions, thus being, insufficient for the perfect evaluation of expansion alternatives of the distribution network.
\end{abstract}

Whereas, the Non Distributed Energy calculus - NDE - a probabilistic approach for failures and a systematic approach for interruptions during the preventive maintenance actions is a more elaborated resource, based on a quantitative concept, for the dimensioning of capacity reserve of the electric systems and therefore, the expansion alternatives.

The introduction of the automatic devices and communication technologies in the distribution network make it possible to do maneuvers and load transfers in order to keep the supply continuity on acceptable levels, substituting, many times, the installation of new structures as feeders or even substations. The result is being cost reduction provided by the optimization from installed capacity, necessary to contingency reserve, without affecting the performance and service quality.

The scope of this work is to propose a planning methodology based on the cost of the NDE, which enables the evaluation of both the automation resources and conventional resources as well.

In this work you shall find an application of the methodology in a case study. 


\section{SUMÁRIO}

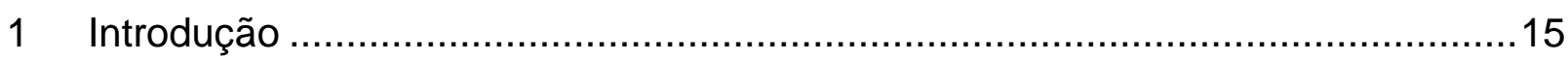

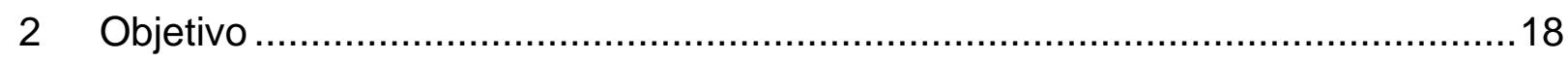

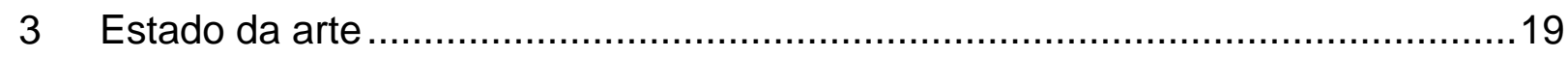

3.1 O planejamento de sistemas de distribuição .................................................................19

3.2 Visão geral da Automação da Distribuição …………………………………………........ 32

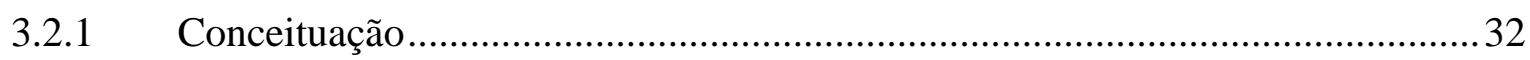

3.2.2 Arquitetura e Características Gerais de Sistemas de Automação .........................36

3.2.3 Automação de alimentadores de distribuição …………………………………....42

3.2.4 Novos dispositivos de Automação .......................................................................43

3.2.5 Sistemas de Comunicação na Automação de Redes de Distribuição ...................44

3.3 Custo da energia não Distribuída ............................................................................

3.4 Avaliação no campo de benefícios da Automação ........................................................54

3.5 Custos e benefícios da automação .............................................................................56

3.6 Alocação de dispositivos automáticos na rede de distribuição ......................................59

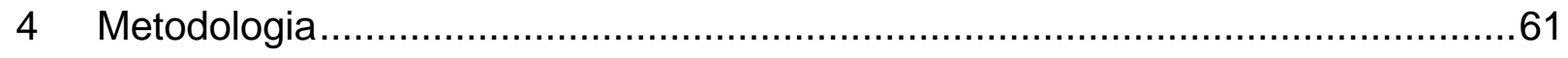

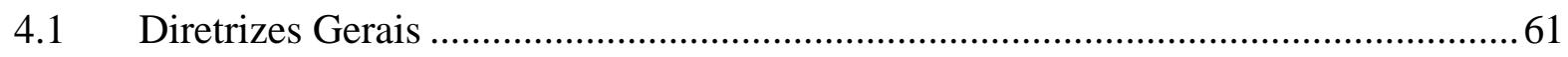

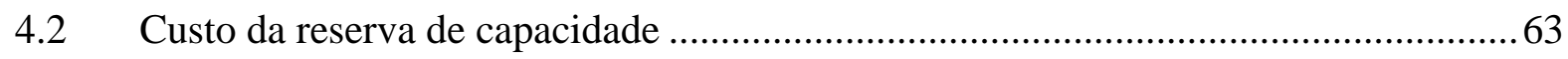

4.3 Planejamento considerando recursos de automação .......................................................

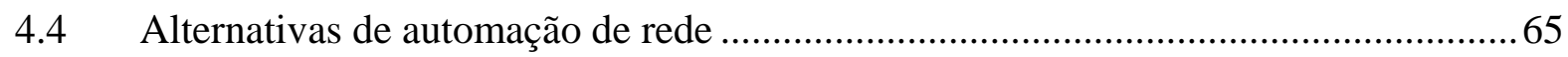

4.4.1 Caracterização das alternativas .............................................................................65

4.4.2 Portfolio de recursos de automação básicos .......................................................... 67

4.5 inserção de automação na rede de distribuição ............................................................75

4.5.1 Critério de Alocação de Recursos de Automação na Rede.....................................75 
4.5.2 Requisitos para Aplicação de Recursos de Automação na Rede 75

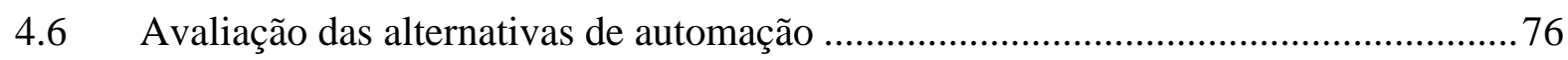

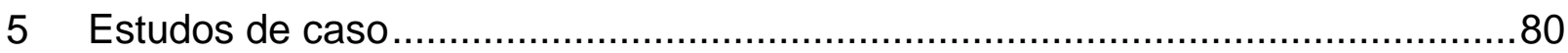

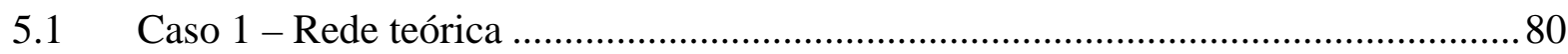

5.1.1 Descrição e alternativas de melhoria .................................................................. 80

5.1.2 Custos das alternativas e análises de sensibilidade..........................................82

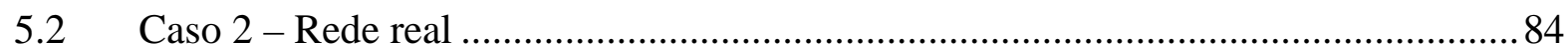

5.2.1 Características do sistema em estudo.......................................................... 84

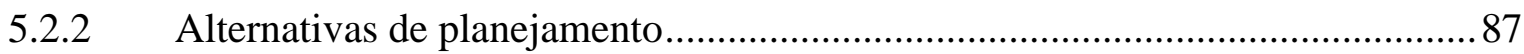

5.2.3 Análise da Alternativa com Recurso de automação ..........................................90

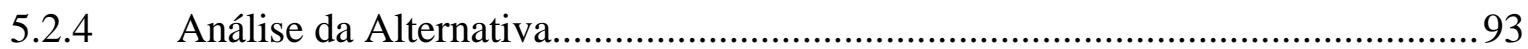

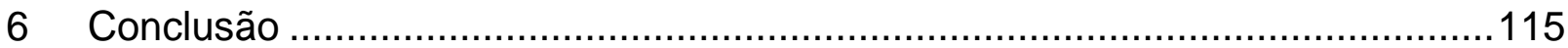

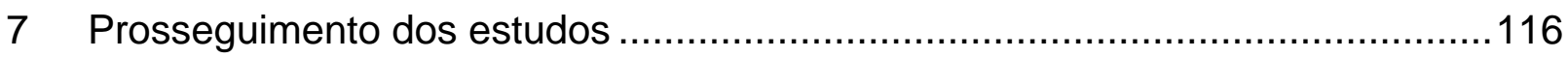

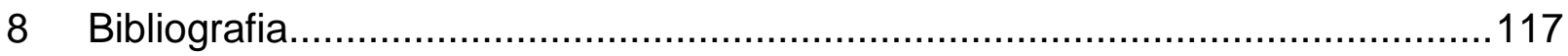

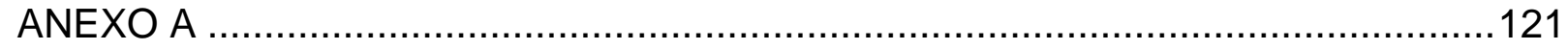




\section{LISTA DE TABELAS}

TABELA 3.1 - Faixas de tensão para pontos de entrega com tensão nominal igual ou inferior a $1 \mathrm{kV}$ 28

TABELA 3.2 - Faixas de tensão para pontos de entrega com tensão nominal superior a $1 \mathrm{kV}$ e inferior a $69 \mathrm{kV}$ 28

TABELA 3.3 - Custos de interrupção de fornecimento levantados na Itália 53

TABELA 3.4 - Benefícios da automação.......................................................... 56

TABELA 3.5 - Benefícios associados a cada funcionalidade de automação .......... 57

TABELA 4.1 - Recursos de automação propostos ……………………………. 74

TABELA 5.1 - Dados do sistema em estudo .................................................... 81

TABELA 5.2 - Cargas supridas e não supridas para cada alternativa durante a contingência do TR1 da SE1 82

TABELA 5.3 - Custos de investimento e manutenção ........................................ 82

TABELA 5.4 - Carregamento dos Alimentadores Envolvidos ………………....... 86

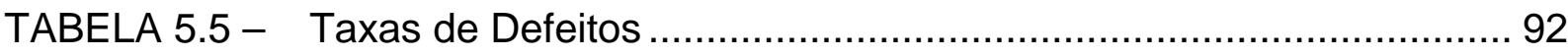

TABELA 5.6 - Tempos para o cálculo de END ……...........................................93

TABELA 5.7 - Carregamento dos Circuitos …......................................................... 95

TABELA 5.8 - Análise dos Blocos dos Troncos dos Circuitos ............................... 97

TABELA 5.9 - Blocos dos troncos dos circuitos com re-alocação de cargas prioritárias ......................................................................... 102

TABELA 5.10 - Benefício da instalação dos religadores "NA" no primeiro ano ..... 104

TABELA 5.11 - Impacto da instalação do religador ao longo do alimentador X2... 105

TABELA 5.12 - Impacto da instalação de dois religadores ao longo do alimentador

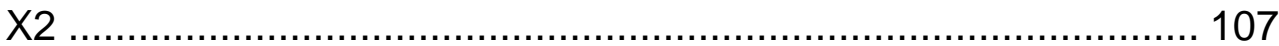

TABELA 5.13 - Impacto da instalação de três religadores ao longo do alimentador $\mathrm{X} 2$ 
TABELA 5.14 - Impacto da instalação de quatro religadores ao longo do alimentador

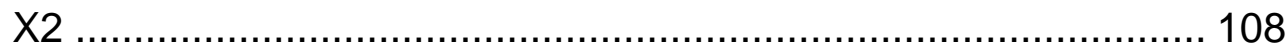

TABELA 5.15 - END Total do alimentador no $1^{\circ}$ ano para as alternativas

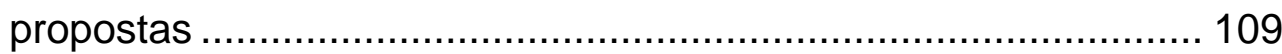

TABELA 5.16 - Tempo de retorno de investimento acumulado para as

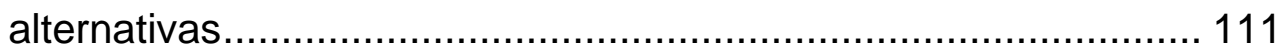

TABELA 5.17 - Tempo de retorno de investimento incremental das alternativas ... 111 


\section{LISTA DE FIGURAS}

FIGURA 3.1 - Planejamento de Redes de Distribuição ................................... 22

FIGURA 3.2 - Insumos para o Planejamento Tático .................................... 23

FIGURA 3.3 - Fluxograma básico do planejamento ..................................... 23

FIGURA 3.4 - Classificação dos Níveis de Tensão ........................................ 29

FIGURA 3.5 - Carregamento de Subestações .......................................... 30

FIGURA 3.6 - Carregamento dos Alimentadores ....................................... 31

FIGURA 3.7 - Elementos de um sistema de automação ................................ 35

FIGURA 4.1 - Representação do balanço entre custos de automação e END...... 62

FIGURA 4.2 - Fluxograma do planejamento com automação .......................... 65

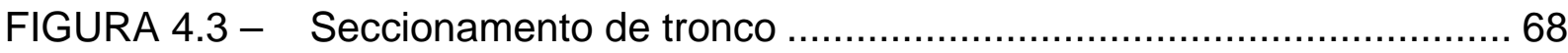

FIGURA 4.4 - Seccionamento de tronco com socorro automático ......................69

FIGURA 4.5 - Seccionamento de tronco de dois alimentadores com vis automático 71

FIGURA 4.6 - Duplo seccionamento de tronco com socorro automático............... 72

FIGURA 4.7 - Transferência automática de alimentadores entre subestações ..... 73

FIGURA 4.8 - Evolução das alternativas de automação................................ 79

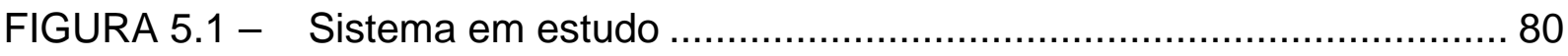

FIGURA 5.2 - Análise de sensibilidade ................................................. 84

FIGURA 5.3 - Topologia da Rede Primária em Estudo ................................. 87

FIGURA 5.4 - Trechos que Atendem Cargas Prioritárias ............................... 91

FIGURA 5.5 - Trechos que Atendem Cargas Prioritárias ................................. 91

FIGURA 5.6 - Trechos que Atendem Cargas Prioritárias ............................... 92

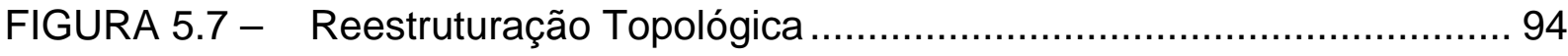


FIGURA 5.8 - Diagrama unifilar do sistema com a inserção de religadores "NA" .. 103

FIGURA 5.9 - Variação da END com o aumento da taxa de falhas para as cinco alternativas.

FIGURA 5.10 - Ganho acumulado das alternativas no primeiro ano 112

FIGURA 5.11 - Ganho anual não acumulado (incremental) das alternativas no primeiro ano

FIGURA 5.12 - Diagrama unifilar da alternativa escolhida para alocação dos religadores 


\section{INTRODUÇÃO}

Analisando a história do planejamento dos sistemas de energia elétrica observa-se que os critérios utilizados foram sempre no sentido de garantir a continuidade do fornecimento de energia através, principalmente, da redundância das instalações.

O "critério $N$-1" considerando reserva de capacidade local, tradicionalmente utilizado pelas concessionárias de distribuição para o planejamento de suas redes, parte do conceito de que o sistema deve continuar operando normalmente em caso de falha de um de seus componentes. Particularmente, nenhum consumidor (independente da potência instalada, tipo de consumidor etc.) deverá ficar sem fornecimento de energia se houver falha em algum componente do sistema supridor do circuito de distribuição que o alimenta ( $1^{\mathrm{a}}$ contingência), incluindo os equipamentos que constituem a subestação, sobretudo transformadores. Para tanto, é prevista uma redundância das instalações de forma a garantir o suprimento da carga em caso de defeitos em um componente.

Na maioria dos casos, a conseqüência da adoção desse critério de planejamento é a ocorrência de baixo fator de utilização da capacidade instalada, requerendo investimentos significativos por parte da concessionária, com longos períodos de retorno e conseqüentes efeitos negativos na tarifa.

No caso das subestações, além do nível de investimento envolvido, as limitações de espaço físico e as questões ambientais incluindo restrições requeridas pela comunidade vizinha e por órgãos do Poder Público são particularmente críticas em regiões urbanas com ocupação concentrada.

Devido à importância dessas questões, diversos estudos vêm sendo desenvolvidos para obtenção de ganhos de compactação física e de fator de utilização de instalações. Esses estudos vêm indicando a conveniência de se considerar a integração das subestações na rede com certo grau de automação. Todavia, a adoção desta prática considerando-se os procedimentos convencionais de 
planejamento e projeto, bem como as práticas operativas de redes não automatizadas, subutiliza as vantagens que poderiam ser obtidas.

Portanto, é necessário revisar critérios de planejamento e projeto para ter em conta os recursos de automação desde a etapa de concepção do plano de obras para atender a expansão do sistema.

Nesse cenário, a proposta de elaboração do planejamento da rede considerando a Energia Não Distribuída - END decorrente de cada alternativa de expansão se mostra razoável, na medida que avalia a confiabilidade que cada uma delas proporciona ao sistema.

Além disso, como a END é um parâmetro que contabiliza o "custo social" de uma interrupção de fornecimento, citada proposta avalia o nível de confiabilidade levando em conta a exigência de continuidade de cada tipo de consumidor.

Esses conceitos de planejamento e projeto devem orientar a especificação e a aplicação da automação, uma vez que a presença desse recurso introduz novas facilidades, recomendando a utilização de novas técnicas e procedimentos. Porém, atualmente nas empresas concessionárias de energia elétrica, sobretudo no setor de distribuição, soluções de automação de rede são tratadas no âmbito da operação do sistema, não sendo consideradas no processo de planejamento. Existe, desta forma, uma oportunidade de aproveitamento da sinergia, entre os recursos considerados nos processos de planejamento e operação.

Esta dissertação propõe que os recursos de automação possam competir com alternativas de expansão das estruturas das redes de distribuição, substituindo-as quando conveniente, de modo a permitir o aumento do fator de utilização das instalações sem prejuízo da qualidade de fornecimento. Assim, o benefício da implementação desses recursos na rede de distribuição em cada alternativa é quantificado, além dos custos de expansão de rede comumente utilizados no processo de planejamento (perdas, investimento etc.), por meio do correspondente custo de END, estabelecendo desta forma, os recursos de automação mais adequados, bem como um paralelo da relação custo/confiabilidade entre as 
alternativas e as soluções convencionais propiciadas pelo "critério $N$-1" de planejamento.

Esta dissertação está organizada em 8 capítulos, de modo que o Capítulo 2 apresenta o objetivo da pesquisa, o seguinte, Capítulo 3, contém o estado da arte com a análise de publicações sobre o tema, bem como conceitos e fundamentos utilizados. O Capítulo 4 apresenta a metodologia proposta, que é ilustrada no Estudo de Caso do capítulo seguinte. Finalizando o texto, o Capítulo 6 apresenta as conclusões do trabalho, o sétimo aponta os tópicos relevantes para o prosseguimento dos estudos e o último, oitavo, a bibliografia consultada. 


\section{OBJETIVO}

O objetivo desta dissertação é a concepção e a proposição de metodologia de planejamento fundamentada no custo da interrupção, como alternativa ao critério N-1, que considera a aplicação de automação como recurso de planejamento para o dimensionamento das instalações de reserva, com a preservação dos níveis de confiabilidade pré-estabelecidos.

Este trabalho contempla uma revisão dos critérios de planejamento utilizados atualmente, considerando parâmetros que permitem a quantificação dos benefícios proporcionados por uma alternativa de expansão, oriundos da automação em termos de Energia Não Distribuída (END).

Através da metodologia de planejamento proposta é avaliado o desempenho de cada alternativa de aumento da oferta de energia pela rede de distribuição, envolvendo a automação de rede, de forma a buscar a operação sinérgica entre seus componentes, visando a obtenção de reserva de capacidade sistêmica ao invés de local. 


\section{ESTADO DA ARTE}

Neste capítulo é apresentado o levantamento do estado da arte dos assuntos relativos ao tema objeto deste trabalho.

É apresentada inicialmente uma breve introdução acerca dos pontos que envolvem o planejamento de redes de distribuição seguido de uma abordagem geral da automação destas redes. Neste item será apresentado o conceito de automação considerado neste trabalho assim como referências bibliográficas que apontem as tendências do setor no que se refere à aplicação de recursos de automação em redes de distribuição, levando-se em conta os novos dispositivos existentes no mercado e os meios de comunicação disponíveis nos dias de hoje para viabilizar este conceito.

$\mathrm{Na}$ seqüência serão apresentados mais quatro itens com, respectivamente, o levantamento do estado da arte acerca da quantificação do custo de Energia Não distribuída, as metodologias propostas para avaliação da aplicação de recursos de automação, o levantamento dos custos e benefícios da aplicação destes recursos em redes de distribuição e, por fim, o levantamento de metodologias para alocação ótima de dispositivos automáticos na rede de distribuição.

\subsection{O PLANEJAMENTO DE SISTEMAS DE DISTRIBUIÇÃO}

Segundo a referência [1], o sistema de distribuição de energia pode ser classificado como:

- Sistema de Distribuição em Alta Tensão - SDAT;

- Sistema de Distribuição em Média Tensão - SDMT.

Embora haja semelhanças no planejamento para cada um dos tipos de sistemas, conforme citada classificação, os correspondentes processos de planejamento destes sistemas apresentam características específicas, justificadas pelas diferentes exigências que cada nível de tensão demanda dos planejadores, desde o processo de 
previsão de carga. Não obstante, o planejamento será abordado de forma geral neste tópico, apenas ressaltando-se as particularidades de cada tipo de sistema.

O planejamento da expansão das redes de alta e média tensão consiste em propor, analisar e selecionar alternativas de expansão da oferta para o atendimento do aumento da demanda, sempre que critérios de qualidade de fornecimento forem transgredidos. A alternativa de menor custo, que atende os critérios citados, é selecionada e produz o Plano de Obras para o período de estudo que compreende o intervalo entre uma data inicial, usualmente a data atual, até o ano horizonte.

$\mathrm{Na}$ referência [2], o autor ressalta a tendência crescente da realização do planejamento de um sistema de distribuição de forma separada para condição normal de operação da rede e para condição de emergência.

Ainda nesse artigo, o autor destaca que entre os resultados principais do planejamento da distribuição estão:

- Localização ótima de subestações;

- Localização ótima de alimentadores;

- Topologia ótima de alimentadores;

- Alocação ótima da reserva de capacidade em subestações.

O estudo de planejamento deve avaliar uma série de aspectos da rede existente que a diagnosticam, como por exemplo: o crescimento de carga da região, as fontes disponíveis em suas redondezas etc., e compatibilizar esses aspectos com os objetivos buscados pelo estudo que são, fundamentalmente, o atendimento da expansão do mercado em diversos cenários, dos anseios da sociedade por melhores níveis de qualidade de fornecimento, das restrições ambientais, considerando os recursos financeiros disponíveis e os condicionantes técnicos e econômicos.

Um estudo de planejamento de redes de distribuição pode ser dividido em três categorias [32]: 
Planejamento Estratégico (Agregado)

Longo prazo (>10 anos)

Planejamento Tático

Médio prazo (>5 anos)

Planejamento Operacional

Curto prazo (dias, semanas, meses)

\section{Planejamento Estratégico:}

É o planejamento de longo prazo visando a obtenção dos níveis de investimento a serem aplicados em toda a área de concessão da empresa. O sistema é analisado por meio de uma classificação e posterior agregação de suas redes em famílias de mesmas características. Como resultado é realizado um Plano Geral de Obras e de investimentos, necessário para atendimento do nível de qualidade almejado. Este Plano é subsídio para o planejamento tático.

\section{Planejamento Tático:}

É o planejamento de médio prazo, onde os componentes do sistema são representados de forma detalhada para a simulação do comportamento do sistema em condição normal e de contingência. A proposição das alternativas de expansão é fundamentada no Plano Geral de Obras proposto pelo Planejamento Agregado. Da alternativa de expansão resulta o Plano de Obras Detalhado.

\section{Planejamento Operacional:}

É o planejamento de curto prazo que considera apenas intervenções operativas na rede, com eventuais reformas de pequeno porte. Assim, são realizadas reconfigurações que alteram a topologia da rede, alocação de capacitores, remanejamento de cargas, pequenas extensões de rede, etc. É freqüente que o planejamento operacional proponha medidas para que a rede suporte atrasos de obras previstas ou aumentos de demanda imprevistos.

A Figura 3.1 apresenta um diagrama representando a relação entre os processos de planejamento de longo e médio prazo aplicados em uma rede de distribuição. 


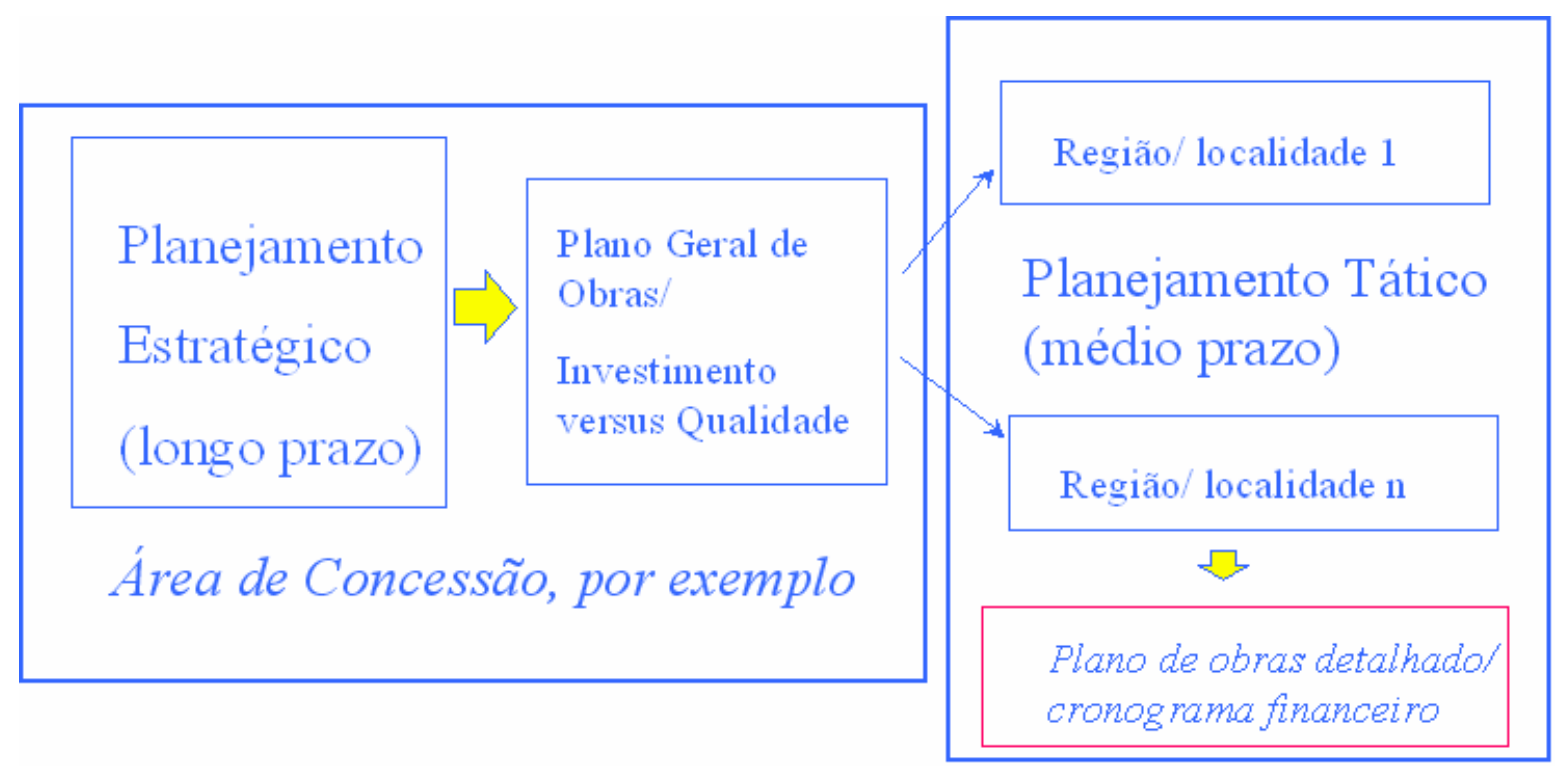

Figura 3.1 - Planejamento de Redes de Distribuição (32)

O foco desta dissertação situa-se no planejamento tático, de forma que esse segmento apresenta maior interesse e, portanto, é visto com maior detalhe a seguir.

O planejamento tático se fundamenta em uma série de premissas e critérios préestabelecidos, bem como na utilização de ferramentas de simulação do comportamento da rede operando em diversas alternativas de expansão propostas. Há vários métodos de otimização que permitem a seleção adequada de alternativas propostas. A partir dos resultados técnicos e econômicos dessas simulações, obtendo-se assim o Plano de Obras Detalhado para a região com proposição de obras e de outras providências para a expansão da oferta.

A Figura 3.2 apresenta os conjuntos de informações que fundamentam o desenvolvimento do planejamento tático de um sistema de distribuição. 


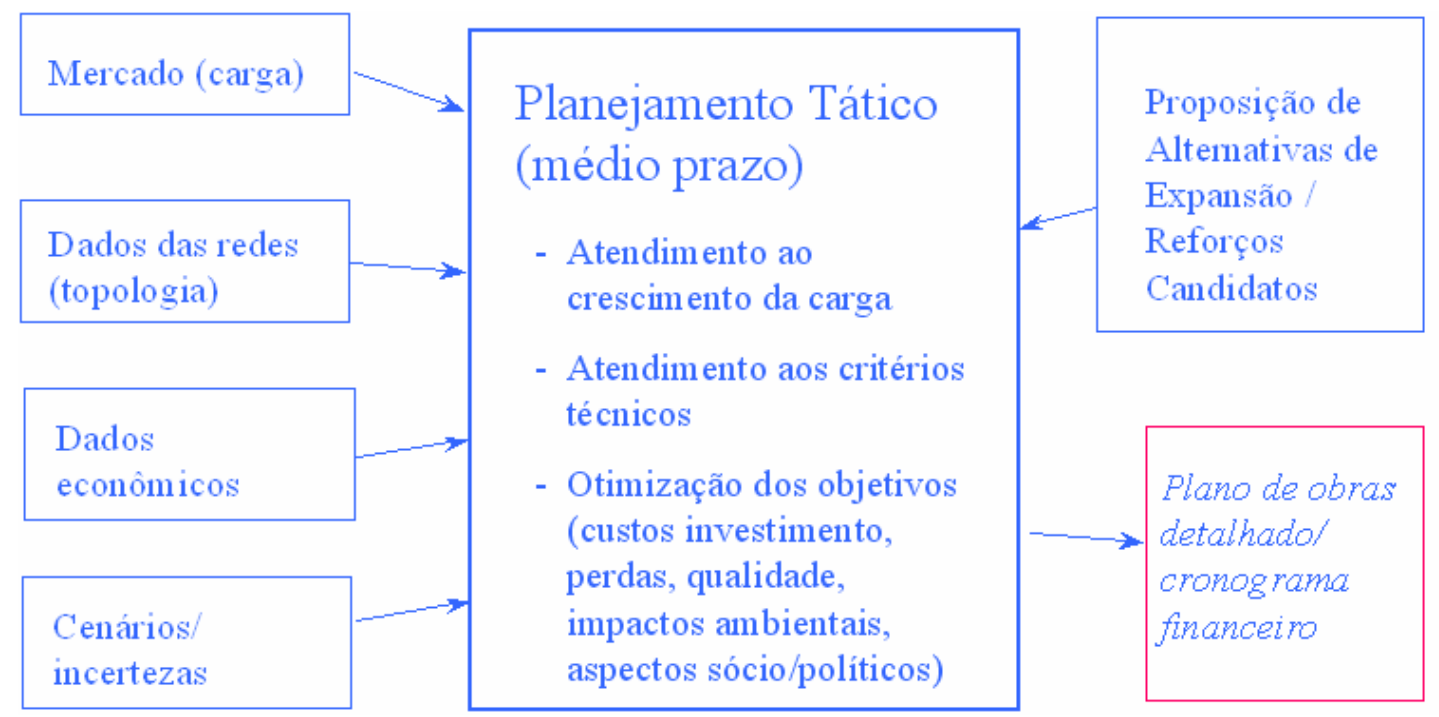

Figura 3.2 - Insumos para o Planejamento Tático (32)

A figura 3.3 apresenta um fluxograma que representa a seqüência de estudos a ser realizada no planejamento tático.

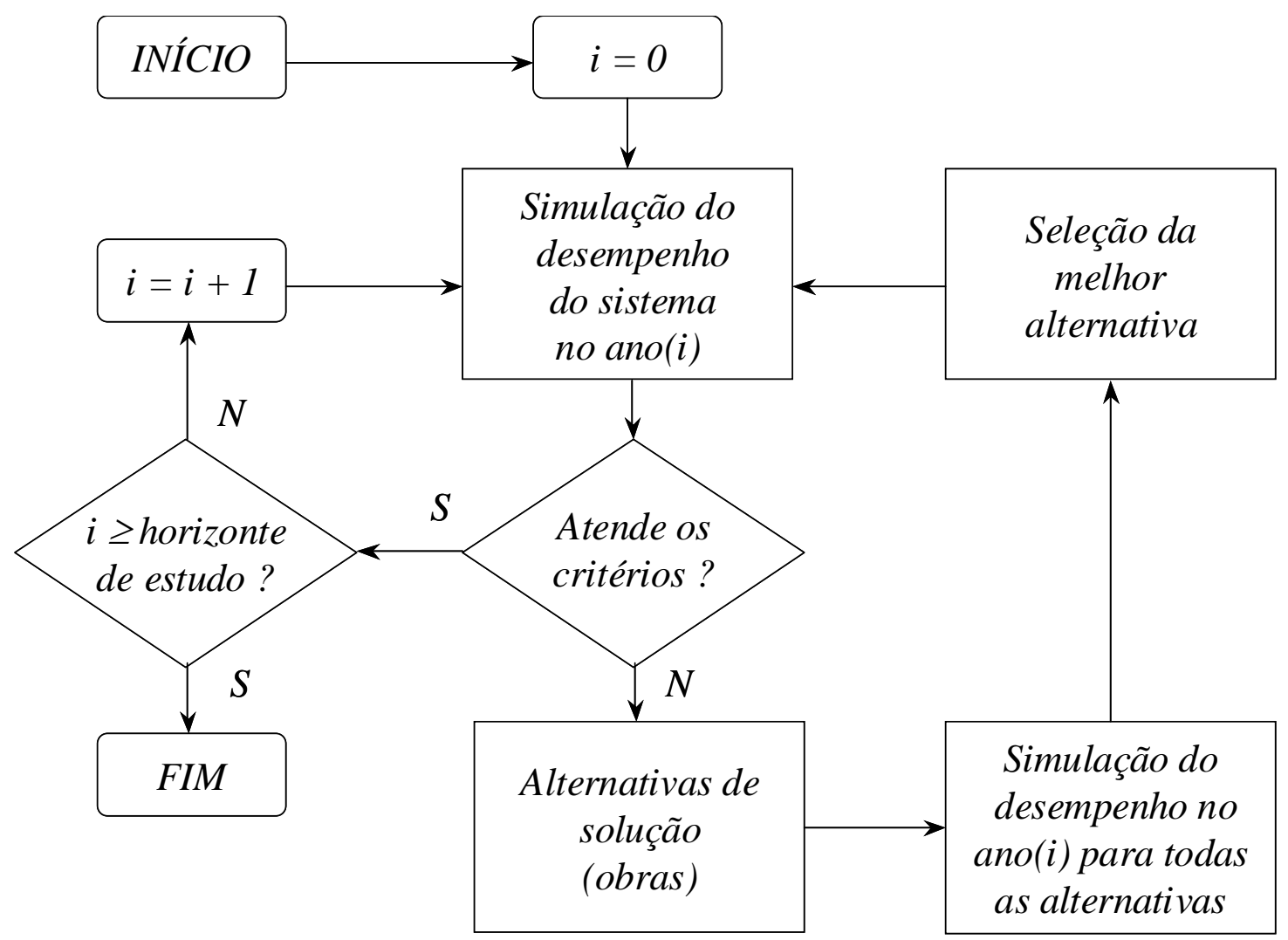

FIGURA 3.3 - Fluxograma básico do planejamento.

No fluxograma da figura 3.3 estão envolvidas as seguintes atividades: 
- Simulação do desempenho do sistema que consiste no processamento de casos de fluxos de potência em condição normal e de contingência para as situações mais relevantes ou críticas do período de estudo, usualmente de 5 anos. A análise da condição de contingência simples avalia o desempenho do sistema quando da saída de operação de cada um dos elementos da rede, a saber: uma unidade transformadora ou um trecho de linha para o planejamento da rede de AT e um trecho de alimentador para o planejamento da rede MT;

- Verificação do atendimento dos critérios de planejamento por meio da avaliação do desempenho da rede face às exigências de atendimento aos critérios de tensão e de carregamento das transformações, LT's e alimentadores, ajustando os fluxos de potência, conforme seja o caso;

- Proposição de alternativas de soluções para as transgressões de critérios, expressas por novas LT's, ampliação ou implantação de novas subestações, novos alimentadores, recondutoramento de alimentadores, reguladores de tensão ou bancos de capacitores, etc;

- Análise do desempenho das alternativas propostas e procedimento de ajustes convenientes, antecipando ou postergando investimentos, considerando a visão global dos reforços necessários para o atendimento da demanda ao longo do período de estudo;

- Seleção da melhor alternativa, entendida como sendo a mais econômica que atenda os critérios de planejamento pré-estabelecidos, a qual define o Plano de Obras que devem ser executadas no período. Entende-se por alternativa mais econômica aquela que apresentar o menor "custo total" e atender o critério préestabelecido de "esforço de investimento". "Custo total" de uma alternativa é a somatória do custo de investimento, de perdas, de END e de imperfeição de tensão, este último abordado a seguir. "Esforço de investimento", por sua vez, é definido por um montante arbitrário e pré-estabelecido de investimento a ser realizado nos "n" primeiros anos do período de estudo. 
Esse roteiro de planejamento pode ser executado com muita interferência do planejador, que utiliza ferramentas convencionais, como fluxo de potência, ou por meio de metodologias de otimização aplicadas em sistemas elétricos de potência.

Em [31] os autores classificam essas técnicas para resolução de problemas em sistemas de potência em três categorias:

- Técnicas baseadas na utilização de métodos de otimização clássicos;

- Modelos híbridos, que utilizam métodos de otimização em conjunto com métodos heurísticos;

- Técnicas que utilizam conceitos ou ferramentas da área de inteligência artificial.

Os autores apontam, para a aplicação em sistemas elétricos de potência, as seguintes técnicas:

\section{$\checkmark$ Programação Linear:}

Consiste em uma técnica que tem por objetivo a maximização ou minimização de uma função linear sujeita a restrições representadas por equações ou inequações lineares. [31]

Possui algumas variações em função da natureza das variáveis envolvidas no processo. Exige simplificações e é de difícil aplicação em casos onde há certo grau de subjetividade no processo, pois necessita de restrições bem claras e definidas, e também em casos onde algumas restrições não variam de forma linear (queda de tensão, perdas etc.).

O problema clássico desta técnica consiste na alocação de recursos limitados a atividades em competição, de forma ótima.

\section{$\checkmark$ Programação Não-Linear:}

Difere da primeira pois naquela a função objetivo e suas restrições são representadas por funções lineares nas variáveis de decisão, enquanto nesta, são representadas por funções não-lineares. 
Os autores em [31] salientam que esta técnica oferece menor robustez do que a primeira, uma vez que está sujeita a existência de soluções ótimas locais, que não representam a solução ótima global do problema.

\section{$\checkmark$ Programação Dinâmica:}

Esta técnica é uma importante alternativa para o tratamento de problemas com múltiplos estágios, como problemas de planejamento de redes. Neste caso o problema consiste na determinação de política ótima que determina a instalação de reforços durante o período de planejamento, considerando os diversos aspectos que envolvem o planejamento de redes de distribuição. [31] Para o problema de planejamento de redes de distribuição, estabelece-se o horizonte de estudo e as intervenções possíveis na rede (obras). Então o problema é decomposto em etapas de decisão que configuram subproblemas do problema geral.

Admite-se que, para um dado estado do problema, a política ótima dos estados subseqüentes não depende da política adotada até o presente estado, reduzindo dessa forma a quantidade de políticas possíveis para a solução do problema.

\section{$\checkmark$ Busca Heurística}

Uma técnica de busca consiste em, uma vez formada uma árvore de soluções possíveis para determinado problema, adotar-se critérios para a determinação de um percurso que resulte em solução que atenda as necessidades estabelecidas.

Tendo em vista a enorme quantidade de percursos possíveis, a aplicação de heurísticas no processo de busca se apresenta como importante solução visando minimizar os tempos de processamento através da otimização dos percursos analisados.

Em [31], heurística foi definida como uma técnica que, com base em informações específicas do domínio de um problema, permite tornar um processo de busca mais eficiente, reduzindo os tempos de processamento que, por muitas vezes, inviabilizam a aplicação de técnicas de busca. 
Os autores chamam a atenção ao fato de esta técnica não garantir solução ótima para o problema, podendo até gerar resultados errôneos caso a heurística não seja concebida de forma adequada.

\section{$\checkmark$ Algoritmo Genético}

Consiste em uma técnica baseada na teoria da evolução das espécies. Utilizase de analogias com mecanismos biológicos para a geração sucessiva de populações (estados dos problemas), de forma que cada geração formada apresente desempenho superior à passada rumo à solução ótima do sistema.

Os autores de [31] apontam que a grande vantagem desta técnica em relação as demais se deve a sua robustez, pois algoritmos genéticos:

- $\quad$ trabalham com uma codificação do conjunto de parâmetros;

- $\quad$ trabalham a partir de uma população de soluções alternativas;

- $\quad$ utilizam-se de informações da função objetivo;

- $\quad$ utilizam regras de transição probabilísticas para busca no espaço de soluções.

Fundamentalmente os critérios de planejamento que o sistema em análise deve respeitar nas simulações de situações operativas são de três naturezas:

a) Critério de Tensão

Considerando-se níveis de tensão pré-estabelecidos nos barramentos do sistema supridor, para situação de carga leve e pesada, o limite dos valores das tensões nas barras de Baixa Tensão e de Média Tensão, em condição normal e de emergência devem situar-se dentro da faixa estabelecida pela Resolução ANEEL 505/2001 conforme apresentam as Tabelas 3.1 e 3.2 para Baixa e Média Tensão, respectivamente

Os recursos permitidos para a obtenção e a manutenção desses níveis de tensão são:

- Ajustes nos tap's dos transformadores da subestação;

- Instalação de reguladores de tensão ao longo do alimentador; 
- Instalação de bancos de capacitores ao longo do alimentador;

- Recondutoramento de um trecho de alimentador;

- Remanejamento da carga entre alimentadores próximos.

TABELA 3.1 - Faixas de tensão para pontos de entrega com tensão nominal igual ou inferior a 1kV [23].

\begin{tabular}{|c|c|c|c|c|}
\hline \multicolumn{5}{|c|}{ TENSÕES NOMINAIS PADRONIZADAS } \\
\hline \multicolumn{2}{|c|}{ Tensão Nominal (TN) } & \multirow{2}{*}{$\begin{array}{c}\text { Faixa de Valores } \\
\text { Adequados das } \\
\text { Tensões de Leitura (TL) em } \\
\text { relação à TN (Volts) }\end{array}$} & \multirow{2}{*}{$\begin{array}{c}\text { Faixa de Valores } \\
\text { Precários das } \\
\text { Tensões de Leitura (TL) em } \\
\text { relação à TN (Volts) }\end{array}$} & \multirow{2}{*}{$\begin{array}{c}\text { Faixa de Valores } \\
\text { Criticos das } \\
\text { Tensões de Leitura (TL) } \\
\text { em relação à TN (Volts) }\end{array}$} \\
\hline Ligação & Volts & & & \\
\hline \multirow{2}{*}{ Trifásica } & $(220) /(127)$ & $\begin{array}{l}(201 \leq \mathrm{TL} \leq 231) / \\
(116 \leq \mathrm{TL} \leq 133)\end{array}$ & $\begin{array}{c}(189 \leq \mathrm{TL}<201 \text { ou } \\
231<\mathrm{TL} \leq 233) / \\
(109 \leq \mathrm{TL}<116 \text { ou } \\
133<\mathrm{TL} \leq 140) \\
\end{array}$ & $\begin{array}{c}(\mathrm{TL}<189 \text { ou } \mathrm{TL}>233) / \\
(\mathrm{TL}<109 \text { ou } \mathrm{TL}>140)\end{array}$ \\
\hline & $(380) /(220)$ & $\begin{array}{c}(348 \leq \mathrm{TL} \leq 396) / \\
(201 \leq \mathrm{TL} \leq 231)\end{array}$ & $\begin{array}{c}(327 \leq \mathrm{TL}<348 \text { ou } \\
396<\mathrm{TL} \leq 403) / \\
(189 \leq \mathrm{TL}<201 \text { ou } \\
231<\mathrm{TL} \leq 233) \\
\end{array}$ & $\begin{array}{l}(\mathrm{TL}<327 \text { ou } \mathrm{TL}>403) / \\
(\mathrm{TL}<189 \text { ou } \mathrm{TL}>233)\end{array}$ \\
\hline \multirow{2}{*}{ Monofásica } & $(254) /(127)$ & $\begin{array}{c}(232 \leq \mathrm{TL} \leq 264) / \\
(116 \leq \mathrm{TL} \leq 132)\end{array}$ & $\begin{array}{c}(220 \leq \mathrm{TL}<232 \text { ou } \\
264<\mathrm{TL} \leq 269) / \\
(109 \leq \mathrm{TL}<116 \text { ou } \\
132<\mathrm{TL} \leq 140) \\
\end{array}$ & $\begin{array}{l}(\mathrm{TL}<220 \text { ou } \mathrm{TL}>269) / \\
(\mathrm{TL}<109 \text { ou } \mathrm{TL}>140)\end{array}$ \\
\hline & $(440) /(220)$ & $\begin{array}{c}(402 \leq \mathrm{TL} \leq 458) / \\
(201 \leq \mathrm{TL} \leq 229)\end{array}$ & $\begin{array}{c}(380 \leq \mathrm{TL}<402 \text { ou } \\
458<\mathrm{TL} \leq 466) / \\
(189 \leq \mathrm{TL}<201 \text { ou } \\
229<\mathrm{TL} \leq 233)\end{array}$ & $\begin{array}{l}(\mathrm{TL}<380 \text { ou } \mathrm{TL}>466) / \\
(\mathrm{TL}<189 \text { ou } \mathrm{TL}>233)\end{array}$ \\
\hline
\end{tabular}

TABELA 3.2 - Faixas de tensão para pontos de entrega com tensão nominal superior a $1 \mathrm{kV}$ e inferior a $69 \mathrm{kV}[23]$.

\begin{tabular}{|c|c|}
\hline Classificação da Tensão de Atendimento (TA) & $\begin{array}{c}\text { Faixa de variação da Tensão de Leitura (TL) em } \\
\text { relação à Tensão Contratada (TC) }\end{array}$ \\
\hline Adequada & 0,93 TC $\leq$ TL $\leq 1,05$ TC \\
\hline Precária & 0,90 TC $\leq$ TL $<0,93$ TC \\
\hline Crítica & TL $<0,90$ TC ou TL $>1,05$ TC \\
\hline
\end{tabular}

Tradicionalmente, o critério de aceitação de uma alternativa, quanto aos níveis de tensão, se fundamenta simplesmente na pertinência dos valores de tensão ao intervalo pré-estabelecido pela citada Resolução, mas a referência [32] propõe uma forma de diferenciar qualitativamente o mérito das alternativas em função dos valores efetivos da tensão de cada barra, por meio da curva apresentada na figura 3.4.

Segundo esse modelo, a energia fornecida sob tensão fora da faixa regulamentada (ou arbitrariamente pré-estabelecida) é tão mais penalizada quanto mais distante dos 
limites admissíveis. As barras que operam com valores de tensão fora da faixa crítica (ou de valores arbitrariamente pré-estabelecidos) contribuirão com uma penalização à alternativa que pertencem, como se não estivessem sendo atendidas.

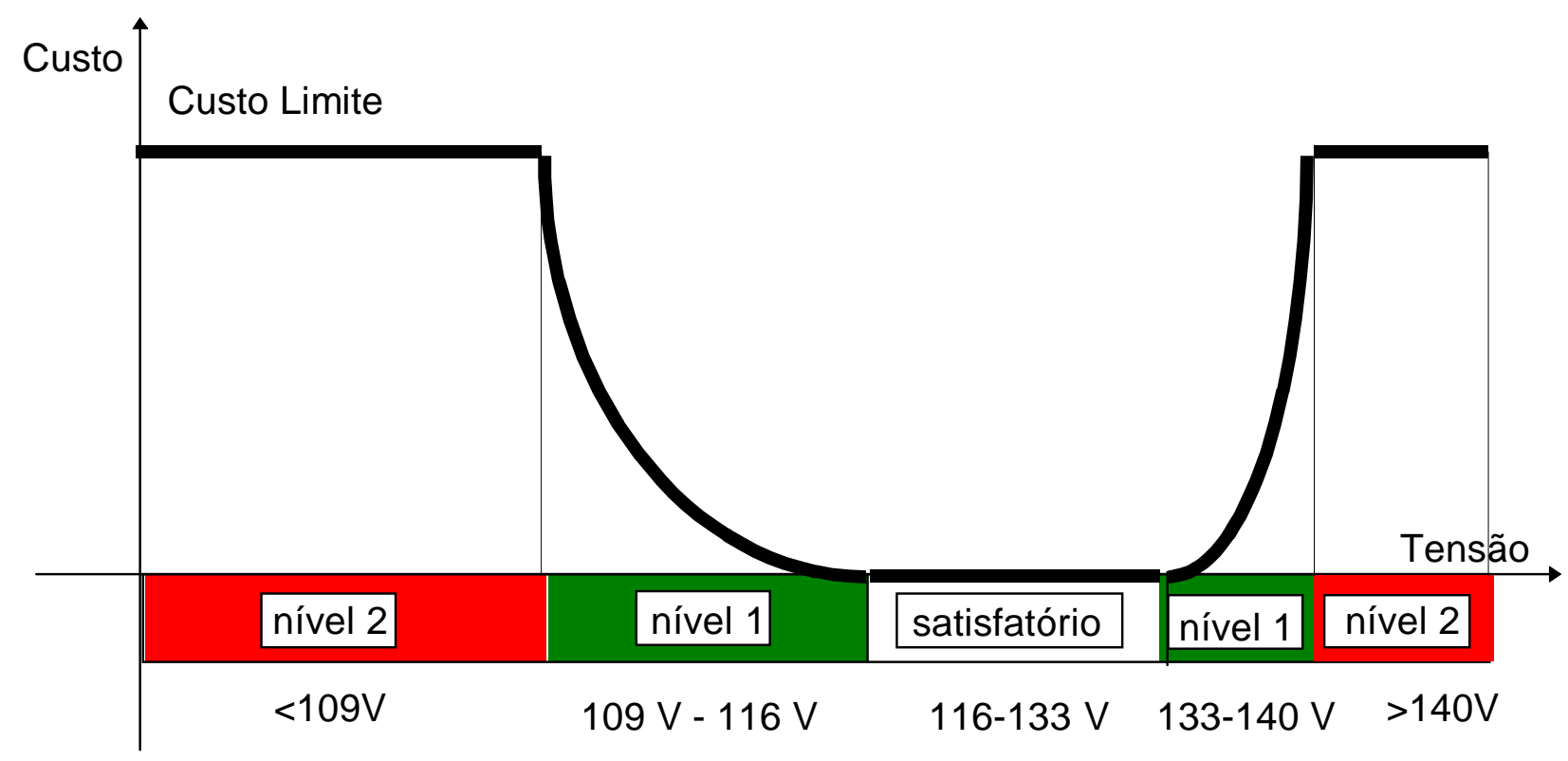

Figura 3.4 - Classificação dos Níveis de Tensão [32]

b) Critério de Carregamento

O carregamento máximo para operação em condição normal e de contingência, conforme o componente:

- Linhas de transmissão:

O limite máximo admissível de corrente é determinado pela temperatura estabelecida em projeto em condição normal (contínua) e de sobrecarga (contingência), que considera a menor distância do condutor ao solo provocada pela dilatação devida ao aquecimento, velocidade de vento e insolação.

- Subestações:

O carregamento máximo dos transformadores de uma subestação é determinado pela sua capacidade de não perder vida útil, operando sob um diagrama de carga típico pré-estabelecido, em condição de contingência de 
uma unidade da subestação. Assim, a capacidade firme de uma subestação $\left(S_{\text {firme }}\right)$ é dada por:

$S_{\text {firme }}=S_{\text {nom }} \cdot f_{\text {sob }} \cdot(n-1)+S_{\text {transf }}$

onde:

$S_{\text {nom }}=$ Potência instalada na subestação;

$f_{\text {sob }}=$ Fator de sobrecarga admissível sem que haja perda de vida;

$S_{\text {transf }}=$ Montante de carga passível de ser transferido à subestação vizinha em caso de contingência;

$n$ = Número de transformadores na subestação.

A figura 3.5 ilustra esse critério.

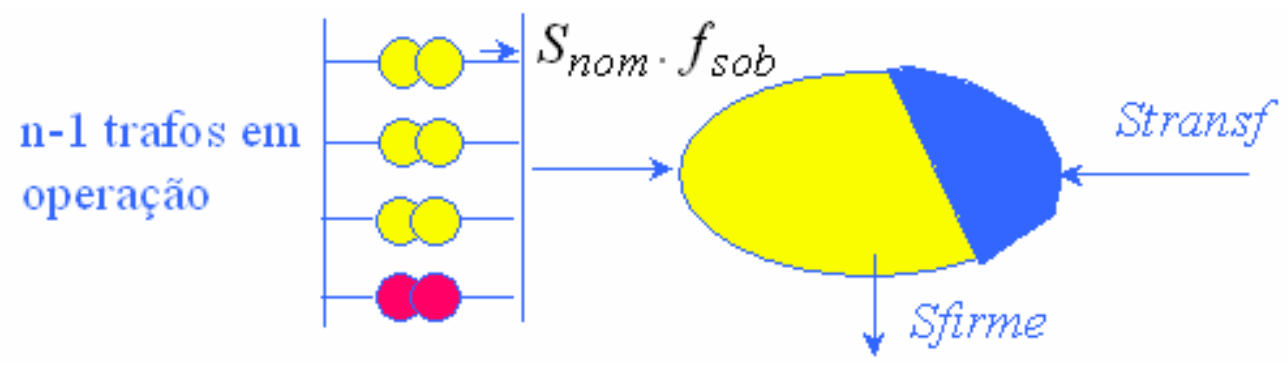

Figura 3.5 - Carregamento de Subestações [32]

Deve-se destacar que a inserção de elementos de automação na rede racionaliza a utilização da capacidade transformadora, porquanto potencializa possibilidades de transferência de carga e possibilita a utilização da reserva de capacidade regional, envolvendo um grupo de subestações.

- Alimentadores:

O limite máximo admissível de corrente é determinado pela temperatura estabelecida pelo fabricante, nas condições de operação contínua (condição normal), limitada pela reserva de capacidade para o atendimento de cargas transferidas por outros alimentadores durante condições de contingência que os afetam. Usualmente é utilizado o critério de 2 alimentadores terem capacidade de atender uma parcela significativa da carga total de um terceiro em contingência, 
com isso, uma regra prática de projeto que vem sendo utilizada é limitar a capacidade de corrente de um alimentador de $75 \%$ a $85 \%$ de sua capacidade máxima admissível.

Assim a capacidade firme do alimentador $\left(S_{\text {regime }}\right)$ é

$$
S_{\text {regime }}=\frac{S_{\text {termico }} \cdot(n-1)+S_{\text {rejeitada }}}{n}
$$

onde:

$S_{\text {térmico }}=$ Limite térmico de condução de corrente do cabo;

$S_{\text {rejeitada }}=$ Carga do bloco onde ocorre o defeito;

$n$ = Número de alimentadores envolvidos nas transferências de carga.

A figura 3.6 ilustra esse critério.

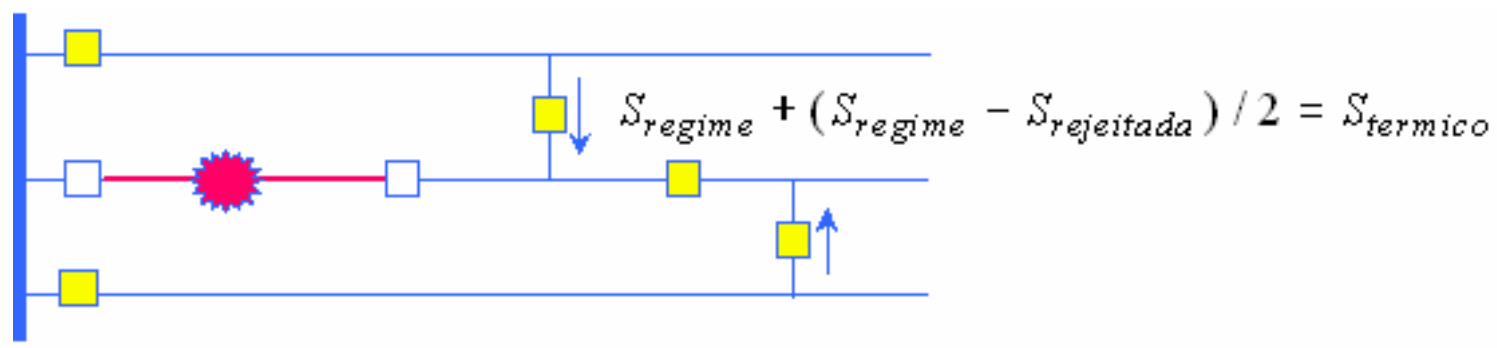

Figura 3.6 - Carregamento dos Alimentadores [32]

Observa-se que o critério mencionado se aplica ao tronco do alimentador e, eventualmente a ramais que integram a trajetória da corrente transferida em situações de contingência quando a configuração da rede é modificada em relação àquela de condição normal de operação.

Ramais que não participam de ações de contingência, sempre atendendo radialmente a cargas conhecidas, devem operar com carregamento limitado à própria corrente máxima admissível. 
À semelhança do que ocorre nas subestações, a utilização de automação pode melhorar o fator de utilização das instalações, pela racionalização e agilização na transferência de cargas, durante contingências.

c) Critério de Continuidade

O sistema em planejamento deve operar em condições de contingências, sem que haja corte de carga superior a um montante pré-estabelecido.

Usualmente a condição de contingência é caracterizada pela operação do sistema em contingência simples, ou seja, o sistema deve operar, sem que haja corte de carga superior a um montante pré-estabelecido, quando um de seus elementos estiver fora de serviço. Entende-se por elemento: um transformador de subestação, um trecho de linha de transmissão ou um trecho de alimentador limitado entre dois equipamentos de chaveamento capazes de isolá-lo. Evidentemente, as cargas atendidas pelo trecho de alimentador fora de serviço só são restabelecidas quando o defeito for reparado.

O montante de carga que pode permanecer sem fornecimento, a cada contingência simples, é pré-estabelecido, fundamentado na expectativa de defeitos e tempo de restabelecimento, de forma que não haja transgressão do limite do indicador regulado de continuidade: DEC - duração equivalente de interrupção.

\subsection{VISÃO GERAL DA AUTOMAÇÃO DA DISTRIBUIÇÃO}

\subsubsection{Conceituação}

Neste texto, recursos de automação são entendidos como um conjunto de instalações que, a partir de informações que expressam as condições de operação do sistema de distribuição, atuam sobre a rede ou subestação, usualmente via chaveamentos remotos.

Dentre as funcionalidades típicas da automação da distribuição pode-se citar: 
- Automação dos alimentadores, incluindo:

- Seccionamento e isolação de faltas;

- Reconfiguração remota;

- Chaveamento de bancos de capacitores

- Monitoramento do carregamento e tensão.

- Automação de subestações, compreendendo:

- Supervisão da operação, incluindo medições e estado dos elementos de seccionamento, balanceamento de cargas entre transformadores

- Telecomando sobre as instalações, incluindo atuação no load tap changer (LTC)

Os Sistemas de Automação são constituídos dos seguintes elementos:

- Sensores e transdutores, que são unidades analógicas ou digitais geradoras de sinais que expressam valores de grandezas ou estados de partes da rede de distribuição, incluindo dentre outros:

- Transformadores de corrente;

- Transformadores de potencial;

- Voltímetros;

- Amperímetros;

- Termômetros;

- Manômetros;

- Indicador de status (aberto/fechado) do equipamento;

- Indicador de falta;

- Medidores digitais.

- Centro de monitoramento e decisão, que recebe e analisa as informações dos sensores/transdutores e a partir delas, toma decisões que resultam em comandos automáticos ou realizados pelo operador (sinalizações) a equipamentos de chaveamento, podendo ser: 
- O próprio operador locado em um centro de operações,

- Operador que opera localmente os equipamentos;

- Processadores autônomos programados (Unidades de Aquisição e Controle);

- Acessório acoplado ao próprio equipamento de chaveamento (por ex.: acionador de seccionalizadoras que opera a partir da contagem de operações seguidas de abertura e fechamento da chave).

- Centro de sinalização que consiste em dispositivo que informa valor ou condição de alguma variável de estado associada a equipamento da rede, acionando alarmes, registrando valores, armazenando variáveis ou promovendo ações dessa natureza, podendo ser:

- Displays;

- Unidade de sinalização ou alarme;

- Unidade de armazenamento.

- Estrutura de comunicação, que é constituída de transdutores e de rede de comunicação que trazem as informações dos sensores de estado ao centro de decisão, deste para o centro de sinalização e ainda, enviam os sinais de comando aos equipamentos de chaveamento. Os tipos de tecnologia disponíveis para comunicação estão apresentados no item 3.2.5 deste trabalho

- Equipamentos de manobra são dispositivos de potência capazes de energizar ou interromper a corrente em condição normal de operação ou em situação de falta, conforme suas características específicas. Dentre outros são:

- Disjuntores;

- Secionadores automatizados;

- Religadores;

- Seccionalizadores associados a religadores.

A figura 3.7 apresenta esses elementos de forma esquemática.: 


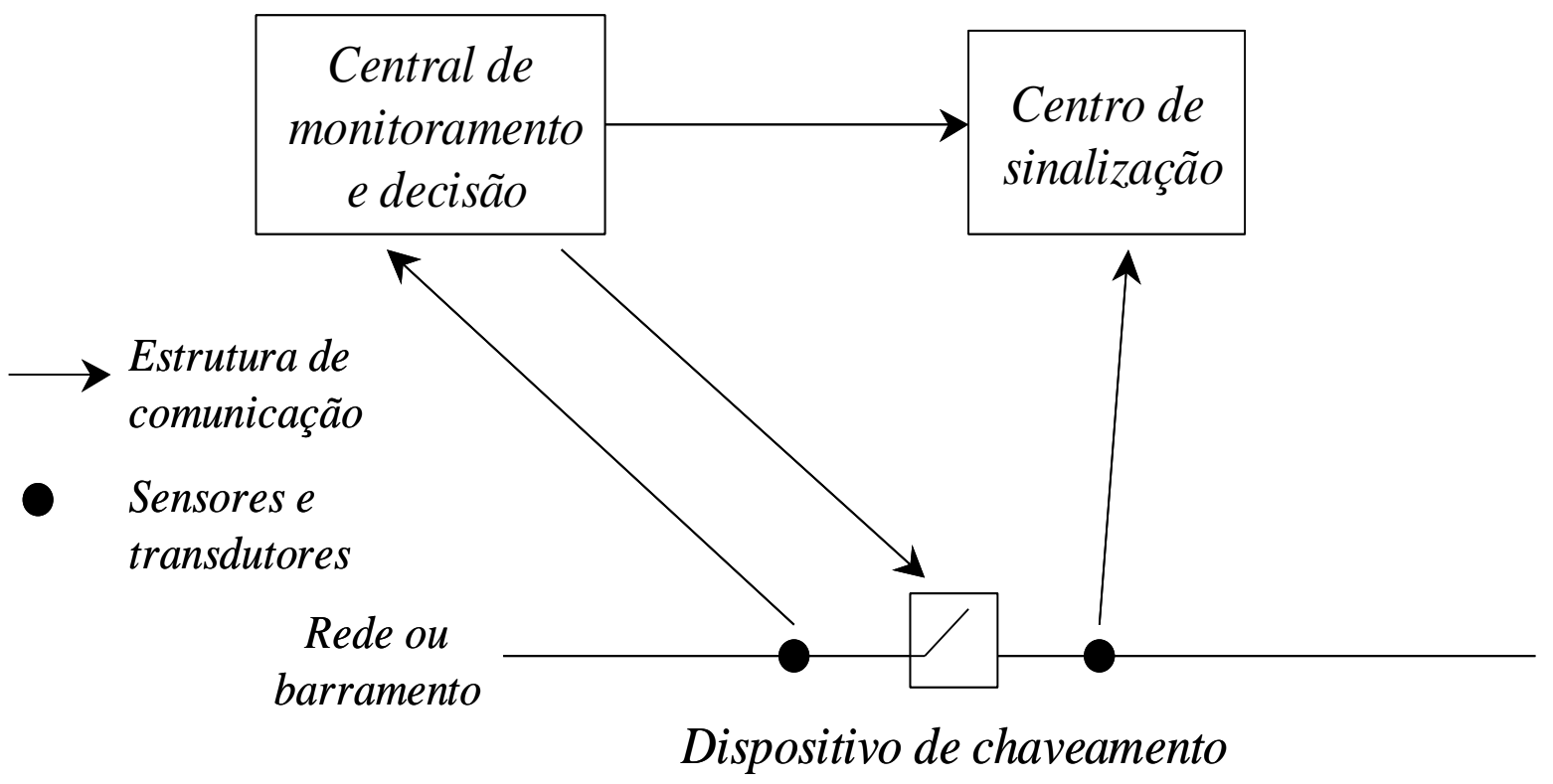

FIGURA 3.7 - Elementos de um sistema de automação.

O sistema de automação pode ser, por exemplo, um simples religador, onde o sensor de estado é um TP que fornece sinal indicando a ausência tensão ao centro de decisão, o qual pode estar situado no próprio religador (relé digital) ou em um centro de operações. O suporte de telecomunicação é o conjunto de cabeamentos locais que conecta os sensores ao contador/temporizador e este ao disjuntor (do religador) e, por sua vez, o equipamento de manobra é o próprio disjuntor do religador. O centro de sinalização é o display do religador, que informa localmente a operação do religador, o número de operações de religamentos etc.

Por outro lado, um sistema de automação poderia ser constituído por um conjunto de religadores (equipamentos de manobra) instalados na rede de alimentadores, que são acionados por comandos que transitam por uma rede de fibra ótica (estrutura de comunicação), partindo de um centro remoto, que por sua vez analisa os sinais da rede (sensores) e toma decisões (centro de decisão) . O centro remoto pode estar sediado no centro de operações da empresa, emitindo informações para displays convenientes (centro de sinalização). 


\subsubsection{Arquitetura e Características Gerais de Sistemas de Automação}

O artigo [3] aborda qualitativamente a aplicação de Automação da Distribuição para melhoria da qualidade de serviço, aumento da flexibilidade e utilização dos ativos da rede, indicando que o planejamento dos novos sistemas deve levar em conta as novas tecnologias que permitam a automatização dos processos que envolvam a operação da rede.

A linha de pesquisa adotada neste artigo visa converter os sistemas atuais em redes com múltiplas alimentações primárias, de forma a obter um aumento de qualidade de fornecimento que evite até mesmo faltas momentâneas de suprimento.

Para isto diversas alterações na forma de realização atual do Planejamento, Proteção e Operação precisam ser introduzidas.

São indicadas quatro linhas a serem desenvolvidas:

- Novos esquemas de proteção, com religadores eletrônicos automatizados;

- Sistemas de telecomunicação de alta velocidade, para isolamento de faltas em poucos ciclos e em porções restritas da rede;

- Controle local, para comandar operações de alimentadores;

- Controle de áreas, com a função de realizar fluxos de potência em tempo real, detectar violações de critérios e executar ações corretivas.

É proposta a divisão do sistema em partes completamente "isoláveis", denominadas de Premium Operating Districts (PODs), pelo seccionamento automático dos alimentadores. Em caso de falta, os consumidores devem perceber apenas interrupções temporárias, necessárias para isolar o defeito e transferir a carga. 
A adoção do conceito de POD é considerada por si só uma mudança nos princípios de planejamento vigentes, requerendo definições de novas topologias e alocação ótima em função da expansão do sistema.

A referência [4], embora não tão recente, apresenta algumas reflexões interessantes sobre aplicação de automação.

Neste artigo as áreas de aplicação de automação estão organizadas da subestação até o consumidor.

Assim, na área de subestações de distribuição cita-se o equilíbrio de cargas nos transformadores e regulação de tensão pela atuação nos comutadores sob carga.

No caso dos alimentadores as aplicações usuais são: isolamento e seccionamento de trechos com defeito, acionamento remoto de chaves de interconexão, chaveamento de bancos de capacitores e monitoramento de tensão.

São mencionadas ainda áreas de atuação em consumidores residenciais, comerciais e industriais, não relevantes para esta dissertação, bem como avaliadas algumas alternativas de automação para monitoramento e controle, tais como:

- Aguardar que outras concessionárias sejam pioneiras, para seguir as experiências positivas e evitar as negativas, devido aos riscos representados pelas novas tecnologias. Segundo o autor esta abordagem não permite um ganho real de experiência e nem sempre gera soluções transplantáveis para outra realidade como aquele que se obtém com um piloto próprio;

- Confiar em dados coletados periodicamente por pessoas ao invés de dispor de relatórios detalhados, confiáveis e automáticos gerados em tempo real, ou quase real;

- Confiar em alarmes de consumidores, que apresentam o inconveniente de praticamente omitir informações de ocorrência de falta temporária, de nível de tensão inadequados e mesmo algumas de faltas persistentes. Nota-se que no 
último caso, a informação ainda deve ser processada por atendente para ser transmitida às turmas de operação;

- Confiar em estimativas sobre o comportamento das cargas, resultantes de condições de operação baseadas em consumo de energia, cuja precisão é insuficiente;

- Executar manualmente tarefas, ainda que seja necessário o aumento do efetivo que, em geral, resulta em elevação de custos e em dificuldades para manter a confiabilidade e o gerenciamento das informações;

- Transferir tarefas simples e de ação limitada a grupo de consumidores voluntários, selecionados por meio de notificação, que recebem em contrapartida algum benefício financeiro pelos encargos assumidos.

De uma forma geral o artigo procura mostrar que as alternativas à automação apresentam custos e desvantagens e que, na prática, a gestão das concessionárias já leva em conta a falta de automação ao estabelecer tarifas ou multas que incentivem hábitos de consumo compatíveis com as metas de fator de carga.

A importância da comunicação nas tecnologias de automação é enfatizada no artigo, uma vez que definem os parâmetros de quantidade e velocidade da informação. Não obstante o artigo seja datado de 1993, algumas das alternativas de sistemas de transmissão de dados citadas são atuais, como celular, power line carrier, etc. Assim, quanto a coleta de dados e ao tratamento das informações são destacados os seguintes pontos importantes para o bom funcionamento de um sistema de automação:

- Consistência e paridade:

É necessário que todos os componentes recebam um sinal de confirmação da efetiva ocorrência de uma ação solicitada. Conforme o caso, uma avaliação agregada (sobre um conjunto de dispositivos) pode substituir a utilização de uma comunicação bi-direcional, para minimizar custos; 
- Integração de Sistemas:

A integração dos sistemas de automação com outros sistemas, como 0 SCADA, o Call Center para reclamações de interrupção e o sistema de cadastro e topologia de redes, por meio de protocolos de comunicação convenientes, podem trazer benefícios importantes para a operação da rede;

- Fontes de dados:

É importante estabelecer critérios e prioridades de armazenamento dos dados coletados pelo sistema de automação, identificando aqueles que devem ser preservados em detrimento dos que devem ser descartados;

- Aplicação piloto:

A avaliação das modalidades e das funcionalidades de sistemas de automação deve ser realizada por meio de aplicações piloto que permitem identificar os procedimentos e recursos ineficazes ("toys") daqueles que efetivamente trazem benefícios ("tools").

Finalmente, em [3] são salientadas questões ligadas aos custos (fixos, incrementais e recorrentes) e benefícios (tangíveis e intangíveis) de forma qualitativa sem, entretanto, apresentar uma modelagem para avaliações dessa natureza.

$\mathrm{Na}$ referência [5], DOLEZILEK oferece uma visão abrangente dos componentes envolvidos num Sistema de Automação da Distribuição, onde Sistema de Automação é conceituado como sendo composto por sub-sistemas de Instrumentação e Controle, Comunicação e Medição Remota (se aplicável), cujos elementos são relacionados a seguir:

- Sub-sistema de instrumentação e controle:

- Transformadores de instrumentação (corrente e tensão);

- Transdutores para conversão de valores ou de CA para CC;

- Unidades de Aquisição e Controle;

- Medidores (tensão, corrente, energia, demanda); 
- Registradores digitais de faltas que iniciam o armazenamento de dados de tensão, freqüência, harmônicos, acionados por um sinal de trigger de uma condição anormal;

- Comutadores sob carga de transformadores (load tap changer);

- Controladores de religadores;

- Fontes de sincronização de tempo;

- Tradutores de protocolo;

- Interfaces homem máquina (IHM), usualmente um computador;

- Controladores lógicos programáveis, para receber sinais e atuar sobre transdutores segundo uma lógica pré-determinada;

- Relés digitais, que podem realizar medições sem necessidade de transdutores;

- Processador de comunicação, que atua como um concentrador de sinais de vários dispositivos do sistema.

- Sub-sistema de Comunicação e Medição Remota :

- Meio de comunicação, como : par trançado de cobre, linha telefônica, power line carrier, fibra óptica, sistemas sem fio;

- Conectores de comunicação (RS 232, RS 485) que operam sob protocolos especificados, como Modbus, DNP 3.0, IEC 60850, IEC 60870-5, proprietários, etc.

ROTH, em [6] , avalia arquiteturas de comunicação com inteligência centralizada ou autônoma, isto é, descentralizada ou local, ressaltando que as principais vantagens deste segundo tipo são a independência de comunicação, a alta sensibilidade e a velocidade de atuação. Todavia, alguns esquemas lógicos mais complexos, mesmo sob pena de algum atraso na atuação, podem requerer uma inteligência central.

Muitos sistemas com inteligência central utilizam chaves seccionadoras controladas remotamente ao passo que esquemas autônomos se baseiam na aplicação de religadores.

O autor propõe que a análise comparativa entre as opções acima seja feita através de índices de confiabilidade relacionados a interrupções momentâneas. Utilizando-se este critério os alimentadores longos com chaves telecontroladas comandadas 
centralizadamente sofrem, em toda a sua extensão, uma "piscada", pois o disjuntor da subestação deve atuar antes da chave abrir, enquanto que sistemas com religadores seccionam somente o trecho com falta. Embora o exemplo apresentado no artigo tenha sido construído para demonstrar as vantagens dos religadores, existem argumentos válidos a serem considerados.

São apresentadas também algumas considerações sobre alcance de proteção, favoráveis aos religadores e sugerindo que este pode ser um critério para alocação dos mesmos.

Em função das muitas possibilidades de dispositivos existentes, é sugerido um roteiro para implantação de sistemas de automação com os seguintes passos:

- Selecionar as informações necessárias para cada dispositivo de modo a otimizar a largura de banda e a resposta de canais de comunicação;

- Verificar a adequação dos protocolos de comunicação às informações desejadas;

- Escolher o meio de comunicação em função da infra-estrutura disponível;

- Determinar as formas de automação e controle para cada dispositivo;

- Avaliar os tempos de resposta e restabelecimento necessários.

O objetivo central do artigo é mostrar as vantagens dos religadores modernos, entre as quais está a capacidade de efetuar proteção direcional, oscilografia e substituir totalmente unidades terminais remotas.

Outro aspecto destacado é a integração entre sistemas de proteção digitais e automação, como mencionado em [7]. De fato, os relés digitais podem atuar como controladores lógicos programáveis para comandar a operação de dispositivos de seccionamento, uma vez que realizam medições de grandezas da rede e monitoram estados dos equipamentos de chaveamento. Desta forma são propostos alguns 
esquemas de automação para alimentadores, com comunicação entre os relés por fibra óptica ou rádio.

\subsubsection{Automação de alimentadores de distribuição}

$\mathrm{Na}$ referência [8], HART apresenta um tratamento atualizado para a automação de alimentadores de distribuição aéreos com religadores e seccionalizadores, tendo em vista requisitos regulatórios e aumento do nível de exigência dos consumidores.

O artigo traz exemplos didáticos que comprovam significativa redução na duração das interrupções obtidas pela utilização de religadores e seccionalizadoras a jusante de blocos de carga importantes.

Outro benefício considerado é a economia na substituição de elos fusíveis, resultante tanto da redução da utilização de material como também do custo de deslocamento de equipe de manutenção corretiva.

Os temas do custo e alocação ótima para dispositivos de seccionamento remoto automático são mencionados, por meio da indicação que o aumento de investimentos tende a não se refletir proporcionalmente na redução da duração das interrupções a partir de certo ponto. É mencionada a utilização de um software para determinação da estratégia otimizada de automação, em função de indicadores de confiabilidade e configuração da rede.

A necessidade de meios de comunicação também é tratada, citando-se formas usuais (físicas ou sem fio), protocolos padronizados, bem como filosofias locais (para um sub-conjunto de alimentadores) ou de aplicação mais ampla na rede.

Ao final é sugerida a montagem de sistemas para atender as necessidades específicas de cada empresa compostos de blocos integráveis (chave de operação remota, interface de comunicação, fontes, unidades terminais remotas, etc) para formar uma funcionalidade de automação bem definida. 
O artigo [9] tem abordagem similar ao acima, com exemplos da aplicação de religadores em alimentadores primários e seu efeito na redução das interrupções de longa duração e custos de implantação.

Cabe salientar que, dependendo da filosofia empregada na aplicação de religadores automáticos na rede de distribuição, há o surgimento de impactos sensíveis na qualidade de fornecimento devido a ocorrências de desligamentos de curta duração, que, dependendo do tipo de consumidor alimentado, pode ser tão prejudicial quanto uma interrupção de longa duração.

\subsubsection{Novos dispositivos de Automação}

Em [17] é apresentada uma chave classe $27 \mathrm{kV}$, cujas características foram projetadas para aplicação em automação. Tal equipamento incorpora sensores para monitoramento da corrente do alimentador em que se encontra, podendo ser acionado por comandos vindos de uma central de operação, a qual "interroga" as várias chaves instaladas ao longo de um trecho de rede, para identificar aquelas pelas quais houve correntes elevadas, permitindo o comando para abertura daquela mais próxima da falta.

Para obter redução de massa e tamanho, além de uma vida útil longa sem manutenção, o projeto do dispositivo adotou a interrupção de corrente através de garrafas a vácuo e isolamento sólido, a base de resina ciclo-alifática. O mecanismo de operação é atuado magneticamente, com consumo de energia de apenas 2 Ampéres.Segundo, o qual permite milhares de ciclos de abertura e fechamento sem recarga da bateria $(48 \mathrm{~V})$.

Do mesmo fabricante é o artigo [18] que trata da substituição de religadores hidráulicos monofásicos por equipamentos eletrônicos com nova tecnologia que inclui três modos de operação:

- Atuação e abertura trifásica;

- Atuação monofásica e abertura trifásica; 
- Atuação e abertura monofásica (restrito a cargas que tenham outros meios de proteção).

Para avaliação dos efeitos sobre os índices de confiabilidade de alimentadores dos diversos modos de atuação, foi desenvolvido um software que utiliza dados relativos de freqüência média de interrupção por faltas permanentes e momentâneas.

Este software é basicamente um simulador de faltas para diversas alocações e modos de atuação dos religadores. Os resultados indicam que a instalação de religadores em tronco de alimentadores melhora também a confiabilidade dos ramais.

\subsubsection{Sistemas de Comunicação na Automação de Redes de Distribuição}

Um dos principais desafios no processo de automação de redes de distribuição é o sistema de comunicação. Este sistema é essencial para o bom funcionamento de um sistema de automação da distribuição, uma vez que os equipamentos automatizados estão distribuídos ao longo da rede havendo a necessidade de transferência de dados entre esses e um centro de controle. [24]

Segundo a referência [24], existem duas classes de sistemas de comunicação, uma que não necessita de rede física para transferência de informações (rádio, celular etc.) e outra onde essa transferência é realizada através de rede física (telefonia, fibra ótica etc.).

No artigo [25] o autor apresenta as seguintes tecnologias como sendo as passíveis de serem utilizadas em um sistema de automação de rede:

\section{a) Rádio}

Esta tecnologia é a mais utilizada atualmente na automação de redes de distribuição. Esse sistema é composto por transmissores, receptores, repetidores, antenas e fontes supridoras de energia, de forma a permitir a comunicação entre 
diferentes pontos do sistema e entre esses e um centro de controle a distâncias de até $50 \mathrm{~km}$. [24]

As vantagens dessa tecnologia são:

$\checkmark$ Banda de dados relativamente larga [25];

$\checkmark$ Transferência de informações sem fio;

$\checkmark$ Funcionamento independente da condição da rede;

$\checkmark$ Custos geralmente mais baixos do que tecnologias que utilizam meio físico para transmissão de dados [24].

Enquanto as desvantagens [25] são:

$\checkmark$ Sensível a obstáculos físicos (relevo, prédios etc.) que dificultam aplicações em locais com relevo irregular e em centros urbanos;

$\checkmark$ Sensível ao clima;

$\checkmark$ Sensível a interferências eletromagnéticas.

b) Telefonia

Segundo [25], esse sistema pode ser de três tipos:

- Telefonia fixa: comunicação através de par telefônico, raramente utilizada nos dias de hoje devido a baixa confiabilidade, bem como banda de dados e taxa de transmissão pequenas.

- Telefonia celular: que consiste na comunicação feita através de rede de telefonia sem fio, utilizada muitas vezes em sistemas de automação de redes. As vantagens deste tipo em relação à telefonia fixa são:

$\checkmark$ Custo de instalação reduzido;

$\checkmark$ Rapidez de implantação;

$\checkmark$ Transferência de informações sem fio;

$\checkmark$ Funcionamento independente da condição da rede.

Enquanto a desvantagens são:

$\checkmark$ Tempo de resposta mais elevado;

$\checkmark$ Alto custo de operação (taxa de serviço). 
- Satélite: é apontado como opção onde não há disponibilidade dos demais sistemas. Sua viabilidade depende da utilização de protocolo compacto e pouca necessidade de comunicação com a central de controle.

O artigo [26] apresenta o caso da empresa Bandeirante Energia, que atende a 28 municípios do estado de São Paulo, onde a necessidade de implantação imediata de supervisão e telecontrole de religadores automáticos instalados na rede primária de distribuição fez com que a empresa desenvolvesse um sistema envolvendo uma micro-remota, que utiliza comunicação via celular, uma vez que a empresa ainda não dispõe dos equipamentos necessários para a implementação de um sistema de rádio.

Esta tecnologia está sendo aplicada em região piloto e vem apresentando desempenho satisfatório, com alta confiabilidade do sistema de comunicação empregado.

\section{c) Fibra Ótica}

Esta é uma tecnologia muito utilizada em sistemas de automação, que consiste em um meio físico muito confiável, porém com alto custo de instalação. Suas vantagens são:

$\checkmark$ Banda de dados larga;

$\checkmark$ Alta confiabilidade;

$\checkmark$ Imunidade a interferências eletromagnéticas;

$\checkmark$ Custo de operação praticamente nulo.

As desvantagens desse tipo de comunicação são:

$\checkmark$ Alto custo de instalação;

$\checkmark$ Sujeito a interrupção pela queda de poste. 
d) PLC - Power Line Communications

É um sistema de comunicação que usa a própria infra-estrutura da rede elétrica para a transmissão de dados em alta freqüência. Tecnologia pouco difundida, ainda em fase de estudo e desenvolvimento.

De acordo com o artigo [27], a empresa AES Eletropaulo que atende a região da Grande São Paulo, vem desenvolvendo estudos no sentido de se utilizar esta tecnologia para automação de redes, entre outras aplicações. Porém este estudo ainda se encontra em fase inicial, não havendo subsídios para avaliação de sua viabilidade.

Uma barreira importante para a adequada expansão e projeto de sistemas de comunicação é o protocolo de comunicação utilizado pelos vários dispositivos que o integram. Especialistas de vários países desenvolveram a norma internacional IEC 61850 que estabelece procedimentos e regras para permitir a comunicação entre diversos equipamentos existentes em uma subestação, considerando os condicionantes dos protocolos de comunicação. [28]

\subsection{CUSTO DA ENERGIA NÃO DISTRIBUÍDA}

Com o crescimento da economia e conseqüente avanço tecnológico, o grau de dependência da sociedade à energia elétrica cresce a cada instante. O aumento da industrialização, a implantação de linhas de produção contínuas e o aparecimento de tecnologias domésticas cada vez mais sensíveis a interrupções de fornecimento de energia promovem o aumento do grau de exigência da sociedade por um serviço de qualidade por parte da concessionária.

Surge então a necessidade de quantificar os danos causados por uma interrupção de fornecimento de maneira a estabelecer valores de referência para posterior análise da necessidade de investimentos em confiabilidade, assim como sua viabilidade financeira. 
Ressalta-se que esses valores dependem de vários fatores como o tipo de consumidor, a região, a disposição do consumidor a pagar por maior confiabilidade do fornecimento, entre outros.

Alguns tipos de processos industriais, por exemplo o têxtil e o papeleiro, são muito sensíveis a interrupções, uma vez que todo o processo pode ser perdido em decorrência de uma falta momentânea de energia. Também alguns tipos de serviços são muito sensíveis a interrupções do fornecimento de energia elétrica, como hospitais e transportes eletrificados urbanos, devido a importância do serviço prestado.

Sob a ótica da concessionária de distribuição de energia, o custo da interrupção, ou custo da END, envolve tanto custos diretos como o não faturamento da concessionária como custos subjetivos, que devem ser avaliados de forma indireta, como o impacto na imagem da empresa junto à sociedade.

No artigo [10] de 1997, os autores sugerem a composição do custo da END através dos seguintes custos:

- Custo do não faturamento: correspondente ao prejuízo obtido pela concessionária pela perda de receita causada pela interrupção de fornecimento, que pode ser estimado de forma direta através da tarifa praticada pela empresa;

- Custo do Déficit: está associado à falta de capacidade instalada para o suprimento da carga ou à restrições energéticas. Tais interrupções costumam ser longas e, por não serem intempestivas na maioria das vezes, permitem aos consumidores se precaverem a fim de minimizar os danos causados.

- Custo da Interrupção: consiste no prejuízo que o cliente terá em decorrência de defeitos intempestivos que são normalmente de curta duração. Neste caso não há a possibilidade do consumidor se precaver dos danos causados pela 
interrupção, a menos que haja fontes de suprimento alternativas que devem ser consideradas no custo da interrupção.

Ressalta-se que os autores não levaram em conta na quantificação do custo da END os impactos qualitativos da interrupção de fornecimento, como impacto na imagem da concessionária etc.

A referência [11] aponta uma metodologia para cálculo dos custos indiretos da interrupção que consiste na disposição dos consumidores a pagar por maior grau de confiabilidade. Esta metodologia, também conhecida por DPG, vem tornando-se uma forte tendência para o cálculo de custos dessa natureza, sendo utilizada para balizamento da distribuição de investimentos em melhoria do serviço. Este conceito acena para a implementação de tarifas diferenciadas para consumidores que estejam dispostos a pagar por melhor nível de qualidade do que aquele exigido pelo órgão regulador.

Na referência [12] são mostrados os resultados de um estudo realizado no Canadá com o intuito inicial de obter uma justificativa econômica para confiabilidade do fornecimento de energia elétrica. Uma vez que este objetivo se mostrou de difícil execução, adotou-se a abordagem complementar, isto é, a estimação do valor financeiro para os clientes da falta de confiabilidade.

A metodologia adotada, nesse artigo, foi o levantamento do impacto das interrupções de fornecimento através de questionários respondidos por clientes. Os questionários foram preparados de modo a entender a forma como o cliente utiliza a energia elétrica e o tipo de atividade envolvida, gerando assim meios de avaliar quantitativamente as perdas financeiras provocadas e sua relação com a duração, freqüência e demanda.

O artigo defende a aplicação de questionários como uma metodologia eficaz para a obtenção dos custos de indisponibilidade de energia. Para isto, a formulação das questões foi preparada para, progressivamente, conscientizar o usuário sobre os efeitos de interrupções de fornecimento, envolvendo aspectos como perdas financeiras, bem como a disposição de aceitar compensações em caso de falta de energia ou de pagar mais pelo aumento de confiabilidade. 
Diferentes questionários foram preparados para consumidores residenciais, comerciais e industriais. Na aplicação dos questionários foi utilizado um processo de seleção aleatória de clientes, não obstante a inclusão de sorteio em áreas com problemas de fornecimento recentes, para avaliar a percepção deste grupo de clientes.

Embora apresentando resultados passíveis de atualização, MASSAUD [13] apresenta em sua publicação de 1994, valores de custo de interrupção levantados no Brasil em 1991 e ressalta o risco da utilização de valores típicos de outros países com realidades sócio-econômicas diferentes. Segundo essa referencia, em 1991, o valor médio das interrupções no Brasil era 1,54 US\$/kWh, o que resulta em cerca de 17 vezes o valor da tarifa, então de 0,09 US\$/kWh.

Num outro trabalho mais recente [14] são mencionados os esforços de uma Força Tarefa do CIGRÈ para estimar o valor para os clientes das interrupções do fornecimento de energia elétrica, com o objetivo de estabelecer o equilíbrio entre acréscimo de custo que proporciona aumento de confiabilidade em um sistema de potência.

O relatório resultante desse artigo publicado pelo CIGRÈ avaliou diversos métodos existentes para avaliação dos custos de interrupção de fornecimento, agrupando-os em três categorias:

- Avaliações analíticas indiretas;

- Estudos de casos de blackouts ocorridos;

- Levantamentos junto aos clientes.

O primeiro método utiliza índices para fazer inferências, enquanto que a maior vantagem da segunda abordagem é o estudo de efeitos e prejuízos reais sentidos pelos clientes. Sua aplicabilidade, todavia, é limitada.

O último método faz uso de questionários elaborados para tentar obter informações sobre os custos de interrupções do suprimento de eletricidade com diversas freqüências e durações, além de ocorrerem em diferentes horários e épocas do ano. 
Apesar de implicar em esforços e despesas maiores que os métodos anteriores, esta técnica tende a ser preferida pelas dificuldades de aplicação das outras duas. O tratamento dos resultados conduz, na maneira mais tradicional, à determinação de um custo de energia não suprida (unidades monetárias/kWh). O autor cita que outros estudos usam dois termos: um proporcional à energia e outro à demanda interrompida (u.m./kW).

Ainda no artigo [14], o autor cita que em desenvolvimentos mais recentes, os resultados dos questionários são representados por funções de dano do consumidor (FDC), as quais expressam os custos pela incapacidade de exercer as suas atividades normais durante uma interrupção.

A aplicabilidade prática das FDC resultantes dos questionários depende muito da transformação dos dados brutos em funções agregadas que possam ser utilizadas para clientes com menor consumo, mas níveis de custo comparáveis. A prática usual para quantificar o valor da energia não fornecida a partir da duração das interrupções é a criação de funções de dano do consumidor setoriais (FDCS).

$\mathrm{Na}$ análise de alternativas de topologias do sistema elétrico ou cenários operativos são identificados setores (ou classes de consumidores) homogêneos atendidos por regiões do sistema, permitindo a obtenção de uma curva para todo o sistema (FDCC função de dano do consumidor composta) por meio da ponderação das FDCS setoriais, considerando a proporcionalidade da quantidade de consumidores de cada região.

Segundo o autor há, alternativamente, os que preferem basear suas estimativas de custo de interrupção na energia interrompida, com denominações como valores da carga perdida (VoLL, do inglês "value of the lost load") ou estimativa da energia interrompida (IEAR, "interrupted energy assessment rate").

Segundo o autor, diversos países (como EUA, Canadá, Austrália, Dinamarca, Nova Zelândia etc.) têm estudos de custo de interrupções para os setores: agrícola, comercial, industrial, grandes consumidores, escritórios e residencial. Estes dados se referem a levantamentos realizados entre 1986 e 1998. 
O autor aponta que existem ainda dados de custos ligados a eventos significativos de interrupção (como black-out de 1977 em Nova lorque), penalidades por não fornecimento, além de alguma literatura teórica sobre o tema.

Ainda em [14], o autor conclui que a utilização de custos de interrupção de fornecimento tanto pelas concessionárias quanto por órgãos reguladores tende a aumentar.

A referência [15] publica recente pesquisa para estimativa do valor das interrupções de fornecimento conduzida na Noruega em 2002, realizada para fundamentar a implementação de base regulatória, cuja remuneração depende dos custos de energia não suprida aos consumidores. Os autores destacam no artigo que, além desta função regulatória, os dados obtidos podem ser utilizados para o planejamento otimizado da capacidade do sistema.

Essa pesquisa foi desenvolvida em duas etapas, a primeira visando obter bases teóricas e a segunda buscando resultados empíricos do valor das interrupções para os clientes. A primeira concentrou-se no estabelecimento da metodologia e na segunda etapa foi realizado um levantamento por meio da postagem de questionários complementados por entrevistas telefônicas quando necessário, visando maior economia em relação ao trabalho de campo.

Os questionários foram dirigidos a classes específicas de consumidores (residencial, industrial, comercial, agricultura, setor público e grandes clientes) tendo uma taxa de resposta entre $25 \%$ e $45 \%$. Para isto o setor residencial e o de agricultura receberam incentivos (bilhetes de concursos lotéricos).

Para aumentar a confiabilidade, houve um processo de consistência dos resultados por meio de uma "triangularização" de informações. As questões propostas objetivaram obter tanto o valor direto ("direct worth") quanto a disposição a pagar para evitar a interrupção ("willingness to pay"). Ambos os valores foram combinados para determinar o custo real do não suprimento. 
A base do tratamento dispensado à qualidade do fornecimento, a partir dos dados precedentes, é similar ao de uma "commodity" de mercado, cujo valor é estabelecido pelo equilíbrio entre oferta e demanda. Além disso, é determinada a tendência em se subestimar a disposição a pagar e superestimar o valor direto, justificando a combinação.

Os resultados obtidos, convertidos de coroa norueguesa para $€$, foram os seguintes :

- 0,93 €/kW (isto é, expressos por demanda) para interrupções de até 3 min;

- $\quad 3,12 € / k W h$ para interrupções programadas acima de $3 \mathrm{~min}$;

- 4,12 €/kWh para interrupções sem pré-informação acima de 3 min;

- $\quad$ 0,67 €/kW para afundamentos de tensão.

Na mesma linha do trabalho da Noruega (e com assessoria SINTEF e SNF) foi conduzido um trabalho pela Autoridade para Energia Elétrica e Gás da Itália [16].

O resultado indicou que, na Itália, a disposição para pagar (DPP) é sistematicamente inferior à disposição em aceitar compensação (DPA).

Os valores obtidos são apresentados na tabela 3.3, incluindo o valor direto (VD), que consiste no prejuízo econômico resultante de um cenário hipotético de interrupção.

TABELA 3.3 - Custos de interrupção de fornecimento levantados na Itália.

\begin{tabular}{|c|c|c|c|c|c|c|}
\hline & \multicolumn{3}{|c|}{ Residências } & \multicolumn{3}{|c|}{ Empresas } \\
\hline & VD & DPP & DPA & VD & DPP & DPA \\
\hline $\begin{array}{c}\text { Interrupções de até } 3 \text { min } \\
(€ / k W)\end{array}$ & 8,02 & 1,38 & 5,35 & 55,16 & 4,90 & 34,16 \\
\hline $1 \mathrm{~h}(€ / \mathrm{kWh})$ & 25,34 & 3,75 & 17,03 & 117,98 & 10,70 & 79,75 \\
\hline $2 \mathrm{~h}(€ / \mathrm{kWh})$ & 20,41 & 2,68 & 13,92 & 83,79 & 7,75 & 57,09 \\
\hline $4 \mathrm{~h}(€ / \mathrm{kWh})$ & 15,73 & 2,25 & 11,24 & 67,18 & 6,63 & 48,42 \\
\hline $8 \mathrm{~h}(€ / \mathrm{kWh})$ & 9,68 & 1,36 & 6,89 & 40,01 & 3,98 & 28,99 \\
\hline
\end{tabular}




\subsection{AVALIAÇÃO NO CAMPO DE BENEFÍCIOS DA AUTOMAÇÃO}

No artigo [19] são apresentados comentários sobre a avaliação na Coréia de um Sistema de Automação desenvolvido através de uma cooperação da KEPCO (Korea Power Company) e fornecedores locais.

Para avaliação no campo foi escolhida uma área que atende 220 mil consumidores de Seul, compreendendo 3 subestações, 25 alimentadores e 125 chaves controláveis remotamente.

O sistema é denominado KODAS (Korean Distribution Automation System) e realiza funções de monitoramento do status de dispositivos, controle remoto de chaves, automação de alimentadores para restabelecimento de serviço em trechos da rede e medição remota automática.

A arquitetura se baseia num controle centralizado de dispositivos, utilizando-se pares trançados de cobre e cabos de TV por assinatura para comunicação.

O fato que vale menção é que, mesmo com muitas das características deste sistema parecendo obsoletas diante dos recursos atuais, a avaliação é positiva, especialmente no que se refere à localização rápida de defeitos.

Cita-se ainda evolução futura do sistema para incluir sistemas de comunicação sem fio e algoritmos de localização de defeitos com lógica difusa.

A referência [20], por sua vez, apresenta uma experiência de aplicação de automação para isolamento de faltas e restabelecimento da alimentação em Londres.

A rede é basicamente subterrânea, com quatro alimentadores por barra da subestação e configuração em anel normalmente aberto, onde cada alimentador se conecta pelo menos com outros dois, havendo freqüentes casos onde há conexão com os três outros alimentadores. 
A totalidade das subestações AT/MT é supervisionada e telecontrolada, enquanto quase 40 \% das subestações secundárias têm sistemas para controle remoto, com comunicação via linha telefônica ou rádio.

A implementação destes controles se constituiu numa fase de pré-automação, a qual teve como benefício uma redução de 33 \% na duração das interrupções, porém uma melhoria limitada a 9 \% na freqüência dos desligamentos.

Para uma diminuição adicional das interrupções, inicialmente foram consideradas alternativas à automação tais como interconexões em baixa tensão e sistemas de seccionamento, tanto em MT como BT, mas foram descartadas pelo custo elevado em relação à redução proporcionada de interrupções.

Esse mesmo artigo relata a implementação de um sistema de automação centralizado conectado às 5000 subestações secundárias, que envolve 861 alimentadores e 1,8 milhão de clientes.

Foi adotada uma filosofia de divisão do alimentador em zonas (usualmente três) e uso de indicadores de defeito nas fronteiras, de modo a permitir o isolamento daquela com falta e o restabelecimento das demais. Para isto são avaliadas as combinações de uma "tabela-verdade", que considera o número de pontos de seccionamento e de zonas.

O desempenho do novo sistema de automação pode ser mensurado pelos seguintes comentários:

- Cerca de $50 \%$ do total de faltas foram restabelecidas em menos de 3 min, com variação entre 25 \% e 75 \% numa base mensal;

- Obteve-se uma melhoria de 18 \% na freqüência das interrupções;

- A duração média das interrupções caiu 19 \%;

- Não foram observadas falhas por lógica de automação incorreta;

- Houve muitas falhas de restabelecimento automático, principalmente por softwares desabilitados, por atrasos do sistema de comunicação e de retroalimentação da BT que inibe o disparo do sistema. 


\subsection{CUSTOS E BENEFÍCIOS DA AUTOMAÇÃO}

A referência bibliográfica [21] avalia os benefícios da Automação da Distribuição no cenário de concessionárias de energia elétrica sob controle de grupos privados, cujo custo adicional de confiabilidade devem dar retorno aos acionistas e ter impacto limitado nas tarifas pagas pelos clientes.

Além das questões acima é assinalada a crescente quantidade de consumidores sensíveis a mínimas interrupções de fornecimento, como centros de comércio eletrônico, provedores de Internet ou indústrias com processos contínuos.

Surge portanto, a necessidade de justificar os benefícios da automação em termos econômico-financeiros considerando os custos de operação e de manutenção, bem como o aumento da satisfação do consumidor.

Uma lista dos benefícios classificados segundo as áreas acima citadas é apresentada na tabela 3.4.

TABELA 3.4 - Benefícios da automação.

\begin{tabular}{|l|l|l|}
\hline \multicolumn{1}{|c|}{ Econômico-financeiros } & \multicolumn{1}{|c|}{ Operação e manutenção } & \multicolumn{1}{c|}{ Satisfação do consumidor } \\
\hline Postergação de investimentos & $\begin{array}{l}\text { Aumento da disponibilidade } \\
\text { pelo menor tempo de } \\
\text { restabelecimento }\end{array}$ & Maior confiabilidade \\
\hline $\begin{array}{l}\text { Aumento de faturamento pela } \\
\text { agilidade de restabelecimento }\end{array}$ & Melhoria da tensão & $\begin{array}{l}\text { Menor custo devido às } \\
\text { interrupções }\end{array}$ \\
\hline $\begin{array}{l}\text { Redução do custo de operação } \\
\text { e manutenção }\end{array}$ & Redução de mão-de-obra & $\begin{array}{l}\text { Qualidade de fornecimento } \\
\text { melhor (continuidade) }\end{array}$ \\
\hline $\begin{array}{l}\text { Aumento de utilização da } \\
\text { capacidade instalada }\end{array}$ & $\begin{array}{l}\text { Dados de operação e } \\
\text { planejamento mais acurados }\end{array}$ & \\
\hline Redução de perdas & $\begin{array}{l}\text { Detecção de faltas e } \\
\text { diagnóstico }\end{array}$ & \\
\hline $\begin{array}{l}\text { Retenção de clientes pela } \\
\text { qualidade do serviço }\end{array}$ & $\begin{array}{l}\text { Melhor gerenciamento e } \\
\text { carregamento de componentes } \\
\text { do sistema }\end{array}$ & \\
\hline
\end{tabular}

As comunicações são tratadas, citando-se que os sistemas legados de rádio 800 $900 \mathrm{MHz}$ não têm capacidade de atender as exigências futuras, sugerindo-se a criação de uma rede própria de fibras ópticas pelas concessionárias para realizar automação. 
Dentre todas as funcionalidades apresentadas, o chaveamento automático de alimentadores para isolação de faltas e restabelecimento de trechos é considerado o mais benéfico, com tempo de retorno de 2,5 a 3 anos.

Nas conclusões, os autores salientam que é possível maximizar os benefícios da automação integrando-se proteção, controle e monitoramento, aproveitando-se dessa facilidade que os dispositivos modernos oferecem.

O artigo [22] apresenta uma metodologia para cálculo computacional do custobenefício de diferentes alternativas de automação, de forma a possibilitar a comparação, a combinação ótima de dispositivos e tecnologias, bem como o cronograma e prioridade de implementação.

Inicialmente são relacionados qualitativamente os benefícios correspondentes às funcionalidades, como indicado na tabela 3.5.

TABELA 3.5 - Benefícios associados a cada funcionalidade de automação.

\begin{tabular}{|c|c|c|c|c|c|c|}
\hline \multirow{2}{*}{ Funcionalidades } & \multicolumn{6}{|c|}{ Benefícios } \\
\hline & $\begin{array}{c}\text { Situações } \\
\text { de } \\
\text { Interrupção }\end{array}$ & $\begin{array}{c}\text { Redução de } \\
\text { Mão de } \\
\text { Obra }\end{array}$ & Investimento & $\begin{array}{l}\text { Controle de } \\
\text { Demanda }\end{array}$ & Perdas & $\begin{array}{l}\text { Qualidade. } \\
\text { (Continuidade.) }\end{array}$ \\
\hline Isolamento remoto de defeitos & $X$ & $X$ & & & & \\
\hline Indicação remota de defeitos & $X$ & $X$ & & & & \\
\hline Localização de defeitos & $X$ & $X$ & & & & \\
\hline Controle de tensão & & & $\mathrm{X}$ & $\mathrm{X}$ & $X$ & $X$ \\
\hline Controle de reativos & & & $x$ & $\mathrm{X}$ & $X$ & $X$ \\
\hline Controle direto de cargas & & & $\mathrm{X}$ & $\mathrm{X}$ & $\mathrm{X}$ & \\
\hline $\begin{array}{l}\text { Estimação de carga e } \\
\text { monitoramento }\end{array}$ & & $X$ & $X$ & & & \\
\hline Otimização de topologia & & $X$ & $\mathrm{X}$ & $\mathrm{X}$ & $X$ & \\
\hline $\begin{array}{l}\text { Medição remota e tarifação } \\
\text { dinâmica }\end{array}$ & & $X$ & & $X$ & $X$ & \\
\hline
\end{tabular}


Para a aplicação da metodologia são apresentadas algumas fórmulas para o cálculo de benefícios associadas às funcionalidades da tabela 3.5. Observa-se, todavia, que poucas expressões são de aplicação geral, motivando a apresentação de outras aplicáveis com hipóteses particulares e, finalmente, a um tratamento qualitativo.

A equação (3.3) resume as fórmulas propostas:

$B=B_{c h}+B_{i d}+B_{l d}+B_{c t r}+B_{o}=C E N D_{m}\left[W\left(R_{c h}+R_{i d}+R_{l d}\right)+\Delta p \Delta t_{m}\right]+B_{o}$

Onde:

Bch: benefício associado ao chaveamento remoto (u.m./alimentador/ano);

Bid: benefício associado aos indicadores de defeito (u.m./alimentador/ano);

Bld: benefício associado à localização de defeito (u.m./alimentador/ano);

Bctr: benefício associado ao controle de tensão e reativos (u.m./alimentador/ano);

Bo: benefícios associados às outras funcionalidades da tabela 3.5 (u.m./alimentador/ano);

CENDm: custo médio da energia não distribuída (u.m./kWh)

W: média anual da energia não suprida antes da introdução da automação (kWh/alimentador/ano);

Rch: redução das interrupções em p.u. pela aplicação do chaveamento remoto;

Rid: redução das interrupções em p.u. pela aplicação de indicadores de defeito;

Rld: redução das interrupções em p.u. pela localização automática de defeitos;

$\Delta p$ : redução das perdas pela introdução da automação $(\mathrm{kW})$;

$\Delta \mathrm{tm}$ : tempo médio aplicável de redução das perdas (h).

Por outro lado o custo da implementação da automação consiste no valor presente das parcelas referentes à :

- Transmissão de dados (comunicação);

- Equipamentos computacionais (hardware e software);

- Componentes adicionais do sistema de potência. 
Os componentes adicionais do sistema são tipicamente chaves, transformadores de medição e indicadores de defeitos.

Deve-se ter em conta que muitos dos custos acima são compartilhados entre funcionalidades, não podendo ser simplesmente considerados como ônus exclusivo do sistema de automação.

\subsection{ALOCAÇÃO DE DISPOSITIVOS AUTOMÁtICOS NA REDE DE DISTRIBUIÇÃO}

A maioria dos trabalhos pesquisados que envolvem a locação ótima de dispositivos de seccionamento, automáticos ou não, em redes de distribuição trata da operação ótima destes dispositivos visando minimizar as perdas do sistema ou restabelecer o serviço enquanto poucos trabalhos são focados na minimização de redundâncias decorrentes do critério de planejamento atual.

As soluções propostas para este problema envolvem, em geral, métodos de otimização baseada em técnicas de programação não-linear, técnicas heurísticas, algoritmos genéticos etc.

O que se observa é que a análise de todas as possibilidades de locação das chaves em uma rede se apresenta como tarefa difícil face à explosão de combinações possíveis. De modo geral, nos métodos propostos para otimizar a localização de chaves seccionadoras são utilizadas técnicas que restringem o universo de soluções possíveis, com o objetivo de acelerar a busca por soluções satisfatórias que apresentam bom desempenho operativo. Isso resulta da dificuldade de encontrar uma metodologia que garanta a obtenção da solução ótima global para o problema.

$\mathrm{Na}$ referência [29] o autor propõe uma metodologia para a determinação da quantidade de chaves seccionadoras e a localização ótima destas através da utilização de uma técnica de otimização chamada "Simulated Annealing". O autor observa que o problema enfrentado é de difícil solução por métodos tradicionais de otimização não-linear. 
A publicação [30] ressalta que, em geral, os trabalhos que tratam este problema propõem soluções baseadas em técnicas heurísticas e que estas não garantem precisão satisfatória das soluções encontradas.

Desta forma é proposto o princípio de otimização de Bellmann para tentar solucionar o problema, que consiste em uma técnica de programação dinâmica para solução de problemas com múltiplos estágios. Segundo este princípio, dado um determinado estágio do processo, a determinação da política ótima para os estágios subseqüentes independe das políticas adotadas até aquele estágio.

Observa-se que, para configurações simples de recursos de automação, uma solução viável é a busca exaustiva pelo melhor ponto de inserção dos dispositivos de seccionamento, testando a alocação bloco a bloco e mensurando seus benefícios através da END evitada. 


\section{METODOLOGIA}

\subsection{DIRETRIZES GERAIS}

Enquanto um planejamento convencional de sistema de distribuição, que objetiva ampliar a oferta de energia em uma região visando atender critérios técnicos e de qualidade de fornecimento pré-estabelecidos, considera a incorporação de recursos estruturais ao sistema, por exemplo uma nova subestação, a metodologia de planejamento proposta nesta dissertação inclui a automação no rol de recursos para aumento da oferta.

Fundamentalmente, três questões são abordadas para a formulação dessa metodologia:

- Quais são os recursos de automação que devem ser incorporados ao planejamento, por meio da constituição de um portfolio de sistemas de automação, compostos por elementos de diferentes níveis de complexidade e de desempenho e, evidentemente, de custo, especificando, ainda que de forma simplificada, as correspondentes funcionalidades;

- Onde deverão ser inseridos os dispositivos de chaveamento que serão parte integrante do sistema de automação especificados no portfolio . Para isto deverão ser levantadas algumas características da rede estudada como, por exemplo, a localização de blocos de cargas críticos, trechos de rede com infra-estrutura de comunicação existente etc;

- Quanto é o custo e o benefício que cada uma das alternativas de sistema de automação aplicadas proporciona, considerando as diversas possibilidades de inserção indicadas anteriormente.

As combinações válidas para a composição do portfolio devem ser tais que executem uma funcionalidade bem definida e formem conjuntos coerentes de componentes (sensores, dispositivos de chaveamento, sistemas de comunicação, etc). Isto é, nem 
todas as combinações de componentes que possam integrar um sistema de automação produzem um conjunto aceitável para implementação prática.

Para efeito deste trabalho, o portfolio de sistemas de automação é composto por algumas combinações pré-estabelecidas de entidades, que serão apresentadas adiante (soluções pré-definidas), mas também há a possibilidade do planejador constituir um sistema específico.

No âmbito do processo de planejamento, sempre que algum critério de desempenho não for atendido, devem ser propostas alternativas para solucionar o problema. Em cada oportunidade de proposição de alternativa de reforço, devem ser explorados recursos de automação, pela aplicação de um dos sistemas presente no portfolio ou por um sistema específico, orientando-se pelas funcionalidades requeridas.

A avaliação do custo da alternativa é resultante do custo de investimento, de operação e de manutenção do sistema de automação proposto e a avaliação do benefício é basicamente determinada pela economia de END que o sistema de automação propicia, nas diversas situações de atendimento de contingência.

Dentre as alternativas que prevêem recursos de automação, a metodologia busca a solução que representa o nível de automação ótimo conforme ilustra a figura 4.1.

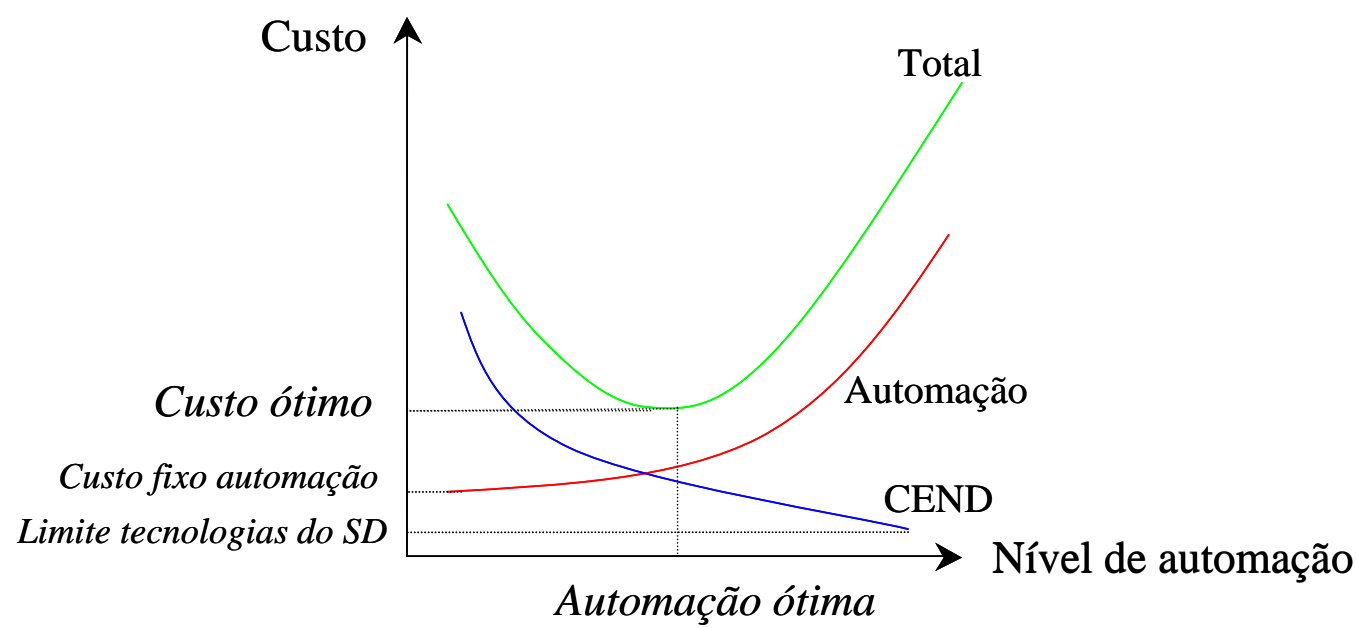

FIGURA 4.1 - Representação do balanço entre custos de automação e END. 


\subsection{CUSTO DA RESERVA DE CAPACIDADE}

A adoção do critério atual de planejamento do sistema de distribuição ("critério N-1"), implica na consideração de um custo implícito da reserva de capacidade.

Com o objetivo de avaliar esse custo implícito realiza-se, a seguir, um cálculo do custo da reserva de capacidade de uma subestação e de uma rede de alimentadores, ambos dimensionados pelo "critério N-1" considerando valores típicos associados.

A partir dos seguintes valores típicos e médios para um transformador de subestação:

- Custo incluindo equipamentos associados: US\$30/kVA;

- Taxa de indisponibilidade média anual em um período plurianual : 1h/ano;

- Fator de carga: 0,6;

- Fator de potência: 0,9;

- Fator de utilização: 0,8;

- Fator de recuperação de capital: 0,11 (10\% a.a, vida útil de 25 anos);

O custo da reserva de capacidade de transformação (CRC) referente a instalação de um segundo transformador pode ser estimado por:

$$
C R C_{\text {Transformador }}=\frac{\text { CustoTrafo } \times \text { FRC }}{\text { Indisp. } \times \text { F.U. } \times \text { F.P. } \times \text { F.C. }}
$$

Nota-se através da análise desta fórmula que o nominador da equação corresponde ao custo anual do transformador a ser instalado, enquanto o denominador consiste na END anual evitada pela instalação do segundo transformador. Aplicando os valores típicos supracitados obtém-se:

$$
C R C_{\text {Transformador }}=\frac{30 \times 0,11}{1 \times 0,8 \times 0,9 \times 0,6} \cong 7,7[\mathrm{US} \$ / \mathrm{kWh}]
$$

Um cálculo semelhante pode ser realizado para alimentadores aéreos, os quais são carregados com aproximadamente $70 \%$ de seu limite máximo de carregamento. 
Neste caso, assumindo um custo de investimento de US\$2/kVA/km e uma taxa de indisponibilidade de $0,25 \mathrm{~h} / \mathrm{km} / \mathrm{ano}$, o custo resulta:

$$
C R C_{\text {Alimentador }}=\frac{2,0 \times 0,11}{0,25 \times(1-0,7) \times 0,9 \times 0,6} \cong 5,4[\mathrm{US} \$ / \mathrm{kWh}]
$$

Neste ponto é interessante comparar os custos intrínsecos da reserva de capacidade com os custos de interrupção de fato.

De acordo com as referências [11] e [21], as conseqüências econômicas para um consumidor no Brasil são da ordem de US\$0,75/kWh a US\$6,95/kWh, com um valor médio de US\$1,54/kWh, dependendo do tipo de consumidor e duração da interrupção.

De forma estimada, a reserva de capacidade possui um valor de custo da ordem de grandeza de até dez vezes o custo de interrupção, com uma média de quatro vezes. Em outras palavras, a maioria dos desligamentos de consumidores é evitada com um custo maior do que o que seria gerado por estes.

Obviamente, isso não significa que o desligamento de consumidores possa ser tolerado com maior intensidade da que se apresenta atualmente, mas que há necessidade e conveniência de pesquisas mais profundas para a busca de alternativas mais econômicas para a expansão da rede.

\subsection{PLANEJAMENTO CONSIDERANDO RECURSOS DE AUTOMAÇÃO}

O procedimento de planejamento da distribuição, incluindo alternativas de automação da rede, é apresentado no fluxograma da figura 4.2, onde se nota que;

- Em cada situação de contingência simples deve-se, quando for o caso, proceder às necessárias e possíveis transferências de carga, propondo recursos de automação, a serem detalhados em item subseqüente, ou 
alternativas de novos reforços estruturais do sistema (LTs, subestações, alimentadores, etc);

- A cada situação de contingência onde houver corte de carga deverá ser computado o custo da energia não distribuída (END), contabilizando-se os correspondentes valores anuais.

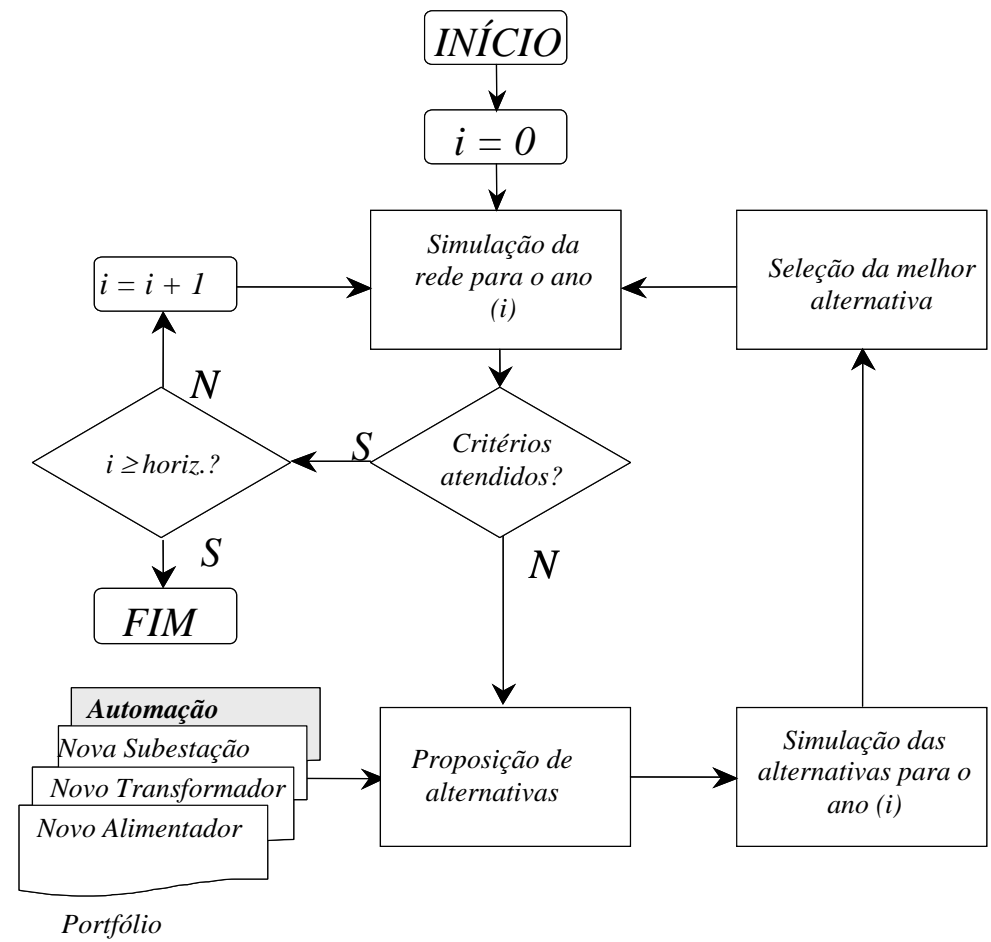

FIGURA 4.2 - Fluxograma do planejamento com automação.

Observa-se que neste processo devem ser aplicadas as técnicas necessárias para analisar a dinâmica do plano de obras no período de estudo, uma vez que recursos de automação podem muitas vezes servir como instrumento para postergação de maiores investimentos na rede.

\subsection{ALTERNATIVAS DE AUTOMAÇÃO DE REDE}

\subsubsection{Caracterização das alternativas}

Pode-se atribuir à denominação "automação da distribuição" diversas funções relacionadas a controle de tensão, transferência de carga, localização de defeitos, medição remota etc. 
Porém, para o propósito deste trabalho, a funcionalidade da automação da distribuição de maior importância é seccionamento automático de alimentadores para isolamento de falta ou transferência de carga, com o objetivo de otimizar o fator de utilização das instalações por meio da substituição ou postergação de novas reservas de capacidade, como a construção de um novo alimentador ou ampliação da capacidade transformadora de uma subestação.

Um recurso de automação é, de fato, um conjunto de equipamentos ou componentes que operam em conjunto para alcançar a funcionalidade desejada (por exemplo, seccionamento automático do alimentador).

Esse conjunto inclui, basicamente, elementos de sensoriamento para medição de tensão ou corrente, dispositivos de chaveamento de rede capazes de seccionar alimentadores e dispositivos de comunicação para interligação dos demais dispositivos e, por vezes, com conexão destes com um dispositivo de controle central. Há casos onde alguns desses dispositivos podem estar integrados em apenas um.

De qualquer forma, cada elemento tem um custo que deve ser levado em conta. Conseqüentemente, a completa caracterização de um recurso de automação deve considerar todos esses componentes para cálculo do custo total, incluindo os serviços para instalação.

Além disso, para sistemas de comunicação, o valor de investimento é comumente composto em custo fixo e custo variável, sendo este função das distâncias de alocação dos componentes do sistema.

O mesmo recurso de automação pode gerar diferentes custos e benefícios, dependendo de sua posição relativa em relação aos blocos mais importantes de carga, à subestação etc.

É necessária, para a eficiente aplicação dos recursos de automação, que se estabeleçam diretrizes para o procedimento de inserção dos recursos, de forma a 
garantir a viabilidade da aplicação, a funcionalidade requerida dos recursos aplicados e os benefícios ótimos que o recurso pode proporcionar.

Essas diretrizes consistem em algumas regras e verificações que devem ser feitas no momento da inserção do recurso, como a observância da capacidade dos alimentadores em receber cargas de outros circuitos, a verificação dos níveis de tensão quando manobrada a rede, a identificação dos blocos de carga que geram maior contribuição para a END da rede.

Identificando esses pontos pode-se estabelecer as diretrizes para o melhor aproveitamento dos recursos, como por exemplo, a alocação dos equipamentos de chaveamento de forma a garantir o restabelecimento de grandes blocos de carga ou consumidores críticos, escolher pontos de transferência de carga onde há maior capacidade de transferência etc.

\subsubsection{Portfolio de recursos de automação básicos}

Visando facilitar a proposição de alternativas no processo de planejamento, foram especificados alguns recursos de automação básicos que integram o portfolio, não obstante a possibilidade de criar novas combinações dos dispositivos de automação.

À título de ilustração, as figuras de 4.3 a 4.7 apresentam exemplos de recursos de automação - "RA-n" - que podem compor um portfólio. 
a) RA-01 - Seccionamento de tronco

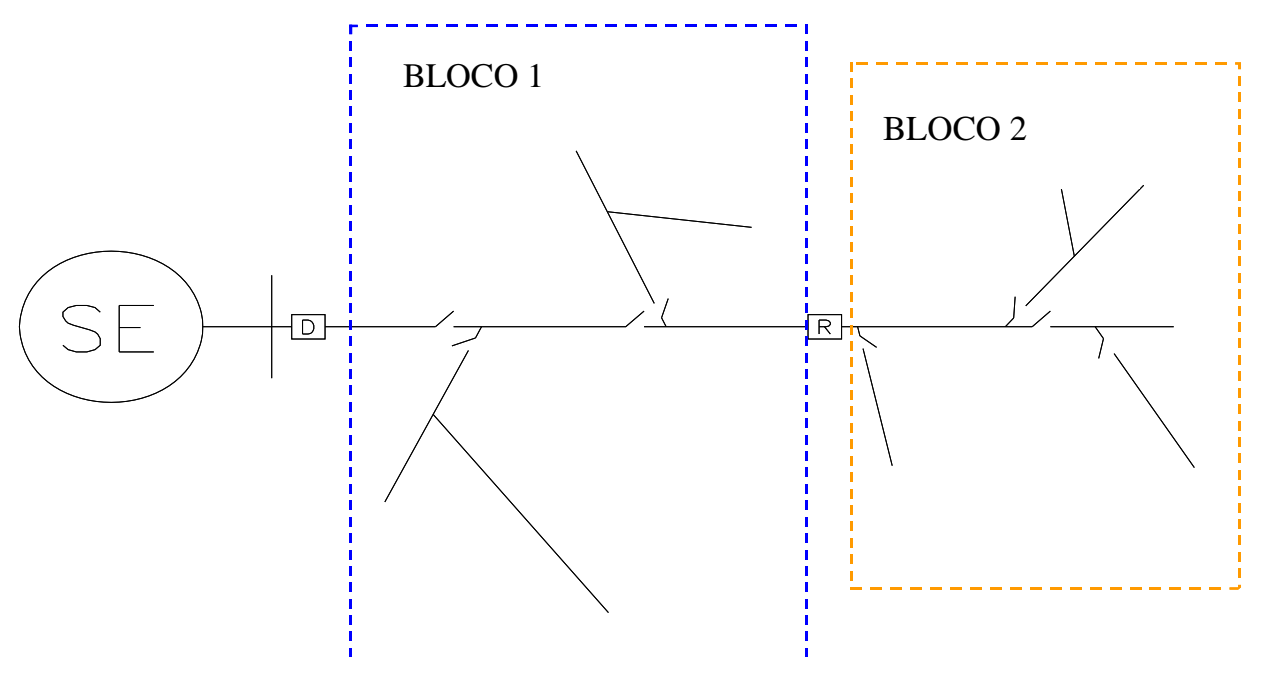

FIGURA 4.3 - Seccionamento de tronco

Funcionalidade: Comumente nas redes de distribuição, o tronco de um alimentador possui apenas dispositivos de seccionamento sem qualquer função de proteção, sendo essa garantida pelo próprio disjuntor da subestação. Isto acarreta em uma perda de confiabilidade uma vez que todo alimentador deve ser desligado em caso de falta em qualquer ponto do tronco.

A alternativa apresentada na figura 4.3 consiste na instalação de um religador automático no tronco do alimentador de maneira a propiciar o seccionamento automático do tronco para defeitos a jusante do religador. Desta forma, o sistema permite o restabelecimento automático da carga à montante do religador para ocorrências á sua jusante. É necessária a realização de um ajuste das proteções de maneira a garantir a seletividade e a coordenação entre o relé da subestação e o religador, bem como deste com os fusíveis a sua jusante.

Uma variante desta alternativa seria a utilização de um seccionalizador automático ao invés da religador proporcionando uma redução de custos. Porém deve ser avaliada a relação custo/benefício desta variante uma vez que a chave não possui função de proteção, sendo assim os blocos de carga a montante sofreriam com os desligamentos momentâneos ocasionados pelos religamentos do disjuntor da subestação até que a chave faça sua contagem e isole o trecho defeituoso. 
O religador automático ou a chave seccionalizadora, nesta filosofia, opera de forma autônoma de acordo com as curvas de atuação existentes no dispositivo de proteção intrínseco do equipamento (no caso do religador) ou com a lógica de contagem de desligamentos (no caso do seccionalizador). Portanto não há a necessidade de rede de comunicação.

b) RA - 02 Seccionamento de tronco com socorro automático

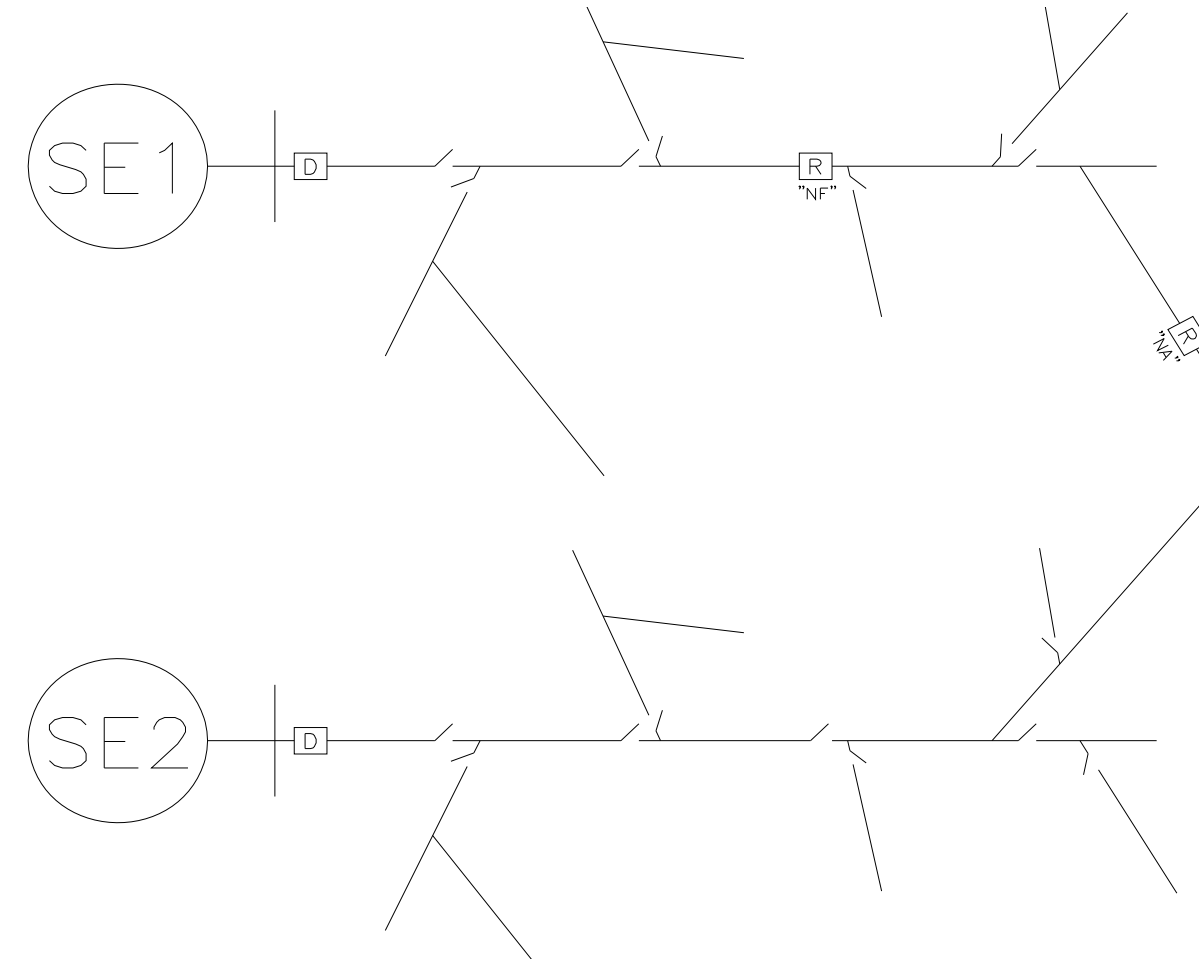

FIGURA 4.4 - Seccionamento de tronco com socorro automático

Funcionalidade: A alternativa anterior privilegiou os blocos de carga a montante do religador, uma vez que não há socorro dos blocos a jusante quando o defeito se dá a montante do mesmo. Porém, nesta alternativa apresentada na figura 4.4 é incorporado este socorro, de forma automática, de maneira a garantir a continuidade no fornecimento também dos blocos a jusante em caso de defeitos a montante do equipamento.

Esse restabelecimento automático das cargas a jusante do religador se dá através de vis automático (religador "NA") com alimentador vizinho da mesma subestação ou de subestação vizinha, enquanto que os blocos a montante não sofrerão influência dos 
defeitos à jusante devido ao dispositivo de proteção do religador, conforme a alternativa anterior.

Cabe ressaltar que no caso de transferência de bloco de cargas entre alimentadores em caso de defeito, haverá uma interrupção de curta duração resultante do tempo existente entre o desligamento do alimentador pelo relé da subestação, a abertura do religador "NF" de maneira a isolar o trecho defeituoso (a sua montante) e posterior fechamento do religador "NA" para restabelecimento da carga do bloco são.

Assim como na alternativa anterior destaca-se que o religador pode ser substituído por uma chave seccionalizadora, com os mesmos benefícios e as mesmas desvantagens supracitadas.

Nesta alternativa há uma lógica de operação e manobra da rede que pode ou não ser realizada através de rede de comunicação.

É possível adotar uma solução sem comunicação em se assumindo riscos de operação. Essa solução consiste em elaborar uma seqüência de eventos utilizando-se de sensores e instrumentos de medição assim como relés auxiliares, de forma a permitir um nível de inteligência local que garanta certo grau de segurança na operação dos equipamentos como, por exemplo, garantir que nenhum equipamento feche seus contatos indevidamente podendo alimentar um curto-circuito ou colocar duas fontes defasadas em paralelo.

Essas "lógicas locais" podem ser realizadas utilizando-se a seqüência de religamentos que os dispositivos de proteção proporcionam.

$\mathrm{Na}$ opção pela utilização de uma rede de comunicação, os equipamentos podem enviar sinais de estados entre si de forma a garantir total segurança em suas aberturas e fechamentos. Medições de grandezas também podem ser transmitidas para que os dispositivos possam ter a garantia do montante de carga passível de ser absorvido por determinado circuito. 
c) RA - 03 Seccionamento de tronco de dois alimentadores com vis automático

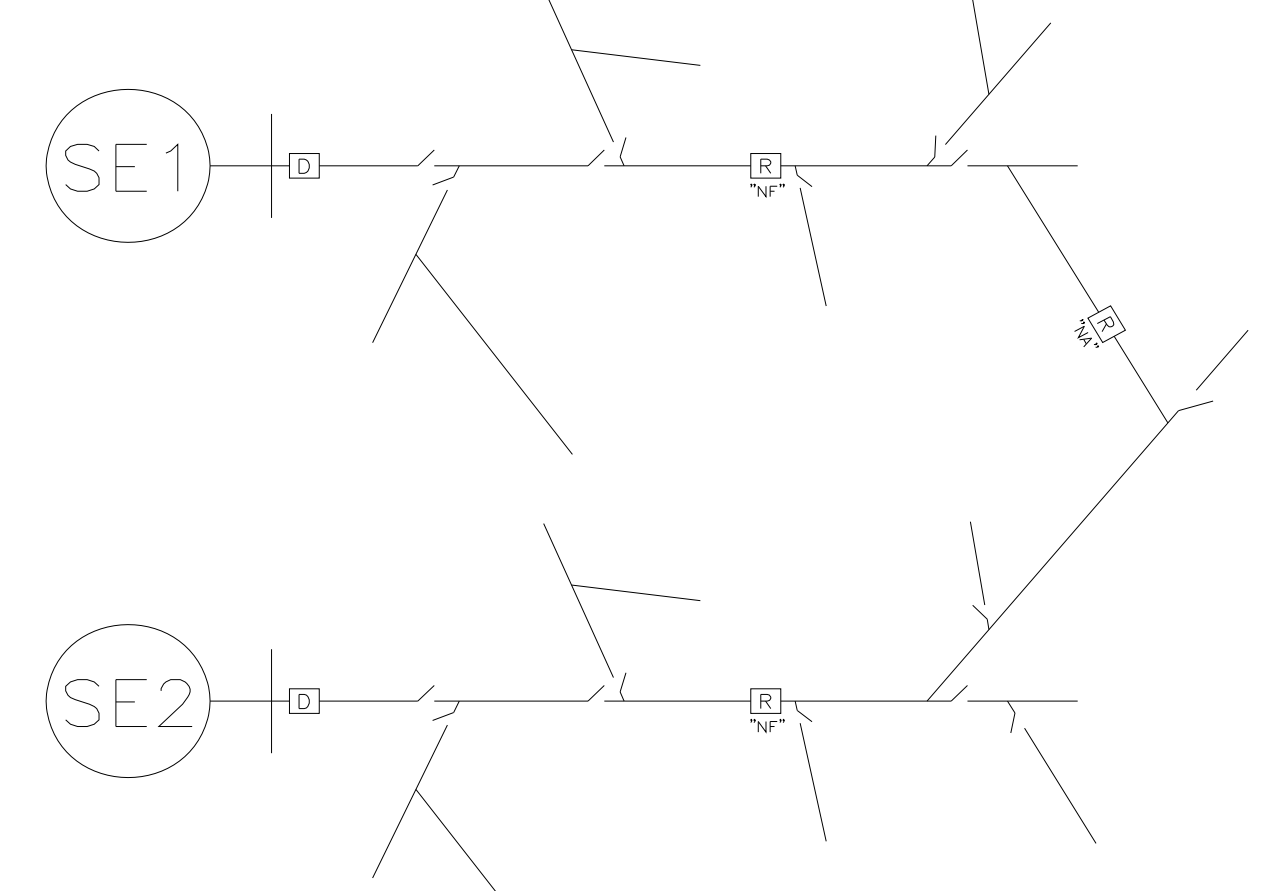

FIGURA 4.5 - Seccionamento de tronco de dois alimentadores com vis automático

Funcionalidade: Esta alternativa é semelhante à anterior, porém envolve o seccionamento de tronco de dois circuitos, devendo o religador "NA" ser bidirecional sendo ajustado de tal forma que consiga garantir suas funções de proteção independente da topologia de rede.

Portanto, a implementação deste sistema permite o restabelecimento automático de metade da carga de cada alimentador para defeitos em qualquer local, através de visà-vis automático entre eles (podendo ser ambos da mesma SE ou de SE's diferentes).

As considerações feitas para a alternativa anterior sobre as pequenas interrupções sofridas pelos blocos de carga a jusante dos religadores "NF" e a possibilidade de utilização de chaves seccionalizadoras ao invés de religadores se aplicam também a esta alternativa.

No que se refere à comunicação, valem as mesmas considerações feitas na alternativa anterior, porém neste caso a realização da lógica de comando e controle das chaves e/ou religadores sem a utilização de rede de comunicação é muito mais 
complexa, uma vez que haverá transferências de blocos de cargas em ambos os sentidos.

Desta forma recomenda-se, para este caso, a utilização de rede de comunicação de maneira a evitar manobras indesejáveis na rede que possam colocar em risco a integridade das instalações e de vidas humanas.

d) RA - 04 Duplo seccionamento de tronco com socorro automático

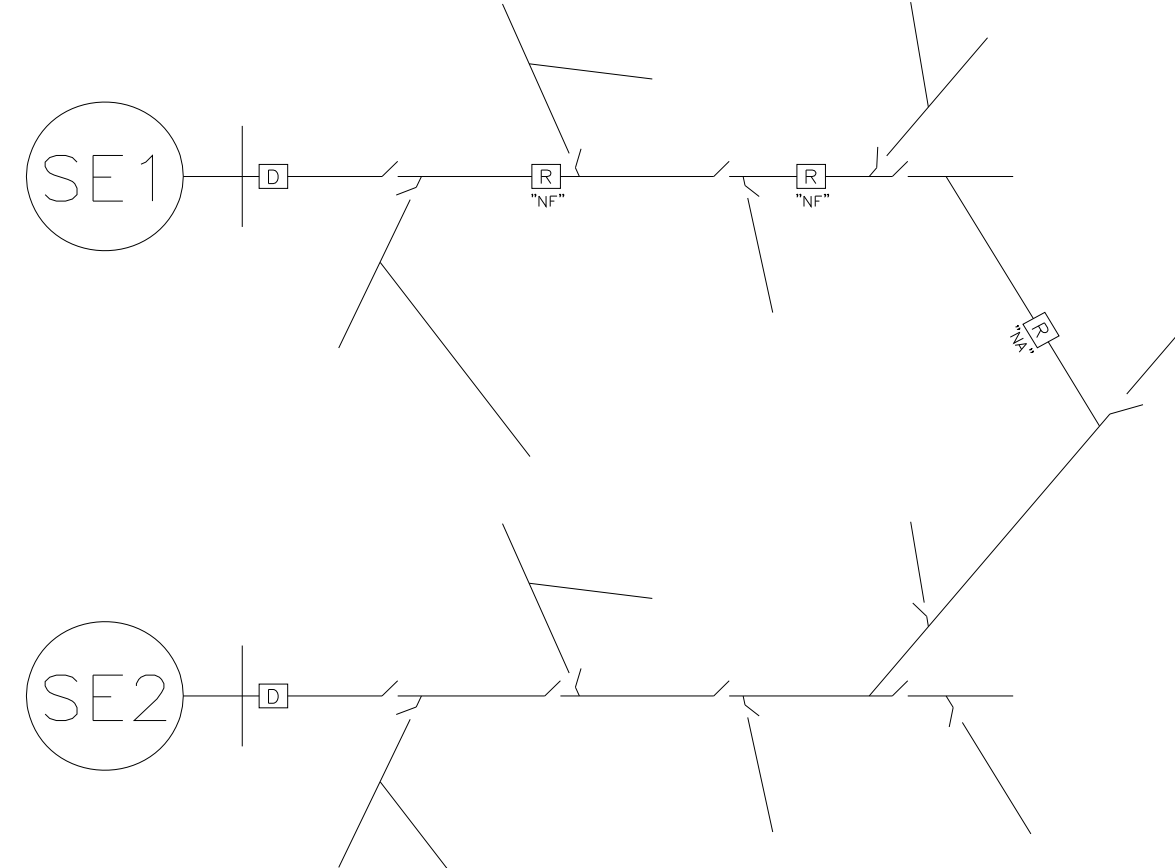

FIGURA 4.6 - Duplo seccionamento de tronco com socorro automático

Funcionalidade: Esta alternativa consiste na aplicação de dois religadores automáticos "NF" ao longo do alimentador sendo que o último bloco possui um vis automático com alimentador vizinho (podendo ser da mesma subestação ou de subestações distintas).

Em caso de defeito em qualquer ponto do alimentador, os religadores "NF" isolam o trecho defeituoso. Caso esse trecho seja o primeiro, os dois blocos seguintes tem seu fornecimento restabelecido através do vis-à-vis automático após a abertura do primeiro religador "NF". Se o defeito ocorrer no segundo bloco, os religadores "NF" isolam trecho automaticamente de maneira que o primeiro bloco permanece sendo alimentado por sua subestação de origem e o terceiro é restabelecido através do vis. 
Para defeitos no terceiro bloco o segundo religador "NF" atua de acordo com suas curvas de proteção isolando o trecho.

Desta forma, a alternativa permite o restabelecimento automático de parte substancial da carga (2/3 se a carga e os chaveamentos forem uniformemente distribuídos) do alimentador para defeitos em qualquer local.

Devido à complexidade da lógica de operação que envolve essa alternativa há a necessidade de rede de comunicação para trânsito e processamento de dados, sendo necessária a realização de algumas consistências desses dados e estados de equipamentos para a correta operação do sistema.

Por essa complexidade operativa, neste caso a substituição dos religadores por chaves seccionalizadoras não é viável.

e) RA - 05 Transferência automática de alimentadores entre subestações

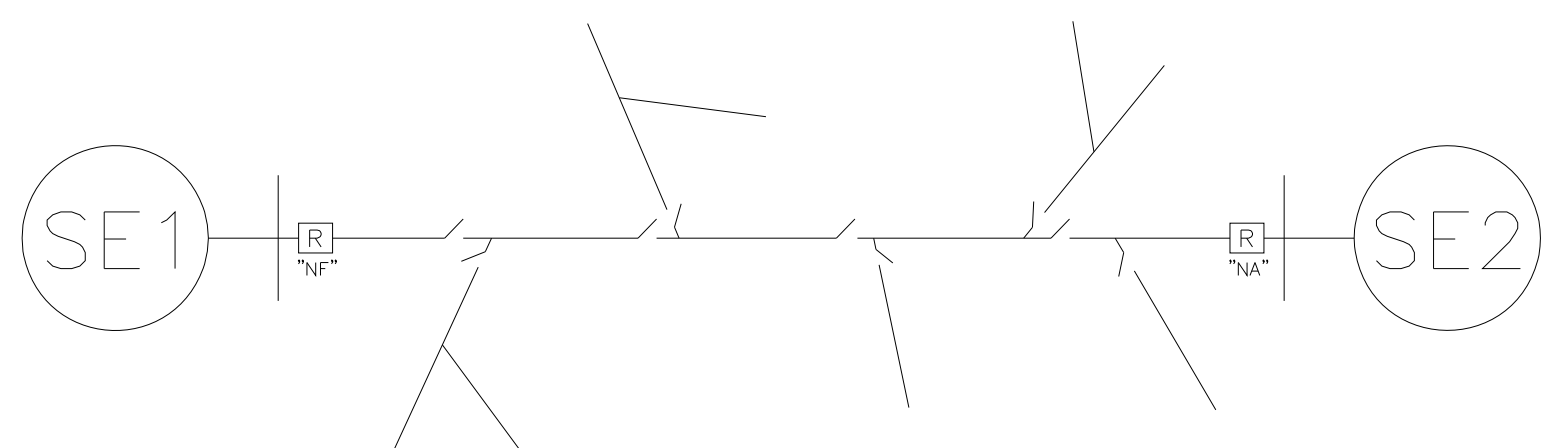

FIGURA 4.7- Transferência automática de alimentadores entre subestações

Funcionalidade: Nesta alternativa não há seccionamento do tronco do alimentador, mas sim a transferência automática de sua carga para outra subestação em caso de defeito da fonte supridora (LT ou SE).

À título de ilustração, a subestação 2 possui outros circuitos e permanece, em situação normal, com seu carregamento limitado para garantir reserva ao sistema. Essa reserva de capacidade que convencionalmente apenas serviria para casos de 
contingências de um de seus transformadores ou linhas de transmissão mas, na metodologia proposta essa capacidade de reserva é "emprestada" à subestação 1 através da alimentação de seus circuitos em caso de contingência da mesma. Esse procedimento pode ser generalizado a várias subestações que atendem uma região, garantindo potência firme sistêmica regional e não mais individual associada a cada uma das subestações.

É possível a realização das manobras envolvidas nessa alternativa sem a presença de rede de comunicação. A utilização de sensores e instrumentação de medição é de extrema importância para verificação das condições necessárias para fechamento dos equipamentos.

Por estarem no interior das subestações, os religadores podem ser comandados remotamente, assim como estarem sujeitos a diagramas esquemáticos que possam bloquear certas ações operativas de acordo com as condições da rede.

A tabela 4.1 apresenta de forma resumida as características das alternativas de recursos de automação apresentadas.

TABELA 4.1 - Recursos de automação propostos.

\begin{tabular}{|c|l|c|c|}
\hline RECURSO & FUNCIONALIDADE & EQUIPAMENTOS & COMUNICAÇÃO \\
\hline RA -01 fig.4.3 & $\begin{array}{l}\text { Restabelecimento } \\
\text { do bloco 1 para } \\
\text { faltas no bloco 2 }\end{array}$ & 1 Religador "NF" & Não \\
\hline RA -02 fig.4.4 & $\begin{array}{l}\text { Restabelecimento } \\
\text { de 50\% da carga de } \\
\text { um alimentador }\end{array}$ & $\begin{array}{l}\text { 1 Religador "NF" } \\
\text { 1 Religador "NA" }\end{array}$ & Opcional \\
\hline RA -03 fig.4.5 & $\begin{array}{l}\text { Restabelecimento } \\
\text { de 50\% da carga } \\
\text { dos dois } \\
\text { alimentadores }\end{array}$ & $\begin{array}{l}\text { 2 Religadores "NF" } \\
\text { 1 Religador "NA" }\end{array}$ & Sim \\
\hline RA -04 fig.4.6 & $\begin{array}{l}\text { Restabelecimento } \\
\text { de 66\% da carga de } \\
\text { um alimentador }\end{array}$ & $\begin{array}{l}\text { 2 Religadores "NF" } \\
\text { 1 Religador "NA" }\end{array}$ & Sim \\
\hline RA -05 fig.4.7 & $\begin{array}{l}\text { Restabelecimento } \\
\text { de 100\% do } \\
\text { alimentador para } \\
\text { defeitos na fonte }\end{array}$ & $\begin{array}{l}\text { 1 Religador "NF" } \\
\text { 1 Religador "NA" }\end{array}$ & Opcional \\
\hline
\end{tabular}




\subsection{INSERÇÃO DE AUTOMAÇÃO NA REDE DE DISTRIBUIÇÃO}

\subsubsection{Critério de Alocação de Recursos de Automação na Rede}

A metodologia proposta é compatível com qualquer critério de alocação de dispositivos, quer seja por inspeção do planejador quer seja por meio de modelo de busca otimizada.

Observa-se, no entanto que, para configurações simples de rede e de recursos de automação, uma solução viável é a busca exaustiva pelo melhor ponto de inserção dos dispositivos de seccionamento, considerando os requisitos tratados no item seguinte, bem como testando a alocação trecho a trecho mensurando seus benefícios através da END evitada.

\subsubsection{Requisitos para Aplicação de Recursos de Automação na Rede}

A aplicação de automação implica na presença de infra-estrutura, que envolve desde equipamentos digitais, que permitam a exportação e a importação de sinais digitais que indiquem seus estados e condições da rede naquele ponto, como sistemas de comunicação que permitem o tráfego destas informações entre os dispositivos envolvidos no processo.

Em muitas subestações, ainda é possível encontrar equipamentos não digitalizados, como relés eletromecânicos instalados há décadas atrás e que, por sua grande longevidade, ainda operam de forma satisfatória.

Porém, este tipo de equipamento não permite qualquer interação com os demais, não sendo possível sua operação em conjunto com outros sistemas instalados na rede. Em muitas destas subestações não há sequer dispositivos digitais que informem as condições do sistema ao centro de operações. 
Desta forma, quando, no processo de planejamento da rede, for considerada a alternativa de expansão da oferta de energia através de recursos de automação de rede, há de se levar em conta as condições apresentadas na subestação onde este será aplicado. Caso a subestação não seja "digitalizada", o custo deste processo (troca dos relés, instalação de rede de comunicação etc.) deve ser acrescido de forma a onerar esta alternativa de planejamento podendo inviabilizar a aplicação de recurso de automação.

Da mesma forma, devem ser consideradas as características da rede estudada, observando a presença ou não de redes de fibra óptica na região, a existência de "sombras" no sinal de celular etc.

No entanto, cabe ressaltar que as instalações de equipamentos digitais em novas subestações e o processo de digitalização das subestações antigas é uma forte tendência atual, de forma que as instalações eletromecânicas são substituídas em sua totalidade quando chegarem ao fim de sua vida útil.

\subsection{AVALIAÇÃO DAS ALTERNATIVAS DE AUTOMAÇÃO}

A base para a determinação do benefício econômico é a determinação da Energia Não Distribuída evitada pela aplicação de determinado recurso [22].

O custo anual da energia não distribuída evitada, em cada situação em que um dado sistema de automação é proposto como um recurso para solucionar uma violação de critério de desempenho, aplicado a uma alternativa de expansão de um sistema de distribuição, é definido como sendo a diferença entre custo da energia não distribuída esperada sem a presença do sistema de automação e com a presença do referido sistema, mantendo-se as demais estruturas da rede de distribuição, conforme explicitado na equação (4.3).

$$
B_{a}(i)=C E N D_{s a}(i)-C E N D_{c a}(i)
$$

Onde: 
$B_{a}(i)=$ Benefício do recurso de automação no ano i $(\mathrm{R} \$)$;

$C E N D_{\text {sa }}(i)=$ Custo da Energia Não Distribuída, sem automação, no ano i $(\mathrm{R} \$)$;

$C E N D_{c a}(i)=$ Custo da Energia Não Distribuída, com automação, no ano i $(\mathrm{R} \$)$.

Os custos totais de interrupção são calculados através da fórmula (4.4).

$\operatorname{CEND}_{x}(i)=\sum_{j=1}^{n}\left[\lambda_{j} \sum_{k=1}^{m}\left(r_{k j} D_{\max k} F C_{k} \operatorname{END}_{k}\right)\right]$

Onde:

$\mathrm{n}=$ número de elementos da rede;

$x=$ expressa a presença / ausência de automação (sa= sem automação e ca= com automação);

$\lambda_{j}=$ Taxa de falha (em vezes por ano) esperada para o elemento da rede em contingência, na condição $j$;

$r_{k j}=$ Tempo de restabelecimento da demanda média atendida pela barra $\mathrm{k}(\mathrm{h}) \mathrm{na}$ condição j;

$m$ = Número de barras do sistema;

$D_{\max k}=$ Demanda máxima da barra $\mathrm{k}$ no ano i (kVA);

$F C_{K}=$ Fator de carga associado à barra $\mathrm{k}$;

$E N D_{k}=$ Valor associado à energia não distribuída aos consumidores da barra $\mathrm{k}$ $(\mathrm{R} \$ / \mathrm{kWh})$

Além da demanda, do crescimento e do fator de carga, a aplicação da equação (4.4) requer o conhecimento de alguns parâmetros de desempenho da rede, como taxas de falhas e tempos médios de restabelecimento. Estes dados são valores médios baseados em informações da operação da rede. 
Entre as alternativas para a obtenção destes dados está a utilização de dados típicos por área geográfica e o tipo de rede (aérea, subterrânea etc.) ou a estimação dos índices de freqüência e duração de interrupção por defeitos nos equipamentos.

Outro parâmetro fundamental é o custo da Energia Não Distribuída associado a cada barra do sistema, obtidos através de estudos específicos para a obtenção desta informação.

Inicialmente é necessária a classificação das barras de acordo com os correspondentes tipos de consumidores conectados. Os grupos propostos são:

- Residencial;

- Comercial;

- Industrial;

- Outros (consumidores altamente críticos como, por exemplo, hospitais.).

Um custo específico é associado a cada classe de consumidores e aplicado à demanda total de cada barra do sistema. Isto obviamente implica na composição deste custo para barras que possuem um conjunto misto de consumidores.

As considerações precedentes para análise de uma alternativa de automação podem ser visualizadas através do fluxograma apresentado na figura 4.8.

Para cada ano do horizonte de planejamento, com violação de pelo menos um critério de desempenho, alternativas de soluções devem ser propostas e avaliadas. A solução de melhor relação custo-benefício deve conter uma combinação de obras de automação e convencionais. Para a escolha do plano de obras final devem ser também considerados os demais critérios de planejamento (perdas, tensão, carregamento etc.), bem como restrições orçamentárias.

Observa-se que esta seqüência está inserida no processo de planejamento apresentado na figura 4.2, sendo assim parte integrante daquele. 


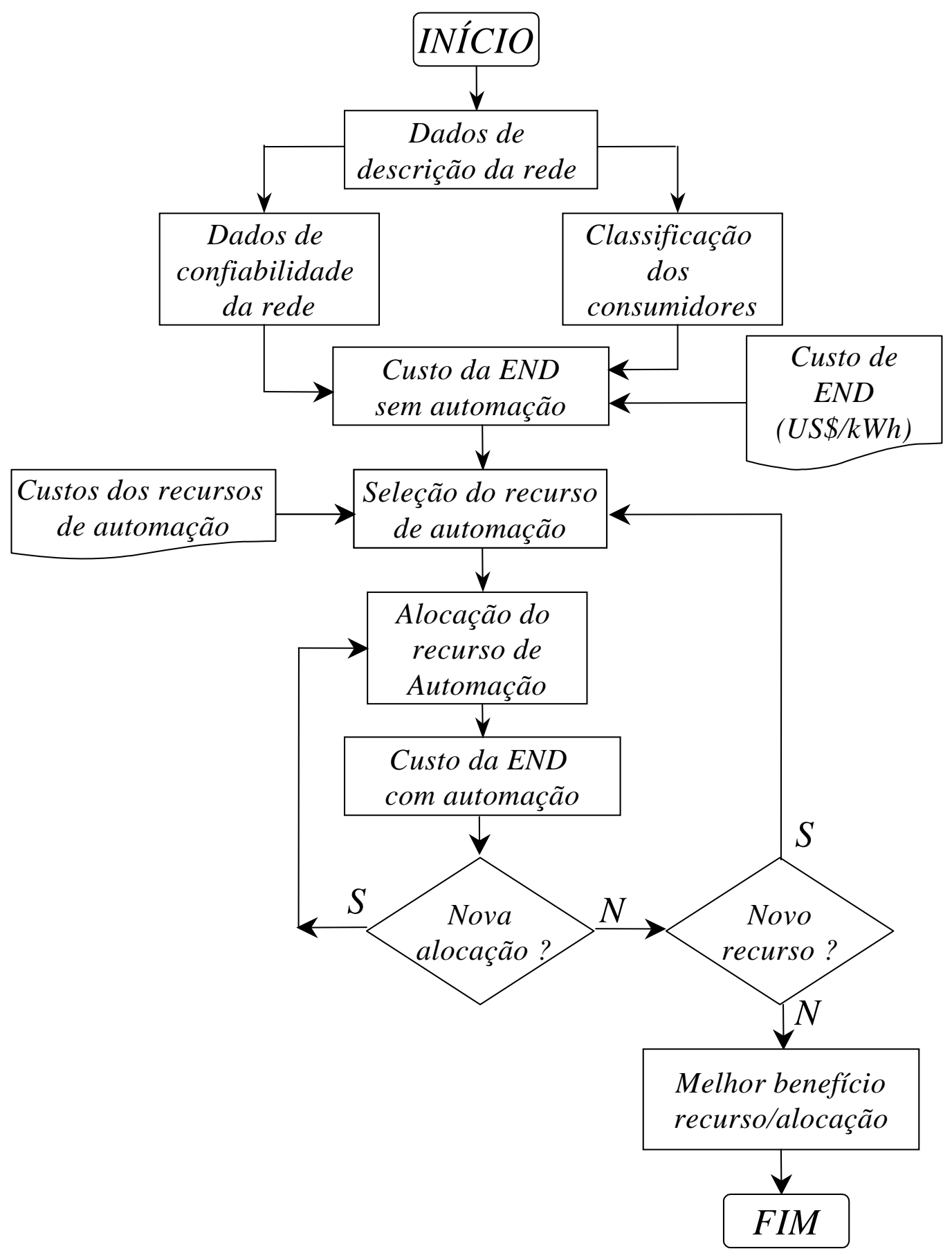

FIGURA 4.8 - Evolução das alternativas de automação 


\section{ESTUDOS DE CASO}

Serão apresentados dois estudos de caso com a aplicação da metodologia proposta: um em uma rede teórica, permitindo uma análise de sensibilidade de acordo com a variação de alguns parâmetros considerados e outro em uma rede real.

\subsection{CASO 1 - REDE TEÓRICA}

\subsubsection{Descrição e alternativas de melhoria}

Uma simples aplicação da metodologia apresentada foi realizada para a rede da figura 5.1. Na condição inicial, as subestações SE1, SE2 e SE3 não estão interconectadas. A contingência do transformador TR1 da subestação SE1 requer a transferência das cargas S1, S2 e S3 para o TR2, enquanto as cargas menos sensíveis, S5 e S6, teriam seu fornecimento interrompido por limitação de capacidade de carregamento.

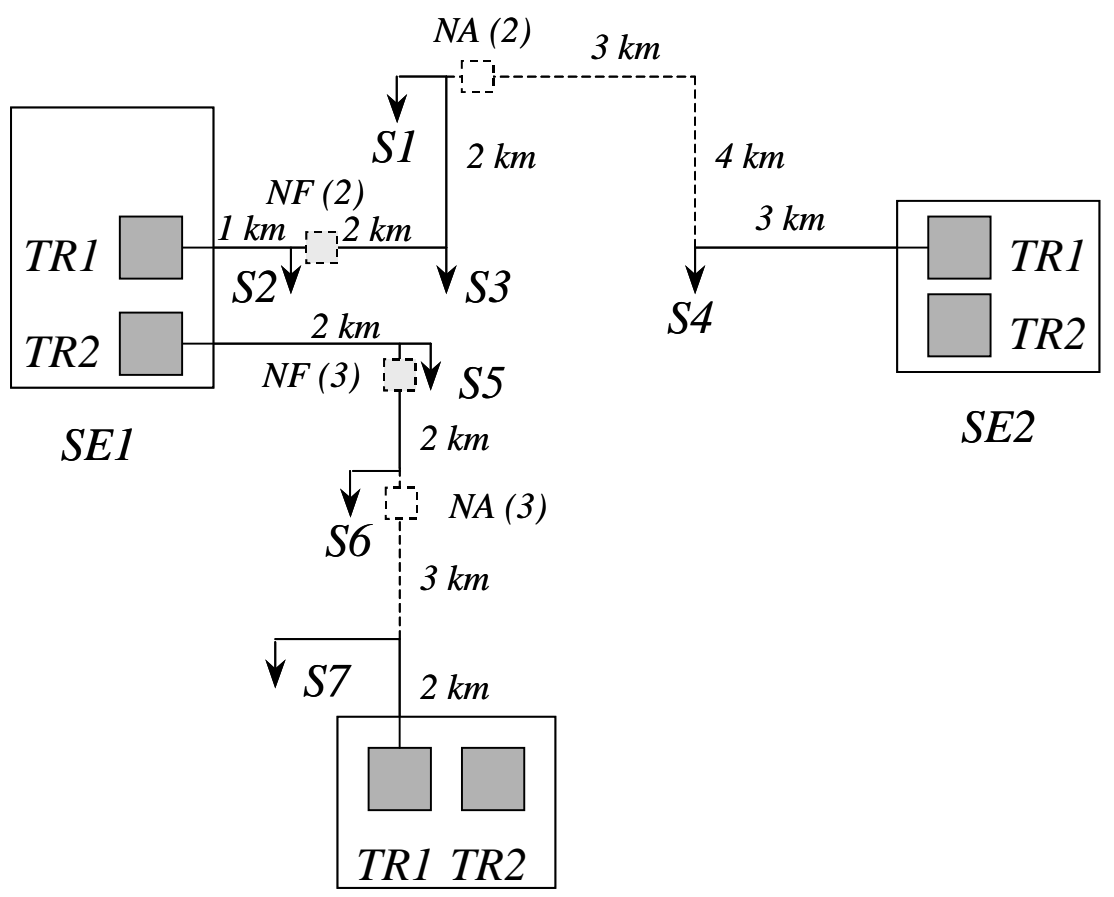

SE3

FIGURA 5.1 - Sistema em estudo 
Os dados de carga são apresentados na tabela 5.1. A indisponibilidade dos alimentadores foi adotada como sendo 0,25h/km/ano e a taxa de crescimento de carga 3\% para todas as cargas.

TABELA 5.1 - Dados do sistema em estudo.

\begin{tabular}{|c|c|c|c|c|}
\hline \multicolumn{2}{|c|}{ Carga } & Tipo & Fator de carga & $\begin{array}{c}\text { Custo da END } \\
\text { (R\$/kWh) }\end{array}$ \\
\cline { 1 - 2 } Identificação & MVA & Hospital & 0,8 & 6,0 \\
\hline S1 & 4,5 & Comercial & 0,6 & 4,0 \\
\hline S2 & 4,0 & Residencial & 0,5 & 2,5 \\
\hline S5 & 2,0 & Comercial & 0,6 & 4,0 \\
\hline S6 & 4,5 & Residencial & 0,5 & 2,5 \\
\hline
\end{tabular}

As alternativas propostas para aumento da continuidade de serviço são as seguintes:

- Alternativa 1: instalação de um novo transformador (TR3) na SE1;

- Alternativa 2: construção de um trecho de alimentador interligando as SE's 1 e 2, com religadores NA e NF, sendo o NF instalado entre as cargas S2 e S3;

- Alternativa 2: Idêntica a alternativa 2 porém com o religador NF instalado entre as cargas S1 e S3;

- Alternativa 3: construção de um trecho de alimentador interligando as SE's 1 e 2 como na alternativa 2 e também uma interligação idêntica entre as SE's 1 e 3.

Na contingência do TR1 da SE1, a Energia Não Distribuída em cada alternativa está associada com o suprimento ou não suprimento das cargas como apresentado na tabela 5.2. Nota-se que a alternativa 2 envolve de fato duas condições (denominadas 2 e 2'), dependendo da alocação do religador NF. 
TABELA 5.2 - Cargas supridas e não supridas para cada alternativa durante a contingência do TR1 da SE1.

\begin{tabular}{|c|c|c|}
\hline Alternativa & Carga suprida & Carga não suprida \\
\hline 1 & S1, S2, S3, S5 E S6 & S2 \\
\hline 2 & S1, S3, S5 e S6 & S2 e S3 \\
\hline 2, & S1, S5 e S6 & - \\
\hline 3 & S1, S2, S3, S5 E S6 & \\
\hline
\end{tabular}

Como uma simplificação adicional assumida, não foram consideradas supostas multas em conseqüência do não fornecimento de energia para algumas cargas.

\subsubsection{Custos das alternativas e análises de sensibilidade}

Os custos de investimento e manutenção envolvidos nas alternativas propostas estão expostos na tabela 5.3.

TABELA 5.3 - Custos de investimento e manutenção.

\begin{tabular}{|c|c|c|c|}
\hline \multirow{2}{*}{ Alternativa } & Investimento (kR\$) & \multicolumn{2}{|c|}{ Custo de manutenção } \\
\cline { 2 - 4 } & & $(\mathrm{kR} \$$ /ano) & $(\%)$ \\
\hline 1 & 600 & 12 & 2 \\
\hline 2 e 2' & 180 & 7 & $5^{\star}$ \\
\hline 3 & 280 & 10 & $5^{\star}$ \\
\hline
\end{tabular}

* Foram desconsiderados custos de manutenção para os religadores

Com base nestes valores, naqueles apresentados na tabela 5.1, nos critérios operativos representados na tabela 5.2 e nas características da rede descritas 
anteriormente, foi calculado, ano a ano, o custo e o benefício de cada alternativa proposta.

Os Valores Presentes da diferença entre o benefício e o custo de cada alternativa, para um período de 10 anos foram obtidos através da fórmula 5.1, considerando a taxa de atualização de capital de 10\% e vida útil das instalações de 25 anos:

$$
V . P .=\frac{1}{(1+j)^{n}} \times P_{n}
$$

Onde:

V.P. = Valor presente;

$\mathrm{J}=$ taxa de atualização de capital;

$\mathrm{n}=\mathrm{ano}$

Pn = Parcela (benefício - custo) no ano "n".

Os resultados estão apresentados a seguir:

- $\quad$ Alternativa 1: (347kR\$);

- Alternativa 2: 65kR\$;

- Alternativa 2': 35kR\$;

- Alternativa 3: (14kR\$).

Os resultados entre parênteses representam valores negativos que correspondem a situações onde o custo é maior que o benefício.

Neste caso, a alternativa 2 se mostrou a melhor. A diferença entre as alternativas 2 e 2' mostra a importância da alocação dos dispositivos automáticos de chaveamento de rede.

Uma vez que as conseqüências econômicas de um desligamento estão sujeitas a uma incerteza relativamente alta dependendo do tipo de consumidor, uma análise de sensibilidade se faz necessária. 
A sensibilidade dos Valores Presentes do exemplo em relação ao custo da interrupção da carga S1 pode ser vista na figura 5.2.

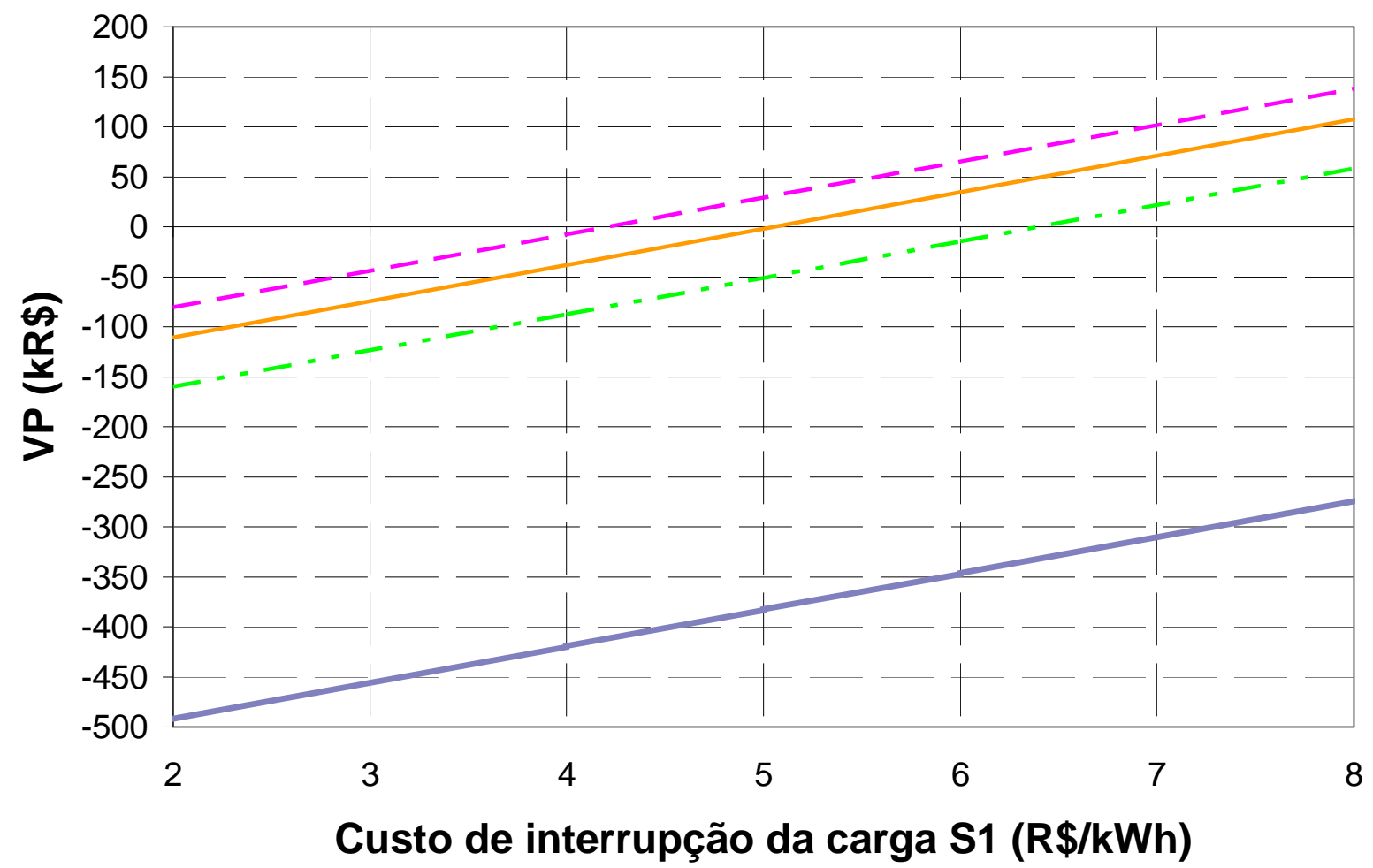

Alt. $1--$ Alt. $2-$ Alt. 2' - - Alt. 3

FIGURA 5.2 - Análise de sensibilidade

\subsection{CASO 2 - REDE REAL}

\subsubsection{Características do sistema em estudo}

Esta aplicação consiste na análise de religadores em 5 alimentadores supridos por 3 subestações que atendem uma região com consumidores com diferentes níveis de requisitos de continuidade. 
As subestações são:

- SUBESTAÇÃO A

- 2 transformadores 138/13,8 kV de 40/60MVA, operando com $85 \%$ da capacidade nominal;

- 16 alimentadores trifásicos aéreos em cabos de alumínio com bitola 336 MCM, dos quais 2 são dedicados ao atendimento do centro de carga.

- SUBESTAÇÃO B

- 2 transformadores 138/13,8 kV de 40/60MVA, operando com $85 \%$ da capacidade nominal;

- 14 alimentadores trifásicos aéreos em cabos de alumínio com bitola 336 MCM, dos quais 1 é dedicado ao atendimento do centro de carga.

\section{- SUBESTAÇÃO C}

- 2 transformadores 88/13,8 kV de 15/20MVA, operando com $75 \%$ da capacidade nominal;

- 9 alimentadores trifásicos aéreos em cabos de alumínio com bitola 336 MCM, dos quais 2 são dedicados ao atendimento do centro de carga.

Os alimentadores considerados, que atendem a região selecionada, são os seguintes:

- SE A:

- A1;

- A2.

- SE B:

- B1.

- SE C:

- $\mathrm{C} 1$; 
- $\mathrm{C} 2$

A tabela 5.4 apresenta a situação de carregamento dos circuitos envolvidos:

\begin{tabular}{|c|c|c|c|}
\hline ALIMENTADOR & CAP (A) & CARGA (A) & PORC \\
\hline A1 & 400 & 450 & $113 \%$ \\
\hline A2 & 400 & 300 & $75 \%$ \\
\hline B1 & 400 & 250 & $63 \%$ \\
\hline C1 & 400 & 480 & $120 \%$ \\
\hline C2 & 400 & 310 & $78 \%$ \\
\hline
\end{tabular}

TABELA 5.4 - Carregamento dos Alimentadores Envolvidos

Os alimentadores têm configuração radial e são constituídos por um tronco principal e ramais secundários, que atendem consumidores primários e transformadores da concessionária.

A topologia inicial da rede é a apresentada na figura 5.3. 


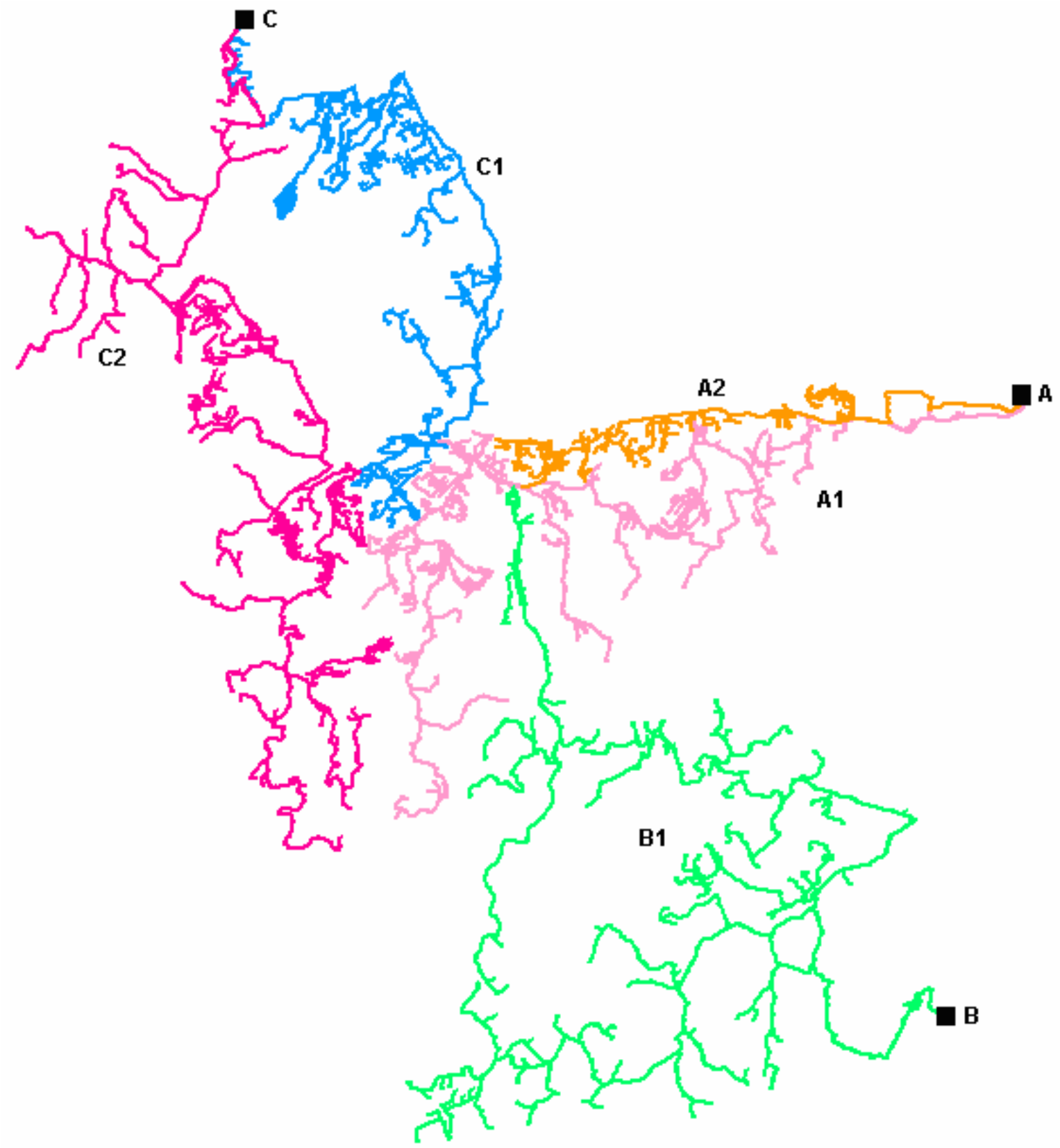

FIGURA 5.3 - Topologia da Rede Primária em Estudo

\subsubsection{Alternativas de planejamento}

Foram consideradas para o atendimento da expansão da rede duas alternativas de planejamento: uma convencional e outra considerando a metodologia proposta nesta dissertação, que inclui a utilização de recursos de automação no planejamento da rede de distribuição, as quais são descritas a seguir. 
a) Alternativa Convencional

A alternativa convencional consiste na instalação de uma nova subestação com três transformadores de 12MVA, suprida por dois alimentadores em $34,5 \mathrm{kV}$ e com quatro alimentadores primários em 13,8kV.

Os custos unitários estimados para a análise econômica da alternativa convencional são:

- Transformador:

$\mathrm{R} \$ 600.000,00$

- Bay AT do transformador e LT:

$\mathrm{R} \$ 60.000,00$

- Bay BT do transformador:

$\mathrm{R} \$ 40.000,00$

- Saída de alimentadores:

$\mathrm{R} \$ 40.000,00$

- Terreno:

$\mathrm{R} \$ 100.000,00$

- Custos adicionais (painéis, civil etc.)

$\mathrm{R} \$ 400.000,00$

- Custos com rede 13,8kV para conexão:

$\mathrm{R} \$ 600.000,00$

Considerando que a subestação terá 3 transformadores, 5 conexões AT (uma para cada LT e uma para cada transformador), 3 conexões BT (uma para cada transformador) e 4 saídas de alimentador, o custo total de investimento aproximado desta alternativa é de $\mathrm{R} \$ 3.480 .000$.

b) Alternativa com Recursos de Automação

A solução considerando recursos de automação, embora possa ser decomposta em várias alternativas intermediárias como será apresentado posteriormente neste trabalho, consiste basicamente na instalação de duas subestações pequenas localizadas no centro de carga, com apenas um transformador de 12 MVA, uma LT de 34,5kV alimentando cada uma das subestações e quatro alimentadores de distribuição em 13,8kV conectados a rede existente através de religadores automáticos.

De forma a garantir a mesma confiabilidade do critério "N-1" para defeitos de fonte, esta alternativa contempla a instalação de religadores automáticos em 
seus alimentadores de forma a garantir a continuidade do fornecimento em casos de defeitos de fonte. Os custos unitários aproximados envolvidos nesta alternativa são os seguintes:

- Transformador:

- Bay AT do transformador:

- Bay BT do transformador:

- Terreno:

- Custos adicionais (painéis, civil etc.)

- Custos com rede $13,8 \mathrm{kV}$ para conexão:

- Custos com automação:
$\mathrm{R} \$ 600.000,00$

$\mathrm{R} \$ 60.000,00$

$\mathrm{R} \$ 40.000,00$

$\mathrm{R} \$ 60.000,00$

$\mathrm{R} \$ 100.000,00$

$\mathrm{R} \$ 200.000,00$

$\mathrm{R} \$ 300.000,00$

Considerando que cada subestação terá 1 transformador, 1 conexão AT e 1 conexão BT (as saídas dos alimentadores se dão através de religadores e estão contempladas no custo de automação), o custo total de investimento aproximado desta alternativa é de $\mathrm{R} \$ \mathbf{2 . 2 2 0 . 0 0 0 , 0 0}$

Através desta análise prévia observa-se que o custo de investimento envolvido em uma alternativa convencional supera aquele envolvido na alternativa que considera recursos de automação em mais de 50\%.

Ambas as alternativas atendem aos critérios de planejamento estabelecidos (queda de tensão, carregamento etc.), observando ainda que a alternativa que contempla recursos de automação, por envolver subestações menores que podem ser alocadas mais próximas do centro de carga, apresentam menor custo de perdas e menores problemas de queda de tensão do que a alternativa convencional, que envolve uma subestação maior tornando difícil a aquisição de terrenos para sua construção próxima ao centro de carga.

Considerando, além das vantagens supracitadas, que a alternativa envolvendo recursos de automação é concebida e projetada para garantir, pelo menos, o mesmo grau de confiabilidade inerente ao critério "N-1" local e que, além disso, ainda permite socorro automático de blocos de carga sensíveis na ocorrência de defeitos na rede de 
distribuição, fica claro que o benefício oriundo desta alternativa, em termos de END, supera aquele proporcionado pela alternativa convencional.

Desta forma, a seguir será aprofundada apenas a análise da alternativa com recurso de automação, considerando algumas de suas variantes, visando encontrar aquela que apresente melhor relação custo-benefício.

\subsubsection{Análise da Alternativa com Recurso de automação}

a) Critérios e hipóteses

Para a realização dos estudos, foram considerados os seguintes critérios e hipóteses:

- Os trechos assinalados em vermelho nas figuras 5.4, 5.5 e 5.6 atendem a cargas prioritárias e sensíveis. O custo da END de determinada carga foi considerado como sendo o produto do custo de interrupção médio para a região pelo fator de sensibilidade (Fs). Este fator exprime o grau de sensibilidade à interrupção de uma carga em relação à média. O valor do custo de interrupção médio foi considerado como sendo $\mathrm{R} \$ 3,00 / \mathrm{kWh}$ e o fator de sensibilidade foi considerado igual a 3 para as cargas mais sensíveis e 1 para as demais; 


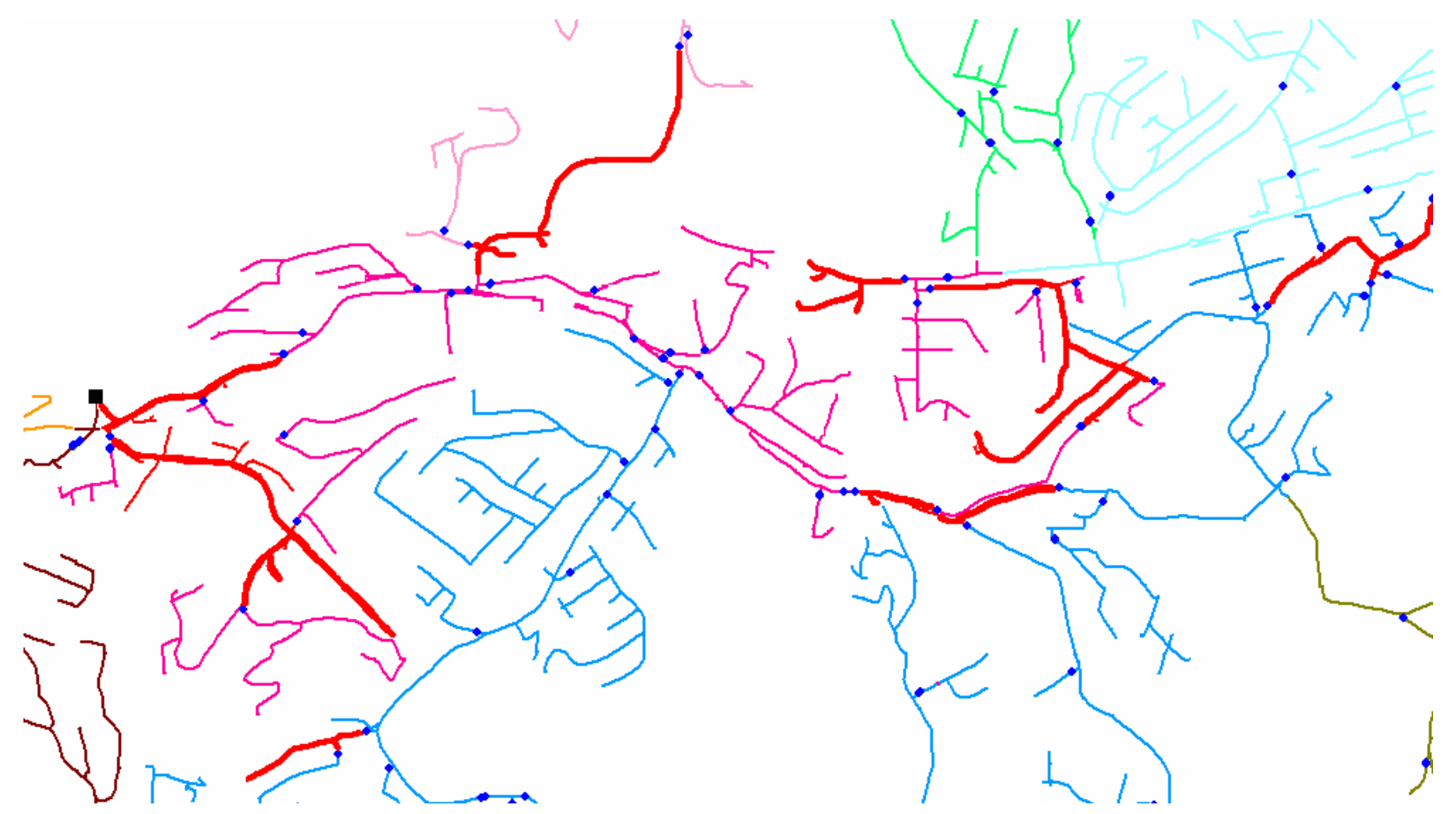

FIGURA 5.4 - Trechos que Atendem Cargas Prioritárias

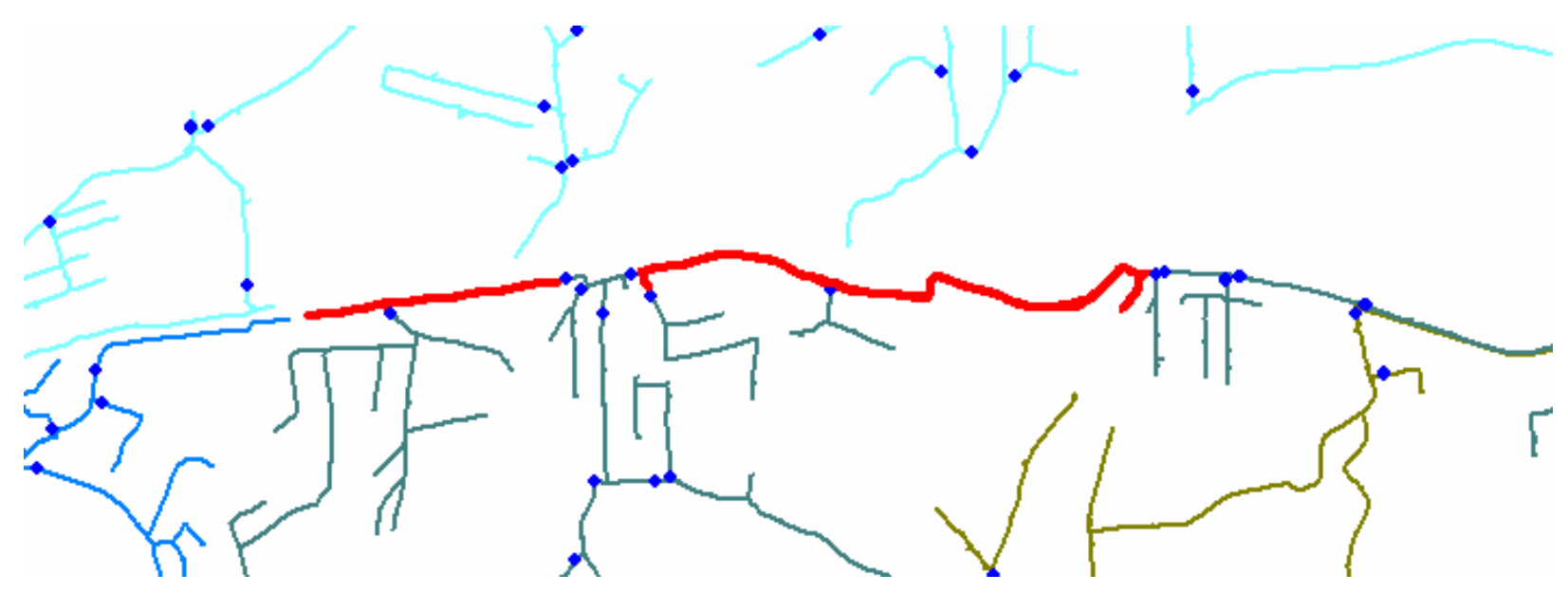

FIGURA 5.5 - Trechos que Atendem Cargas Prioritárias 


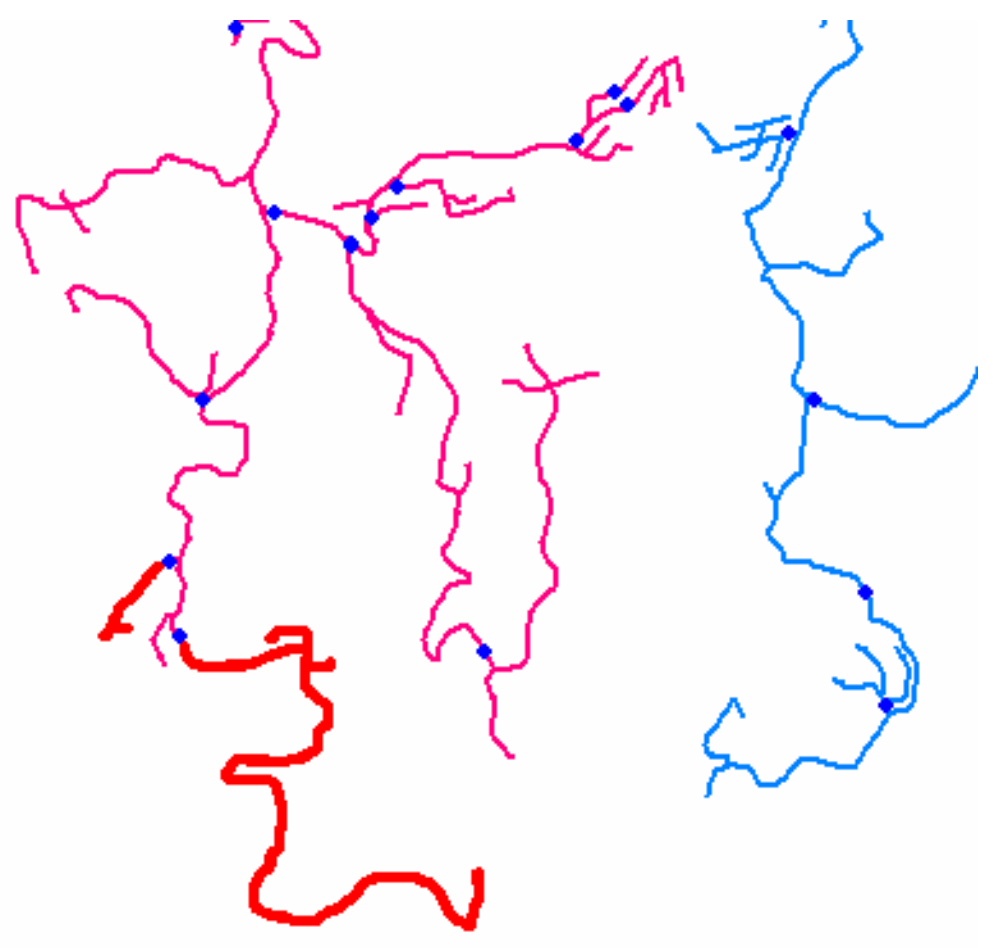

FIGURA 5.6 - Trechos que Atendem Cargas Prioritárias

- As taxas de defeito dos circuitos A1 e A2 foram extraídas de registros da concessionária e para os demais circuitos adotou-se o valor médio das taxas de defeito da região (tabela 5.5);

TABELA 5.5 - Taxas de Defeitos

\begin{tabular}{|c|c|}
\hline ALIMENTADOR & TAXAS DE DEFEITOS (DEF/km/ano) \\
\hline A1 & 2,9 \\
\hline A2 & 3,8 \\
\hline B1 & 3,4 \\
\hline C1 & 3,4 \\
\hline C2 & 3,4 \\
\hline
\end{tabular}

- A porcentagem considerada de defeitos permanentes é $30 \%$ do total de defeitos;

- A taxa de defeito dos transformadores das subestações é de 0,1def./ano;

- Os tempos para cálculo da Energia não Distribuída durante interrupções - END são os apresentados na tabela 5.6; 
TABELA 5.6 - Tempos para o cálculo de END

\begin{tabular}{|c|c|c|}
\hline \multicolumn{2}{|c|}{ T1 (h) - Restabelecimento dos blocos sem defeito } & \multirow{2}{*}{$\begin{array}{c}\text { 2 (h) - Reparo do bloco } \\
\text { defeituoso }\end{array}$} \\
\hline Restabelecimento Manual & Restabelecimento Autom. & 0,5 \\
\hline 0,5 & 0,02 & 0 \\
\hline
\end{tabular}

- Não há transferências de cargas entre os alimentadores em estudo e os demais;

- O fator de carga é 0,6 para todos os alimentadores em estudo;

- O custo de religador é $\mathrm{R} \$ 30.000,00$;

- A taxa de crescimento de carga da região é $5 \%$ a. a.;

- A taxa de retorno de investimento adotada é $15 \%$ a. a.;

- As tensões nos barramentos das Subestações foram ajustadas de forma que as tensões ao longo dos alimentadores permanecessem dentro de faixas admissíveis;

- Cada linha 34,5 kV que alimenta as subestações novas tem comprimento de $5 \mathrm{~km}$, estrutura compacta e apresenta taxa de falha de 0,75 def/km/ano, das quais $50 \%$ são permanentes.

\subsubsection{Análise da Alternativa}

A alternativa base consiste na topologia apresentada na figura 5.7, onde se observa a conexão de quatro alimentadores provenientes das duas novas subestações compactas à rede existente. 


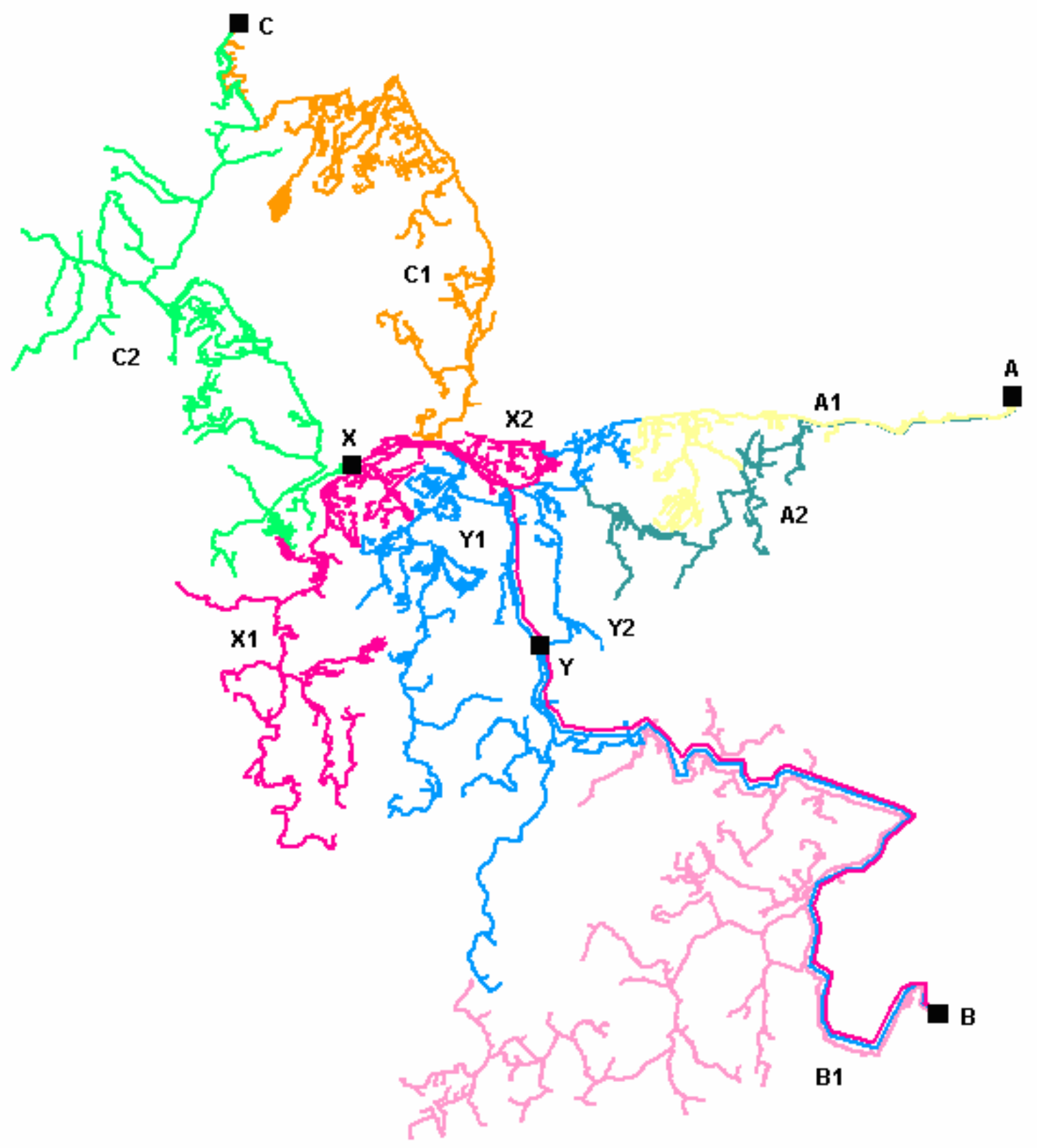

FIGURA 5.7 - Reestruturação Topológica

A tabela 5.7 apresenta as condições de carregamento dos alimentadores envolvidos antes e depois da alteração topológica proposta, determinadas por meio de fluxo de potência. 
TABELA 5.7 - Carregamento dos Circuitos

\begin{tabular}{|c|c|c|c|c|c|c|}
\hline \multirow{2}{*}{ ALIMENTADOR } & \multicolumn{6}{|c|}{ CORRENTE (A) } \\
\cline { 2 - 8 } & \multicolumn{2}{|c|}{ CONFIGURAÇÃO INICIAL } & \multicolumn{2}{c|}{ CONFIGURAÇÃO PROPOSTA } \\
\cline { 2 - 8 } & FASE D & FASE E & FASE F & FASE D & FASE E & FASE F \\
\hline A1 & 452 & 384 & 501 & 89 & 107 & 96 \\
\hline A2 & 198 & 292 & 257 & 80 & 118 & 105 \\
\hline B1 & 204 & 248 & 230 & 178 & 221 & 168 \\
\hline C1 & 298 & 316 & 489 & 290 & 255 & 409 \\
\hline C2 & 149 & 353 & 306 & 179 & 198 & 175 \\
\hline X1 & - & - & - & 61 & 145 & 144 \\
\hline X2 & - & - & - & 211 & 231 & 258 \\
\hline Y1 & - & - & - & 128 & 104 & 168 \\
\hline Y2 & - & - & - & 106 & 126 & 148 \\
\hline
\end{tabular}

Com a redistribuição das cargas de acordo com a alternativa topológica proposta, foram identificados os diferentes níveis de sensibilidade de cada um dos blocos de carga, entendidos como sendo um trecho de alimentador entre chaves consecutivas. Para tanto os blocos de carga dos alimentadores envolvidos foram numerados (ANEXO A).

Esta análise permitiu a avaliação do desempenho da configuração proposta no atendimento das cargas de modo geral e, em particular aos blocos que atendem consumidores sensíveis, conforme estabelecido nos critérios e hipóteses. Desta análise resultou a identificação dos alimentadores mais críticos em condição normal e de contingência, quanto aos níveis de tensão, carregamento e continuidade de serviço.

Considerando as cargas dos ramais concentradas no tronco foi realizado o cálculo da END resultante da ocorrência de defeito em cada um dos blocos do tronco, cujo resultado está apresentado na tabela 5.8, onde:

- $\mathrm{L}=$ Comprimento do bloco com defeito $(\mathrm{km})$;

- $\quad$ TMA1 = Tempo de preparo e localização do bloco com defeito (h); 
- TMA2 = Tempo de reparo do bloco com defeito (h);

- F. S. = Fator de Sensibilidade da carga do bloco i;

- $\mathrm{kW}_{\mathrm{i}}=$ Carga do bloco i $(\mathrm{kW})$;

- Def. ano = quantidade de defeitos por ano no bloco com defeito;

- C. $E .=$ Custo Médio da END (R\$/kWh);

ENDPREP+LOC $=$ Custo da END devido ao tempo de preparação e de localização do bloco com defeito $(\mathrm{R} \$)$;

$$
E N D_{P R E P+L O C}=\left(\sum k W_{i} \times F . S_{\bullet_{i}}\right) \times \text { Def. } . \text { ano }_{B L O C O} \times C . E . \times T M A 1
$$

$E_{N D} D_{R E A R O}=$ Custo da END devido ao tempo de reparo do bloco com defeito $(R \$)$;

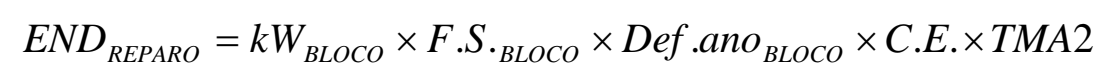

Nota-se que apenas o bloco com defeito permanece sem atendimento durante 0 tempo de reparo porque a topologia proposta prevê que todos os demais blocos possam ser restabelecidos por meio de chaveamentos

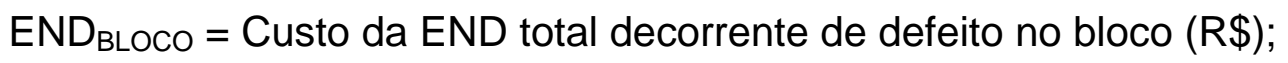

$$
E N D_{B L O C O}=E N D_{P R E P+L O C}+E N D_{R E P A R O}
$$

As linhas destacadas em azul correspondem aos blocos que contem cargas prioritárias ou sensíveis. 


\begin{tabular}{|c|c|c|c|c|c|c|c|c|c|c|c|c|}
\hline \multirow{2}{*}{ Alimentador } & \multirow{2}{*}{ A1 } & \multirow{2}{*}{$\mathrm{L}(\mathrm{km})$} & \multirow{2}{*}{$\begin{array}{l}\text { Taxa de defeito } \\
\text { (def./km./ano) }\end{array}$} & \multirow{2}{*}{ Defeitos/Ano } & \multirow{2}{*}{$\begin{array}{l}\text { TMA1 } \\
\text { (h) }\end{array}$} & \multirow{2}{*}{$\begin{array}{l}\text { TMA2 } \\
\text { (h) }\end{array}$} & \multirow{2}{*}{$\begin{array}{l}\text { Carga do } \\
\text { bloco } \\
\mathrm{kVA}_{\text {Médio }}\end{array}$} & \multirow{2}{*}{$\begin{array}{l}\text { Custo da } \\
\text { Energia } \\
(\mathrm{R} \$ / \mathrm{kWh})\end{array}$} & \multirow{2}{*}{ F. S. } & \multicolumn{3}{|c|}{ Custo da Energia Não Distribuída (R\$) } \\
\hline & & & & & & & & & & $\begin{array}{l}\text { END (Prep. } \\
\quad+\text { Loc.) }\end{array}$ & END (Reparo) & END TOTAL \\
\hline \multirow{7}{*}{ Blocos } & 1 & 3,8 & 2,9 & 3,31 & \multirow{7}{*}{0,50} & \multirow{7}{*}{0,50} & 19 & \multirow{7}{*}{3} & 1 & 7126 & 95 & 7221 \\
\hline & 2 & 2,95 & 2,9 & 2,57 & & & 942 & & 1 & 5532 & 3626 & 9159 \\
\hline & 6 & 0,23 & 2,9 & 0,20 & & & 13 & & 1 & 431 & 4 & 435 \\
\hline & 7 & 1,1 & 2,9 & 0,96 & & & 90 & & 1 & 2063 & 129 & 2192 \\
\hline & 9 & 1,55 & 2,9 & 1,35 & & & 81 & & 1 & 2907 & 164 & 3071 \\
\hline & 10 & 0,63 & 2,9 & 0,55 & & & 20 & & 1 & 1181 & 17 & 1198 \\
\hline & 12 & 2,11 & 2,9 & 1,84 & & & 271 & & 1 & 3957 & 747 & 4704 \\
\hline \multirow[b]{2}{*}{ Alimentador } & \multirow[b]{2}{*}{ A2 } & \multirow[b]{2}{*}{$\mathrm{L}(\mathrm{km})$} & \multirow{2}{*}{$\begin{array}{l}\text { Taxa de defeito } \\
\text { (def./km./ano) }\end{array}$} & \multirow[b]{2}{*}{ Defeitos/Ano } & \multirow{2}{*}{$\begin{array}{l}\text { TMA1 } \\
\text { (h) }\end{array}$} & \multirow{2}{*}{$\begin{array}{l}\text { TMA2 } \\
\text { (h) }\end{array}$} & \multirow{2}{*}{$\begin{array}{l}\text { Carga do } \\
\text { bloco } \\
\mathrm{kVA}_{\text {Médio }}\end{array}$} & \multirow{2}{*}{$\begin{array}{l}\text { Custo da } \\
\text { Energia } \\
(\mathrm{R} \$ / \mathrm{kWh})\end{array}$} & \multirow[b]{2}{*}{ F. S. } & \multicolumn{3}{|c|}{ Custo da Energia Não Distribuída (R\$) } \\
\hline & & & & & & & & & & $\begin{array}{l}\text { END (Prep. } \\
\quad+\text { Loc.) }\end{array}$ & END (Reparo) & END TOTAL \\
\hline \multirow{9}{*}{ Blocos } & 1 & 1,89 & 3,8 & 2,15 & \multirow{9}{*}{0,50} & \multirow{9}{*}{0,50} & 355 & \multirow{9}{*}{3} & 1 & 7786 & 1146 & 8932 \\
\hline & 2 & 0,27 & 3,8 & 0,31 & & & 15 & & 1 & 1112 & 7 & 1119 \\
\hline & 3 & 0,84 & 3,8 & 0,96 & & & 6 & & 1 & 3460 & 9 & 3469 \\
\hline & 4 & 1,42 & 3,8 & 1,62 & & & 251 & & 1 & 5850 & 610 & 6460 \\
\hline & 6 & 0,29 & 3,8 & 0,33 & & & 131 & & 1 & 1195 & 65 & 1260 \\
\hline & 8 & 1,51 & 3,8 & 1,72 & & & 225 & & 3 & 6220 & 1743 & 7963 \\
\hline & 12 & 0,28 & 3,8 & 0,32 & & & 235 & & 3 & 1153 & 337 & 1490 \\
\hline & 13 & 0,54 & 3,8 & 0,62 & & & 109 & & 1 & 2224 & 101 & 2325 \\
\hline & 16 & 3,83 & 3,8 & 4,37 & & & 163 & & 1 & 15777 & 1065 & 16842 \\
\hline
\end{tabular}




\begin{tabular}{|c|c|c|c|c|c|c|c|c|c|c|c|c|}
\hline \multirow{2}{*}{ Alimentador } & \multirow{2}{*}{ B1 } & \multirow{2}{*}{$\mathrm{L}(\mathrm{km})$} & \multirow{2}{*}{$\begin{array}{l}\text { Taxa de defeito } \\
\text { (def./km./ano) }\end{array}$} & \multirow{2}{*}{ Defeitos/Ano } & \multirow{2}{*}{$\begin{array}{l}\text { TMA1 } \\
\text { (h) }\end{array}$} & \multirow{2}{*}{$\begin{array}{l}\text { TMA2 } \\
\text { (h) }\end{array}$} & \multirow{2}{*}{$\begin{array}{c}\text { Carga do } \\
\text { bloco } \\
\text { kVA }_{\text {Médio }}\end{array}$} & \multirow{2}{*}{$\begin{array}{c}\text { Custo da } \\
\text { Energia } \\
\text { (R\$/kWh) }\end{array}$} & \multirow{2}{*}{ F. S. } & \multicolumn{3}{|c|}{ Custo da Energia Não Distribuída (R\$) } \\
\hline & & & & & & & & & & $\begin{array}{l}\text { END (Prep. } \\
\quad+\text { Loc.) }\end{array}$ & END (Reparo) & END TOTAL \\
\hline \multirow{10}{*}{ Blocos } & 1 & 4,38 & 3,4 & 4,47 & \multirow{10}{*}{0,50} & \multirow{10}{*}{0,50} & 247 & \multirow{10}{*}{3} & 1 & 18580 & 1653 & 20233 \\
\hline & 2 & 1,25 & 3,4 & 1,28 & & & 28 & & 1 & 5303 & 53 & 5355 \\
\hline & 3 & 3,44 & 3,4 & 3,51 & & & 167 & & 1 & 14593 & 878 & 15471 \\
\hline & 5 & 2,74 & 3,4 & 2,79 & & & 164 & & 1 & 11623 & 689 & 12312 \\
\hline & 6 & 5,85 & 3,4 & 5,97 & & & 49 & & 1 & 24816 & 435 & 25251 \\
\hline & 9 & 14,5 & 3,4 & 14,79 & & & 243 & & 1 & 61510 & 5391 & 66901 \\
\hline & 12 & 11,5 & 3,4 & 11,73 & & & 940 & & 1 & 48784 & 16532 & 65316 \\
\hline & 13 & 4,7 & 3,4 & 4,79 & & & 242 & & 1 & 19938 & 1743 & 21681 \\
\hline & 20 & 1,6 & 3,4 & 1,63 & & & 281 & & 1 & 6787 & 687 & 7475 \\
\hline & 21 & 1,4 & 3,4 & 1,43 & & & 413 & & 1 & 5939 & 884 & 6823 \\
\hline \multirow[b]{2}{*}{ Alimentador } & \multirow[b]{2}{*}{ C1 } & \multirow[b]{2}{*}{$\mathrm{L}(\mathrm{km})$} & \multirow{2}{*}{$\begin{array}{l}\text { Taxa de defeito } \\
\text { (def./km./ano) }\end{array}$} & \multirow[b]{2}{*}{ Defeitos/Ano } & \multirow{2}{*}{$\begin{array}{l}\text { TMA1 } \\
\text { (h) }\end{array}$} & \multirow{2}{*}{$\begin{array}{l}\text { TMA2 } \\
\text { (h) }\end{array}$} & \multirow{2}{*}{$\begin{array}{c}\text { Carga do } \\
\text { bloco } \\
\text { kVA }_{\text {Médio }}\end{array}$} & \multirow{2}{*}{$\begin{array}{c}\text { Custo da } \\
\text { Energia } \\
(\mathrm{R} \$ / \mathrm{kWh})\end{array}$} & \multirow[b]{2}{*}{ F. S. } & \multicolumn{3}{|c|}{ Custo da Energia Não Distribuída (R\$) } \\
\hline & & & & & & & & & & $\begin{array}{l}\text { END (Prep. } \\
\quad+\text { Loc.) }\end{array}$ & END (Reparo) & END TOTAL \\
\hline \multirow{7}{*}{ Blocos } & 1 & 2,85 & 3,4 & 2,91 & \multirow{7}{*}{0,50} & \multirow{7}{*}{0,50} & 384 & \multirow{7}{*}{3} & 1 & 22919 & 1674 & 24593 \\
\hline & 2 & 1,9 & 3,4 & 1,94 & & & 1260 & & 1 & 15279 & 3663 & 18942 \\
\hline & 4 & 1,5 & 3,4 & 1,53 & & & 552 & & 1 & 12063 & 1267 & 13329 \\
\hline & 6 & 1,63 & 3,4 & 1,66 & & & 930 & & 1 & 13108 & 2319 & 15427 \\
\hline & 11 & 1,92 & 3,4 & 1,96 & & & 801 & & 1 & 15440 & 2353 & 17793 \\
\hline & 14 & 2,4 & 3,4 & 2,45 & & & 780 & & 1 & 19300 & 2864 & 22164 \\
\hline & 19 & 1,3 & 3,4 & 1,33 & & & 183 & & 3 & 10454 & 1092 & 11546 \\
\hline
\end{tabular}




\begin{tabular}{|c|c|c|c|c|c|c|c|c|c|c|c|c|}
\hline \multirow{2}{*}{ Alimentador } & \multirow{2}{*}{$\mathrm{C} 2$} & \multirow{2}{*}{$\mathrm{L}(\mathrm{km})$} & \multirow{2}{*}{$\begin{array}{l}\text { Taxa de defeito } \\
\text { (def./km./ano) }\end{array}$} & \multirow{2}{*}{ Defeitos/Ano } & \multirow{2}{*}{$\begin{array}{l}\text { TMA1 } \\
\text { (h) }\end{array}$} & \multirow{2}{*}{$\begin{array}{l}\text { TMA2 } \\
\text { (h) }\end{array}$} & \multirow{2}{*}{$\begin{array}{c}\text { Carga do } \\
\text { bloco } \\
\text { kVA }_{\text {Médio }}\end{array}$} & \multirow{2}{*}{$\begin{array}{l}\text { Custo da } \\
\text { Energia } \\
(\mathrm{R} \$ / \mathrm{kWh})\end{array}$} & \multirow{2}{*}{ F. S. } & \multicolumn{3}{|c|}{ Custo da Energia Não Distribuída (R\$) } \\
\hline & & & & & & & & & & $\begin{array}{l}\text { END (Prep. } \\
+ \text { +Loc.) }\end{array}$ & END (Reparo) & END TOTAL \\
\hline \multirow{5}{*}{ Blocos } & 1 & 2,6 & 3,4 & 2,65 & \multirow{5}{*}{0,50} & \multirow{5}{*}{0,50} & 146 & \multirow{5}{*}{3} & 1 & 12953 & 582 & 13536 \\
\hline & 3 & 3,7 & 3,4 & 3,77 & & & 206 & & 1 & 18433 & 1165 & 19598 \\
\hline & 6 & 7,1 & 3,4 & 7,24 & & & 1057 & & 1 & 35372 & 11478 & 46850 \\
\hline & 18 & 2,94 & 3,4 & 3,00 & & & 1364 & & 1 & 14647 & 6135 & 20782 \\
\hline & 26 & 3 & 3,4 & 3,06 & & & 484 & & 1 & 14946 & 2220 & 17166 \\
\hline \multirow[b]{2}{*}{ Alimentador } & \multirow[b]{2}{*}{$\mathrm{X} 1$} & \multirow[b]{2}{*}{$\mathrm{L}(\mathrm{km})$} & \multirow{2}{*}{$\begin{array}{l}\text { Taxa de defeito } \\
\text { (def./km./ano) }\end{array}$} & \multirow[b]{2}{*}{ Defeitos/Ano } & \multirow{2}{*}{$\begin{array}{c}\text { TMA1 } \\
\text { (h) }\end{array}$} & \multirow{2}{*}{$\begin{array}{l}\text { TMA2 } \\
\text { (h) }\end{array}$} & \multirow{2}{*}{$\begin{array}{l}\text { Carga do } \\
\text { bloco } \\
\text { kVA }\end{array}$} & \multirow{2}{*}{$\begin{array}{l}\text { Custo da } \\
\text { Energia } \\
(\mathrm{R} \$ / \mathrm{kWh})\end{array}$} & \multirow[b]{2}{*}{ F. S. } & \multicolumn{3}{|c|}{ Custo da Energia Não Distribuída (R\$) } \\
\hline & & & & & & & & & & $\begin{array}{l}\text { END (Prep. } \\
\quad+\text { Loc.) }\end{array}$ & END (Reparo) & END TOTAL \\
\hline \multirow{2}{*}{ Blocos } & 1 & 10,94 & 3,4 & 11,16 & \multirow{2}{*}{0,50} & \multirow{2}{*}{0,50} & 1391 & \multirow{2}{*}{3} & 3 & 74679 & 69838 & 144518 \\
\hline & 7 & 1,75 & 3,4 & 1,79 & & & 289 & & 1 & 11946 & 774 & 12720 \\
\hline \multirow[b]{2}{*}{ Alimentador } & \multirow[b]{2}{*}{$\mathrm{X} 2$} & & ТТу⿰冫中 dofaito & & TMA 1 & TMA & Carga do & Custo da & & Custo & Energia Não Dis & lída $(\mathrm{R} \$)$ \\
\hline & & $\mathrm{L}(\mathrm{km})$ & (def./km./ano) & Defeitos/Ano & (h) & (h) & $\begin{array}{c}\text { bloco } \\
\text { kVA }_{\text {Médio }}\end{array}$ & $\begin{array}{l}\text { Energia } \\
\text { (R\$/kWh) }\end{array}$ & F. S. & $\begin{array}{l}\text { END (Prep. } \\
\quad+\text { Loc.) }\end{array}$ & END (Reparo) & END TOTAL \\
\hline & 6 & 1,25 & 3,4 & 1,28 & & & 1103 & & 3 & 14375 & 6327 & 20702 \\
\hline & 11 & 0,48 & 3,4 & 0,49 & & & 197 & & 1 & 5520 & 145 & 5665 \\
\hline & 12 & 0,95 & 3,4 & 0,97 & & & 736 & & 1 & 10925 & 1069 & 11994 \\
\hline Plocos & 17 & 0,94 & 3,4 & 0,96 & 050 & 0.50 & 376 & 2 & 1 & 10810 & 541 & 11351 \\
\hline Divens & 20 & 0,3 & 3,4 & 0,31 & ס & & 226 & J & 3 & 3450 & 311 & 3761 \\
\hline & 21 & 0,53 & 3,4 & 0,54 & & & 8 & & 1 & 6095 & 6 & 6101 \\
\hline & 22 & 2,1 & 3,4 & 2,14 & & & 532 & & 3 & 24150 & 5130 & 29279 \\
\hline & 26 & 0,25 & 3,4 & 0,26 & & & 206 & & 3 & 2875 & 236 & 3111 \\
\hline
\end{tabular}




\begin{tabular}{|c|c|c|c|c|c|c|c|c|c|c|c|c|}
\hline \multirow{2}{*}{ Alimentador } & \multirow{2}{*}{ Y1 } & \multirow{2}{*}{$\mathrm{L}(\mathrm{km})$} & \multirow{2}{*}{$\begin{array}{l}\text { Taxa de defeito } \\
\text { (def./km./ano) }\end{array}$} & \multirow{2}{*}{ Defeitos/Ano } & \multirow{2}{*}{$\begin{array}{l}\text { TMA1 } \\
\text { (h) }\end{array}$} & \multirow{2}{*}{$\begin{array}{l}\text { TMA2 } \\
\text { (h) }\end{array}$} & \multirow{2}{*}{$\begin{array}{c}\text { Carga do } \\
\text { bloco } \\
\text { kVA }_{\text {Médio }}\end{array}$} & \multirow{2}{*}{$\begin{array}{c}\text { Custo da } \\
\text { Energia } \\
(\mathrm{R} \$ / \mathrm{kWh})\end{array}$} & \multirow{2}{*}{ F. S. } & \multicolumn{3}{|c|}{ Custo da Energia Não Distribuída (R\$) } \\
\hline & & & & & & & & & & $\begin{array}{l}\text { END (Prep. } \\
\quad+\text { Loc.) }\end{array}$ & END (Reparo) & END TOTAL \\
\hline \multirow{4}{*}{ Blocos } & 1 & 3,32 & 3,4 & 3,39 & \multirow{4}{*}{0,50} & \multirow{4}{*}{0,50} & 370 & \multirow{4}{*}{3} & 1 & 21593 & 1880 & 23474 \\
\hline & 2 & 4,33 & 3,4 & 4,42 & & & 547 & & 1 & 28162 & 3625 & 31788 \\
\hline & 4 & 6,1 & 3,4 & 6,22 & & & 310 & & 1 & 39675 & 2889 & 42564 \\
\hline & 10 & 2,38 & 3,4 & 2,43 & & & 1008 & & 3 & 15480 & 11012 & 26491 \\
\hline \multirow{2}{*}{ Alimentador } & \multirow{2}{*}{$\mathrm{Y} 2$} & \multirow{2}{*}{$\mathrm{L}(\mathrm{km})$} & \multirow{2}{*}{$\begin{array}{l}\text { Taxa de defeito } \\
\text { (def./km./ano) }\end{array}$} & \multirow{2}{*}{ Defeitos/Ano } & \multirow{2}{*}{$\begin{array}{c}\text { TMA1 } \\
\text { (h) }\end{array}$} & \multirow{2}{*}{$\begin{array}{l}\text { TMA2 } \\
\text { (h) }\end{array}$} & \multirow{2}{*}{$\begin{array}{c}\text { Carga do } \\
\text { bloco } \\
\text { kVA }_{\text {Médio }}\end{array}$} & \multirow{2}{*}{$\begin{array}{c}\text { Custo da } \\
\text { Energia } \\
\text { (R\$/kWh) }\end{array}$} & \multirow{2}{*}{ F. S. } & \multicolumn{3}{|c|}{ Custo da Energia Não Distribuída (R\$) } \\
\hline & & & & & & & & & & $\begin{array}{c}\text { END (Prep. } \\
+ \text { Loc.) }\end{array}$ & END (Reparo) & END TOTAL \\
\hline \multirow{5}{*}{ Blocos } & 1 & 0,94 & 3,4 & 0,96 & \multirow{5}{*}{0,50} & \multirow{5}{*}{0,50} & 19 & \multirow{5}{*}{3} & 1 & 3530 & 27 & 3557 \\
\hline & 3 & 3,17 & 3,4 & 3,23 & & & 302 & & 1 & 11905 & 1467 & 13372 \\
\hline & 6 & 0,5 & 3,4 & 0,51 & & & 44 & & 3 & 1878 & 102 & 1980 \\
\hline & 7 & 2,54 & 3,4 & 2,59 & & & 1201 & & 1 & 9539 & 4668 & 14207 \\
\hline & 12 & 0,9 & 3,4 & 0,92 & & & 266 & & 3 & 3380 & 1100 & 4480 \\
\hline
\end{tabular}

TABELA 5.8 - Análise dos Blocos dos Troncos dos Circuitos 
O alimentador X2 apresenta o maior número de cargas sensíveis e alimenta a região central da cidade, atendendo a cargas de extrema importância (hospitais, etc.).

Tendo isto em vista, o objetivo foi concentrar a maior quantidade de cargas sensíveis nesse circuito, de forma que, em se garantindo o restabelecimento adequado a esse circuito se obtém adequados níveis de END.

Analisando-se as possibilidades de transferências de carga para o referido alimentador, observa-se que as cargas sensíveis alimentadas pelo bloco 19 do circuito C1 e pelo bloco 6 do circuito Y2 poderiam ser deslocadas para o circuito X2 sem grande dificuldade, conforme tabela 5.9. Assim, foi proposta uma configuração de alocação dos religadores de maneira que em situação de contingência na alimentação ou nos transformadores das subestações, a carga alimentada por uma SE possa ser transferida automaticamente com o menor tempo de interrupção possível. 


\begin{tabular}{|c|c|c|c|c|c|c|c|c|c|c|c|c|}
\hline \multirow[b]{2}{*}{ Circuito } & \multirow[b]{2}{*}{$\mathrm{C} 1$} & \multirow{2}{*}{$\begin{array}{c}\mathrm{L} \\
(\mathrm{km})\end{array}$} & \multirow{2}{*}{$\begin{array}{l}\text { Taxa de defeito } \\
\text { (def./km./ano) }\end{array}$} & \multirow{2}{*}{$\begin{array}{l}\text { Defeitos/ } \\
\text { Ano }\end{array}$} & \multirow[b]{2}{*}{ TMA1 (h) } & \multirow[b]{2}{*}{ TMA2 (h) } & \multirow{2}{*}{$\begin{array}{c}\text { Carga do } \\
\text { bloco } \\
\mathrm{kVA}_{\text {Médio }}\end{array}$} & \multirow{2}{*}{$\begin{array}{c}\text { Custo da } \\
\text { Energia } \\
\text { (R\$/kWh) }\end{array}$} & \multirow[b]{2}{*}{ F. S. } & \multicolumn{3}{|c|}{ Custo da Energia Não Distribuída (R\$) } \\
\hline & & & & & & & & & & $\begin{array}{l}\text { END (Prep. } \\
\quad+\text { Loc.) }\end{array}$ & END (Reparo) & END TOTAL \\
\hline \multirow{6}{*}{ Blocos } & 1 & 2,85 & 3,4 & 9,69 & \multirow{6}{*}{0,50} & \multirow{6}{*}{0,50} & 384 & \multirow{6}{*}{3} & 1 & 22792 & 1674 & 24467 \\
\hline & 2 & 1,9 & 3,4 & 6,46 & & & 1260 & & 1 & 15195 & 3663 & 18858 \\
\hline & 4 & 1,5 & 3,4 & 5,10 & & & 552 & & 1 & 11996 & 1267 & 13263 \\
\hline & 6 & 1,63 & 3,4 & 5,54 & & & 930 & & 1 & 13036 & 2319 & 15355 \\
\hline & 11 & 1,92 & 3,4 & 6,53 & & & 801 & & 1 & 15355 & 2353 & 17708 \\
\hline & 14 & 2,4 & 3,4 & 8,16 & & & 1300 & & 1 & 19194 & 4774 & 23967 \\
\hline \multirow[b]{2}{*}{ Circuito } & \multirow[b]{2}{*}{$\mathrm{Y} 2$} & \multirow{2}{*}{$\begin{array}{c}\mathrm{L} \\
(\mathrm{km})\end{array}$} & \multirow{2}{*}{$\begin{array}{l}\text { Taxa de defeito } \\
\text { (def./km./ano) }\end{array}$} & \multirow{2}{*}{$\begin{array}{l}\text { Defeitos/ } \\
\text { Ano }\end{array}$} & \multirow[b]{2}{*}{ TMA1 (h) } & \multirow[b]{2}{*}{ TMA2 (h) } & \multirow{2}{*}{$\begin{array}{c}\text { Carga do } \\
\text { bloco } \\
\text { kVA }_{\text {Médio }}\end{array}$} & \multirow{2}{*}{$\begin{array}{c}\text { Custo da } \\
\text { Energia } \\
\text { (R\$/kWh) }\end{array}$} & & \multicolumn{3}{|c|}{ Custo da Energia Não Distribuída (R\$) } \\
\hline & & & & & & & & & F. S. & $\begin{array}{l}\text { END (Prep. } \\
\quad+\text { Loc.) }\end{array}$ & END (Reparo) & END TOTAL \\
\hline \multirow{3}{*}{ Blocos } & 1 & 0,94 & 3,4 & 3,20 & \multirow{3}{*}{0,50} & \multirow{3}{*}{0,50} & 19 & \multirow{3}{*}{3} & 1 & 3339 & 27 & 3365 \\
\hline & 3 & 3,17 & 3,4 & 10,78 & & & 302 & & 1 & 11259 & 1467 & 12726 \\
\hline & 7 & 2,54 & 3,4 & 8,64 & & & 1201 & & 1 & 9021 & 4668 & 13690 \\
\hline \multirow[b]{2}{*}{ Circuito } & \multirow[b]{2}{*}{$\mathrm{X} 2$} & & & & & & Carga do & Custo da & & Custo d & Energia Não Dis & buída (R\$) \\
\hline & & $(\mathrm{km})$ & (def./km./ano) & Ano & TMA1 (h) & TMA2 (h) & $\begin{array}{c}\text { bloco } \\
\text { kVA } A_{\text {Médio }}\end{array}$ & $\begin{array}{c}\text { Energia } \\
\text { (R\$/kWh) }\end{array}$ & F. S. & $\begin{array}{l}\text { END (Prep. } \\
\quad+\text { Loc.) }\end{array}$ & END (Reparo) & END TOTAL \\
\hline & 6 & 1,25 & 3,4 & 4,25 & & & 1103 & & 3 & 16464 & 6327 & 22792 \\
\hline & $11(19)$ & 0,48 & 3,4 & 1,63 & & & 380 & & 3 & 6322 & 838 & 7160 \\
\hline & 12 & 0,95 & 3,4 & 3,23 & & & 736 & & 1 & 12513 & 1069 & 13582 \\
\hline Blocos & 17 & 0,94 & 3,4 & 3,20 & 0.50 & 050 & 376 & 3 & 1 & 12381 & 541 & 12922 \\
\hline & 20 & 0,3 & 3,4 & 1,02 & סט, & (ס, & 226 & S & 3 & 3951 & 311 & 4262 \\
\hline & $21(6)$ & 0,53 & 3,4 & 1,80 & & & 52 & & 3 & 6981 & 127 & 7108 \\
\hline & 22 & 2,1 & 3,4 & 7,14 & & & 532 & & 3 & 27660 & 5130 & 32790 \\
\hline & 26 & 0,25 & 3,4 & 0,85 & & & 206 & & 3 & 3293 & 236 & 3529 \\
\hline
\end{tabular}

TABELA 5.9 - Blocos dos troncos dos circuitos com re-alocação de cargas prioritárias 
A alternativa base com utilização de recursos de automação consiste na instalação das duas subestações e de três religadores automáticos "NA" com o objetivo de restabelecer as cargas alimentadas por estas em caso de contingências de fonte.

A solução proposta para este restabelecimento é a instalação de um religador vis-àvis entre o bloco 20 do circuito $\mathrm{X} 2$ e o bloco 01 do circuito $\mathrm{Y} 1$ e de mais dois religadores sendo um entre os alimentadores $X 1$ e $C 2$ e o outro entre os alimentadores Y2 e A1, como apresentado na figura 5.8 .

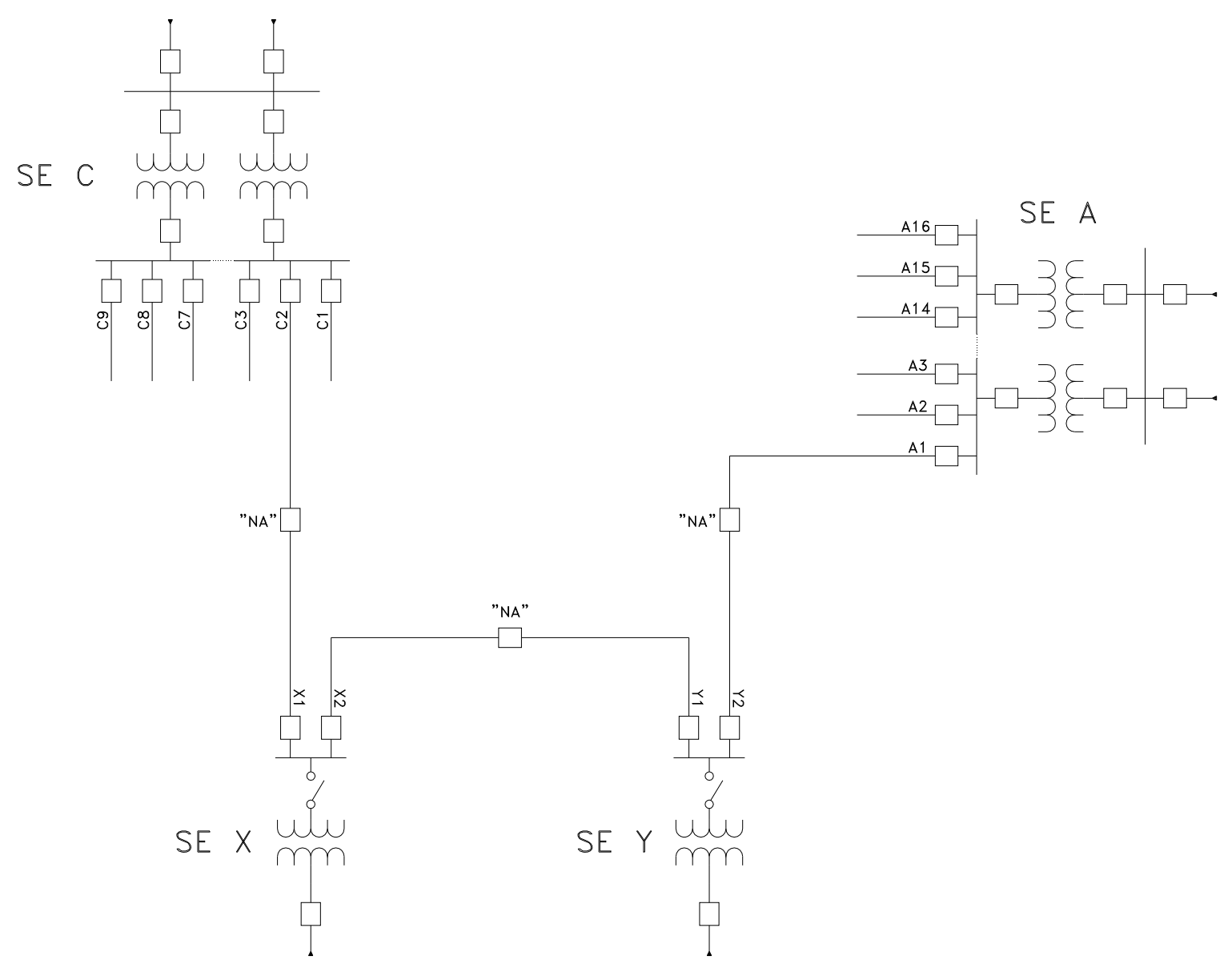

FIGURA 5.8 - Diagrama unifilar do sistema com a inserção de religadores "NA"

A tabela 5.10 apresenta o beneficio da aplicação destes religadores "NA" no ano inicial, levando-se em conta as taxas de falha dos transformadores e das linhas de $34,5 \mathrm{kV}$, em contingências da fonte. 
TABELA 5.10 - Benefício da instalação dos religadores "NA" no primeiro ano

\begin{tabular}{|c|c|c|c|c|c|}
\hline \multirow{2}{*}{ Subestação } & \multirow{2}{*}{$\begin{array}{c}\text { Taxa de falha } \\
\text { Trafo } \\
\text { (def./ano) }\end{array}$} & \multirow{2}{*}{$\begin{array}{l}\text { Def./ano } \\
\text { LT34,5kV }\end{array}$} & \multirow{2}{*}{ Alimentadores } & \multicolumn{2}{|c|}{$\begin{array}{l}\text { Custo de Energia Não } \\
\text { distribuída (R\$/ano) }\end{array}$} \\
\hline & & & & Individual & Total \\
\hline \multirow{2}{*}{$x$} & \multirow{2}{*}{0,1} & \multirow{2}{*}{3,75} & $X 1$ & 5020 & \multirow{4}{*}{21018} \\
\hline & & & $\mathrm{X} 2$ & 8458 & \\
\hline \multirow{2}{*}{ Y } & \multirow{2}{*}{0,1} & \multirow{2}{*}{3,75} & Y1 & 4782 & \\
\hline & & & Y2 & 2759 & \\
\hline
\end{tabular}

Considerando que um religador tem uma vida útil de aproximadamente 10 anos, que seu custo é de aproximadamente $\mathrm{R} \$ 30.000,00$ e levando-se em conta um custo adicional da rede de comunicação de aproximadamente $\mathrm{R} \$ 10.000,00$, calcula-se 0 período de retorno deste investimento igualando-se 0 valor presente dos investimentos com a somatória dos valores presentes dos benefícios anuais.

O período de retorno do investimento da aplicação de três religadores "NA" para restabelecimento dos alimentadores em casos de defeitos de fonte é de aproximadamente 5 anos.

Outras variantes da alternativa base são propostas, incluindo, além dos 3 religadores "NA" vis-a-vís presentes nela, outros religadores "NF" que seccionam o tronco do alimentador, visando o restabelecimento de blocos de carga sensíveis na ocorrência de defeitos na rede primária.

Tais religadores "NF" serão instalados nos limites de blocos que contem cargas sensíveis, de modo a preservar a correspondente continuidade para defeitos externos a esses blocos, isolando os blocos à jusante se lá estiver o defeito ou transferindo-o se o defeito for à montante. Isto introduz o conceito de "carga firme", que corresponde à carga do bloco que mantém a continuidade a despeito de defeitos na rede.

A tabela 5.11 apresenta uma análise do impacto da instalação do religador em várias posições no alimentador $\mathrm{X} 2$, onde TMA3 é o tempo de restabelecimento automático das cargas não alimentadas pelo bloco de defeito (h). As tabelas 5.12, 5.13 e 5.14 apresentam os resultados obtidos com a instalação de 2, 3 e 4 religadores "NF" em pontos estratégicos do alimentador. 


\begin{tabular}{|c|c|c|c|c|c|c|c|c|c|c|c|c|c|}
\hline \multicolumn{14}{|c|}{ Religador no fim do bloco 6} \\
\hline \multirow[b]{2}{*}{ Circuito } & \multirow[b]{2}{*}{$\mathrm{X} 2$} & \multirow[b]{2}{*}{$\mathrm{L}(\mathrm{km})$} & \multirow{2}{*}{$\begin{array}{l}\text { Taxa de defeito } \\
\text { (def./km./ano) }\end{array}$} & \multirow{2}{*}{$\begin{array}{c}\text { Defeitos/ } \\
\text { Ano }\end{array}$} & \multirow{2}{*}{$\begin{array}{l}\text { TMA1 } \\
\text { (h) }\end{array}$} & \multirow{2}{*}{$\begin{array}{l}\text { TMA2 } \\
\text { (h) }\end{array}$} & \multirow{2}{*}{$\begin{array}{l}\text { TMA3 } \\
\text { (h) }\end{array}$} & \multirow{2}{*}{$\begin{array}{l}\text { Carga do bloco } \\
\text { kVA }_{\text {Médio }}\end{array}$} & \multirow{2}{*}{$\begin{array}{c}\text { Custo da } \\
\text { Energia } \\
(\mathrm{R} \$ / \mathrm{kWh})\end{array}$} & \multirow[b]{2}{*}{ F. S. } & \multicolumn{3}{|c|}{ Custo da Energia Não Distribuída (R\$) } \\
\hline & & & & & & & & & & & $\begin{array}{l}\text { END (Prep. } \\
\quad+\text { Loc.) }\end{array}$ & END (Reparo) & END TOTAL \\
\hline \multirow{8}{*}{ Blocos } & 6 & 1,25 & 3,4 & 4,25 & \multirow{8}{*}{0,50} & \multirow{8}{*}{0,50} & \multirow{8}{*}{0,02} & 1103 & \multirow{8}{*}{3} & 3 & 6384 & 6327 & 12711 \\
\hline & $11(19)$ & 0,48 & 3,4 & 1,63 & & & & 380 & & 3 & 3906 & 838 & 4744 \\
\hline & 12 & 0,95 & 3,4 & 3,23 & & & & 736 & & 1 & 7731 & 1069 & 8800 \\
\hline & 17 & 0,94 & 3,4 & 3,20 & & & & 376 & & 1 & 7649 & 541 & 8191 \\
\hline & 20 & 0,3 & 3,4 & 1,02 & & & & 226 & & 3 & 2441 & 311 & 2752 \\
\hline & $21(6)$ & 0,53 & 3,4 & 1,80 & & & & 52 & & 3 & 4313 & 127 & 4440 \\
\hline & 22 & 2,1 & 3,4 & 7,14 & & & & 532 & & 3 & 17089 & 5130 & 22219 \\
\hline & 26 & 0,25 & 3,4 & 0,85 & & & & 206 & & 3 & 2034 & 236 & 2271 \\
\hline \multicolumn{14}{|c|}{ Religador no fim do bloco 11} \\
\hline \multirow[b]{2}{*}{ Circuito } & \multirow[b]{2}{*}{$\mathrm{X} 2$} & \multirow[b]{2}{*}{$\mathrm{L}(\mathrm{km})$} & \multirow{2}{*}{$\begin{array}{l}\text { Taxa de defeito } \\
\text { (def./km./ano) }\end{array}$} & \multirow{2}{*}{$\begin{array}{c}\text { Defeitos/ } \\
\text { Ano }\end{array}$} & \multirow{2}{*}{$\begin{array}{l}\text { TMA1 } \\
\text { (h) }\end{array}$} & \multirow{2}{*}{$\begin{array}{l}\text { TMA2 } \\
\text { (h) }\end{array}$} & \multirow{2}{*}{$\begin{array}{l}\text { TMA3 } \\
\text { (h) }\end{array}$} & \multirow{2}{*}{$\begin{array}{l}\text { Carga do bloco } \\
\text { kVA }_{\text {Médio }}\end{array}$} & \multirow{2}{*}{$\begin{array}{c}\text { Custo da } \\
\text { Energia } \\
(\mathrm{R} \$ / \mathrm{kWh})\end{array}$} & \multirow[b]{2}{*}{ F. S. } & \multicolumn{3}{|c|}{ Custo da Energia Não Distribuída (R\$) } \\
\hline & & & & & & & & & & & $\begin{array}{l}\text { END (Prep. } \\
+ \text { Loc.) }\end{array}$ & END (Reparo) & END TOTAL \\
\hline & 6 & 1,25 & 3,4 & 4,25 & & & & 1103 & & 3 & 8554 & 6327 & 14881 \\
\hline & $11(19)$ & 0,48 & 3,4 & 1,63 & & & & 380 & & 3 & 3285 & 838 & 4123 \\
\hline & 12 & 0,95 & 3,4 & 3,23 & & & & 736 & & 1 & 6081 & 1069 & 7151 \\
\hline Blocos & 17 & 0,94 & 3,4 & 3,20 & 050 & 050 & רח0 & 376 & 3 & 1 & 6017 & 541 & 6558 \\
\hline Divers & 20 & 0,3 & 3,4 & 1,02 & ט, & ט, & 0,02 & 226 & J & 3 & 1920 & 311 & 2231 \\
\hline & $21(6)$ & 0,53 & 3,4 & 1,80 & & & & 52 & & 3 & 3393 & 127 & 3520 \\
\hline & 22 & 2,1 & 3,4 & 7,14 & & & & 532 & & 3 & 13443 & 5130 & 18573 \\
\hline & 26 & 0,25 & 3,4 & 0,85 & & & & 206 & & 3 & 1600 & 236 & 1837 \\
\hline
\end{tabular}


Religador no fim do bloco 12

\begin{tabular}{|c|c|c|c|c|c|c|c|c|c|c|c|c|c|}
\hline \multirow{2}{*}{ Circuito } & \multirow{2}{*}{$\mathrm{X} 2$} & \multirow{2}{*}{$\mathrm{L}(\mathrm{km})$} & \multirow{2}{*}{$\begin{array}{l}\text { Taxa de defeito } \\
\text { (def./km./ano) }\end{array}$} & \multirow{2}{*}{$\begin{array}{c}\text { Defeitos/ } \\
\text { Ano }\end{array}$} & \multirow{2}{*}{$\begin{array}{l}\text { TMA1 } \\
\text { (h) }\end{array}$} & \multirow{2}{*}{$\begin{array}{c}\text { TMA2 } \\
\text { (h) }\end{array}$} & \multirow{2}{*}{$\begin{array}{l}\text { TMA3 } \\
\text { (h) }\end{array}$} & \multirow{2}{*}{$\begin{array}{l}\text { Carga do bloco } \\
\text { kVA }_{\text {Médio }}\end{array}$} & \multirow{2}{*}{$\begin{array}{c}\text { Custo da } \\
\text { Energia } \\
\text { (R\$/kWh) }\end{array}$} & \multirow{2}{*}{ F. S. } & \multicolumn{3}{|c|}{ Custo da Energia Não Distribuída (R\$) } \\
\hline & & & & & & & & & & & $\begin{array}{l}\text { END (Prep. } \\
\text { +Loc.) }\end{array}$ & END (Reparo) & END TOTAL \\
\hline \multirow{8}{*}{ Blocos } & 6 & 1,25 & 3,4 & 4,25 & \multirow{8}{*}{0,50} & \multirow{8}{*}{0,50} & \multirow{8}{*}{0,02} & 1103 & \multirow{8}{*}{3} & 3 & 9953 & 6327 & 16280 \\
\hline & $11(19)$ & 0,48 & 3,4 & 1,63 & & & & 380 & & 3 & 3822 & 838 & 4660 \\
\hline & 12 & 0,95 & 3,4 & 3,23 & & & & 736 & & 1 & 7564 & 1069 & 8634 \\
\hline & 17 & 0,94 & 3,4 & 3,20 & & & & 376 & & 1 & 4965 & 541 & 5506 \\
\hline & 20 & 0,3 & 3,4 & 1,02 & & & & 226 & & 3 & 1585 & 311 & 1895 \\
\hline & $21(6)$ & 0,53 & 3,4 & 1,80 & & & & 52 & & 3 & 2800 & 127 & 2927 \\
\hline & 22 & 2,1 & 3,4 & 7,14 & & & & 532 & & 3 & 11093 & 5130 & 16223 \\
\hline & 26 & 0,25 & 3,4 & 0,85 & & & & 206 & & 3 & 1321 & 236 & 1557 \\
\hline
\end{tabular}

Religador no fim do bloco 17

\begin{tabular}{|c|c|c|c|c|c|c|c|c|c|c|c|c|c|}
\hline \multirow{2}{*}{ Circuito } & \multirow{2}{*}{$\mathrm{X} 2$} & \multirow{2}{*}{$\mathrm{L}(\mathrm{km})$} & \multirow{2}{*}{$\begin{array}{l}\text { Taxa de defeito } \\
\text { (def./km./ano) }\end{array}$} & \multirow{2}{*}{$\begin{array}{c}\text { Defeitos/ } \\
\text { Ano }\end{array}$} & \multirow{2}{*}{$\begin{array}{l}\text { TMA1 } \\
\text { (h) }\end{array}$} & \multirow{2}{*}{$\begin{array}{c}\text { TMA2 } \\
\text { (h) }\end{array}$} & \multirow{2}{*}{$\begin{array}{c}\text { TMA3 } \\
\text { (h) }\end{array}$} & \multirow{2}{*}{$\begin{array}{l}\text { Carga do bloco } \\
\text { kVA }_{\text {Médio }}\end{array}$} & \multirow{2}{*}{$\begin{array}{c}\text { Custo da } \\
\text { Energia } \\
\text { (R\$/kWh) }\end{array}$} & & \multicolumn{3}{|c|}{ Custo da Energia Não Distribuída (R\$) } \\
\hline & & & & & & & & & & & $\begin{array}{l}\text { END (Prep. } \\
\quad+\text { Loc.) }\end{array}$ & END (Reparo) & END TOTAL \\
\hline \multirow{8}{*}{ Blocos } & 6 & 1,25 & 3,4 & 4,25 & \multirow{8}{*}{0,50} & \multirow{8}{*}{0,50} & \multirow{8}{*}{0,02} & 1103 & \multirow{8}{*}{3} & 3 & 10669 & 6327 & 16996 \\
\hline & $11(19)$ & 0,48 & 3,4 & 1,63 & & & & 380 & & 3 & 4097 & 838 & 4935 \\
\hline & 12 & 0,95 & 3,4 & 3,23 & & & & 736 & & 1 & 8108 & 1069 & 9177 \\
\hline & 17 & 0,94 & 3,4 & 3,20 & & & & 376 & & 1 & 8023 & 541 & 8564 \\
\hline & 20 & 0,3 & 3,4 & 1,02 & & & & 226 & & 3 & 1413 & 311 & 1724 \\
\hline & $21(6)$ & 0,53 & 3,4 & 1,80 & & & & 52 & & 3 & 2496 & 127 & 2623 \\
\hline & 22 & 2,1 & 3,4 & 7,14 & & & & 532 & & 3 & 9891 & 5130 & 15021 \\
\hline & 26 & 0,25 & 3,4 & 0,85 & & & & 206 & & 3 & 1177 & 236 & 1414 \\
\hline
\end{tabular}

TABELA 5.11 -Impacto da instalação do religador ao longo do alimentador X2 


\begin{tabular}{|c|c|c|c|c|c|c|c|c|c|c|c|c|c|}
\hline \multicolumn{14}{|c|}{ Chaves Religadoras no fim dos blocos 1 e 17} \\
\hline \multirow{2}{*}{ Circuito } & \multirow{2}{*}{$\mathrm{X} 2$} & \multirow{2}{*}{$\mathrm{L}(\mathrm{km})$} & \multirow{2}{*}{$\begin{array}{l}\text { Taxa de defeito } \\
\text { (def./km./ano) }\end{array}$} & \multirow{2}{*}{$\begin{array}{l}\text { Defeitos/ } \\
\text { Ano }\end{array}$} & \multirow{2}{*}{$\begin{array}{c}\text { TMA1 } \\
\text { (h) }\end{array}$} & \multirow{2}{*}{$\begin{array}{c}\text { TMA2 } \\
\text { (h) }\end{array}$} & \multirow{2}{*}{$\begin{array}{c}\text { TMA3 } \\
\text { (h) }\end{array}$} & \multirow{2}{*}{$\begin{array}{l}\text { Carga do bloco } \\
\text { kVA }_{\text {Médio }}\end{array}$} & \multirow{2}{*}{$\begin{array}{c}\text { Custo da } \\
\text { Energia } \\
\text { (R\$/kWh) }\end{array}$} & & \multicolumn{3}{|c|}{ Custo da Energia Não Distribuída (R\$) } \\
\hline & & & & & & & & & & & $\begin{array}{l}\text { END (Prep. } \\
+ \text { +Loc.) }\end{array}$ & END (Reparo) & END TOTAL \\
\hline \multirow{8}{*}{ Blocos } & 6 & 1,25 & 3,4 & 4,25 & \multirow{8}{*}{0,50} & \multirow{8}{*}{0,50} & \multirow{8}{*}{0,02} & 1103 & \multirow{8}{*}{3} & 3 & 6384 & 6327 & 12711 \\
\hline & 11 (19) & 0,48 & 3,4 & 1,63 & & & & 380 & & 3 & 1681 & 838 & 2519 \\
\hline & 12 & 0,95 & 3,4 & 3,23 & & & & 736 & & 1 & 3326 & 1069 & 4395 \\
\hline & 17 & 0,94 & 3,4 & 3,20 & & & & 376 & & 1 & 3291 & 541 & 3832 \\
\hline & 20 & 0,3 & 3,4 & 1,02 & & & & 226 & & 3 & 1413 & 311 & 1724 \\
\hline & $21(6)$ & 0,53 & 3,4 & 1,80 & & & & 52 & & 3 & 2496 & 127 & 2623 \\
\hline & 22 & 2,1 & 3,4 & 7,14 & & & & 532 & & 3 & 9891 & 5130 & 15021 \\
\hline & 26 & 0,25 & 3,4 & 0,85 & & & & 206 & & 3 & 1177 & 236 & 1414 \\
\hline
\end{tabular}

TABELA 5.12 - Impacto da instalação de dois religadores ao longo do alimentador X2

\begin{tabular}{|c|c|c|c|c|c|c|c|c|c|c|c|c|c|}
\hline \multicolumn{14}{|c|}{ Chaves Religadoras no fim dos blocos 1,12 e 20} \\
\hline \multirow[b]{2}{*}{ Circuito } & \multirow[b]{2}{*}{$\mathrm{X} 2$} & \multirow[b]{2}{*}{$\mathrm{L}(\mathrm{km})$} & \multirow{2}{*}{$\begin{array}{l}\text { Taxa de defeito } \\
\text { (def./km./ano) }\end{array}$} & \multirow{2}{*}{$\begin{array}{c}\text { Defeitos/ } \\
\text { Ano }\end{array}$} & \multirow{2}{*}{$\begin{array}{c}\text { TMA1 } \\
\text { (h) }\end{array}$} & \multirow{2}{*}{$\begin{array}{c}\text { TMA2 } \\
\text { (h) }\end{array}$} & \multirow{2}{*}{$\begin{array}{c}\text { TMA3 } \\
\text { (h) }\end{array}$} & \multirow{2}{*}{$\begin{array}{c}\text { Carga do bloco } \\
\text { kVA }_{\text {Médio }}\end{array}$} & \multirow{2}{*}{$\begin{array}{c}\text { Custo da } \\
\text { Energia } \\
\text { (R\$/kWh) }\end{array}$} & & \multicolumn{3}{|c|}{ Custo da Energia Não Distribuída (R\$) } \\
\hline & & & & & & & & & & & $\begin{array}{l}\text { END (Prep. } \\
\text { +Loc.) }\end{array}$ & END (Reparo) & END TOTAL \\
\hline \multirow{8}{*}{ Blocos } & 6 & 1,25 & 3,4 & 4,25 & \multirow{8}{*}{0,50} & \multirow{8}{*}{0,50} & \multirow{8}{*}{0,02} & 1103 & \multirow{8}{*}{3} & 3 & 6384 & 6327 & 12711 \\
\hline & $11(19)$ & 0,48 & 3,4 & 1,63 & & & & 380 & & 3 & 1406 & 838 & 2244 \\
\hline & 12 & 0,95 & 3,4 & 3,23 & & & & 736 & & 1 & 2782 & 1069 & 3852 \\
\hline & 17 & 0,94 & 3,4 & 3,20 & & & & 376 & & 1 & 1575 & 541 & 2116 \\
\hline & 20 & 0,3 & 3,4 & 1,02 & & & & 226 & & 3 & 503 & 311 & 813 \\
\hline & $21(6)$ & 0,53 & 3,4 & 1,80 & & & & 52 & & 3 & 1950 & 127 & 2077 \\
\hline & 22 & 2,1 & 3,4 & 7,14 & & & & 532 & & 3 & 7728 & 5130 & 12858 \\
\hline & 26 & 0,25 & 3,4 & 0,85 & & & & 206 & & 3 & 920 & 236 & 1156 \\
\hline
\end{tabular}

TABELA 5.13 - Impacto da instalação de três religadores ao longo do alimentador X2 


\begin{tabular}{|c|c|c|c|c|c|c|c|c|c|c|c|c|c|}
\hline \multicolumn{14}{|c|}{ Chaves Religadoras no fim dos blocos 1,12 , 17 e 21} \\
\hline \multirow{2}{*}{ Circuito } & \multirow{2}{*}{$\mathrm{X} 2$} & \multirow{2}{*}{$\mathrm{L}(\mathrm{km})$} & \multirow{2}{*}{$\begin{array}{l}\text { Taxa de defeito } \\
\text { (def./km./ano) }\end{array}$} & \multirow{2}{*}{$\begin{array}{l}\text { Defeitos/ } \\
\text { Ano }\end{array}$} & \multirow{2}{*}{$\begin{array}{l}\text { TMA1 } \\
\text { (h) }\end{array}$} & \multirow{2}{*}{$\begin{array}{c}\text { TMA2 } \\
\text { (h) }\end{array}$} & \multirow{2}{*}{$\begin{array}{c}\text { TMA3 } \\
\text { (h) }\end{array}$} & \multirow{2}{*}{$\begin{array}{l}\text { Carga do bloco } \\
\text { kVA }_{\text {Médio }}\end{array}$} & \multirow{2}{*}{$\begin{array}{c}\text { Custo da } \\
\text { Energia } \\
\text { (R\$/kWh) }\end{array}$} & & \multicolumn{3}{|c|}{ Custo da Energia Não Distribuída (R\$) } \\
\hline & & & & & & & & & & & $\begin{array}{l}\text { END (Prep. } \\
+ \text { +Loc.) }\end{array}$ & END (Reparo) & END TOTAL \\
\hline \multirow{8}{*}{ Blocos } & 6 & 1,25 & 3,4 & 4,25 & \multirow{8}{*}{0,50} & \multirow{8}{*}{0,50} & \multirow{8}{*}{0,02} & 1103 & \multirow{8}{*}{3} & 3 & 6384 & 6327 & 12711 \\
\hline & $11(19)$ & 0,48 & 3,4 & 1,63 & & & & 380 & & 3 & 1406 & 838 & 2244 \\
\hline & 12 & 0,95 & 3,4 & 3,23 & & & & 736 & & 1 & 2782 & 1069 & 3852 \\
\hline & 17 & 0,94 & 3,4 & 3,20 & & & & 376 & & 1 & 607 & 541 & 1148 \\
\hline & 20 & 0,3 & 3,4 & 1,02 & & & & 226 & & 3 & 402 & 311 & 713 \\
\hline & $21(6)$ & 0,53 & 3,4 & 1,80 & & & & 52 & & 3 & 711 & 127 & 838 \\
\hline & 22 & 2,1 & 3,4 & 7,14 & & & & 532 & & 3 & 7228 & 5130 & 12358 \\
\hline & 26 & 0,25 & 3,4 & 0,85 & & & & 206 & & 3 & 860 & 236 & 1097 \\
\hline
\end{tabular}

TABELA 5.14 -Impacto da instalação de quatro religadores ao longo do alimentador X2 
Analisando a tabela 5.11, nota-se que o ponto adequado para a instalação de um religador "NF" seria ao final do bloco 12 , desta maneira, se minimizaria os custos de END.

As tabelas 5.12, 5.13 e 5.14 apresentam os resultados obtidos com a instalação de 2, 3 e 4 religadores "NF" em pontos estratégicos do alimentador.

Considerando a END Total do alimentador como sendo a soma das END's dos blocos obtém-se os valores apresentados na tabela 5.15 para as alternativas analisadas.

TABELA 5.15 - END Total do alimentador no $1^{\circ}$ ano para as alternativas propostas

\begin{tabular}{|c|c|c|c|c|c|}
\cline { 2 - 6 } \multicolumn{1}{c|}{} & \multicolumn{5}{c|}{ Número de religadores "NF" no circuito X2 } \\
\cline { 2 - 6 } & 0 & 1 & 2 & 3 & 4 \\
\hline $\begin{array}{c}\text { Custo da } \\
\text { END Total } \\
\text { do X2 } \\
\begin{array}{c}\text { 10 Ano } \\
\text { (R\$) }\end{array}\end{array}$ & 104145 & 57682 & 44238 & 37827 & 34960 \\
\hline
\end{tabular}

Deve-se ressaltar que os valores de END variam em função da taxa de falhas do circuito, assumida igual a 3,4 def/km/ano conforme hipótese de trabalho. Desta maneira foram simuladas as cinco situações acima citadas com taxa de falhas variando entre 0 e 4 def./km/ano. Os resultados desta simulação estão apresentados no gráfico da figura 5.9 . 


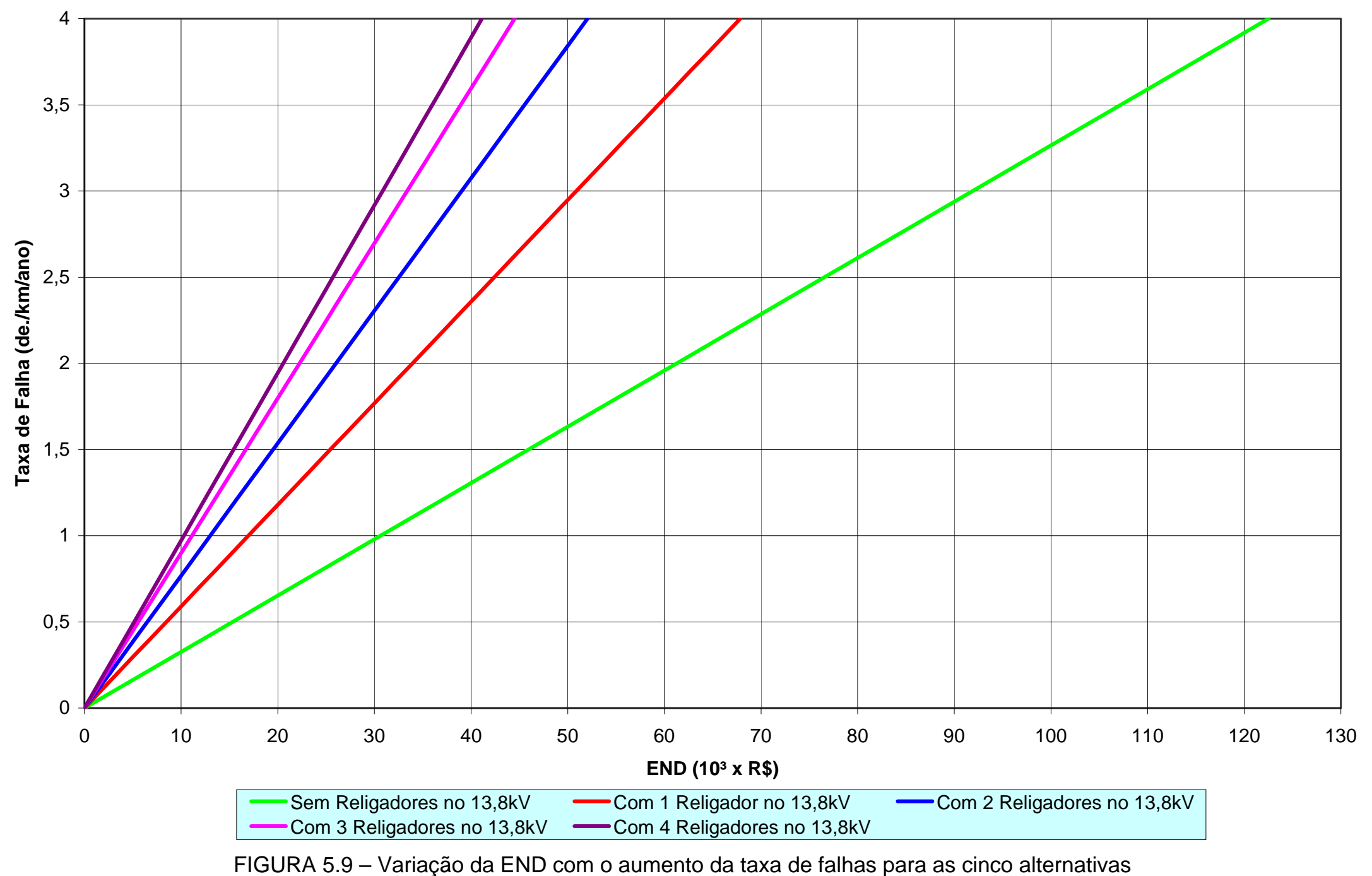


Selecionando alguns valores de taxa de falha (de 1,0 def/km/ano a 3,8 def/km/ano) é possível a construção de dois gráficos (figuras 5.10 e 5.11) que apresentam, respectivamente: o ganho (em $\mathrm{R} \$$ ) no primeiro ano obtido de uma alternativa em relação a outra (ganho incremental) e o ganho no primeiro ano acumulado (em $\mathrm{R} \$$ ) das alternativas (ganho em relação a alternativa sem religadores "NF" no circuito).

Assim o período de retorno de investimento das cinco alternativas propostas foi calculado a partir dos ganhos acumulados das alternativas (tabela 5.16) e dos ganhos incrementais (tabela 5.17), considerando que a carga cresce 5\% ao ano.

TABELA 5.16 - Tempo de retorno de investimento acumulado para as alternativas

\begin{tabular}{|c|c|c|c|c|}
\hline Retorno de Investimento & \multicolumn{5}{c|}{ Acumulado em Religadores NF (anos) } \\
\hline \multirow{2}{*}{$\begin{array}{c}\text { Taxa de Falha } \\
\text { def/km/ano }\end{array}$} & \multicolumn{4}{c|}{ Número de Religadores } \\
\cline { 2 - 5 } & 1 & 2 & 3 & 4 \\
\hline 1,0 & 2,9 & 5,1 & 8,4 & 15,4 \\
\hline 1,4 & 1,9 & 3,2 & 4,9 & 7,1 \\
\hline 1,8 & 1,4 & 2,4 & 3,5 & 4,8 \\
\hline 2,2 & 1,2 & 1,9 & 2,7 & 3,7 \\
\hline 2,6 & 1,0 & 1,6 & 2,2 & 3,0 \\
\hline 3,0 & 0,8 & 1,3 & 1,9 & 2,5 \\
\hline 3,4 & 0,7 & 1,2 & 1,6 & 2,2 \\
\hline 3,8 & 0,6 & 1,0 & 1,4 & 1,9 \\
\hline
\end{tabular}

TABELA 5.17 - Tempo de retorno de investimento incremental das alternativas

\begin{tabular}{|c|c|c|c|c|}
\hline \multicolumn{4}{|c|}{ Retorno de Investimento Incremental em Religadores NF (anos) } \\
\hline \multirow{2}{*}{$\begin{array}{c}\text { Taxa de Falha } \\
\text { Def/km/ano }\end{array}$} & \multicolumn{4}{|c|}{ Número de Religadores } \\
\cline { 2 - 5 } & $0-1$ & $1-2$ & $2-3$ & $3-4$ \\
\hline 1,0 & 2,9 & $\mathrm{~s} /$ retorno & $\mathrm{s} /$ retorno & $\mathrm{s} /$ retorno \\
\hline 1,4 & 1,9 & 12,0 & $\mathrm{~s} /$ retorno & $\mathrm{s} /$ retorno \\
\hline 1,8 & 1,4 & 7,2 & $\mathrm{~s} /$ retorno & s/ retorno \\
\hline 2,2 & 1,2 & 5,2 & $\mathrm{~s} /$ retorno & s/ retorno \\
\hline 2,6 & 1,0 & 4,1 & 17,9 & s/ retorno \\
\hline 3,0 & 0,8 & 3,4 & 11,4 & s/ retorno \\
\hline 3,4 & 0,7 & 2,9 & 8,7 & s/ retorno \\
\hline 3,8 & 0,6 & 2,5 & 7,1 & s/ retorno \\
\hline
\end{tabular}




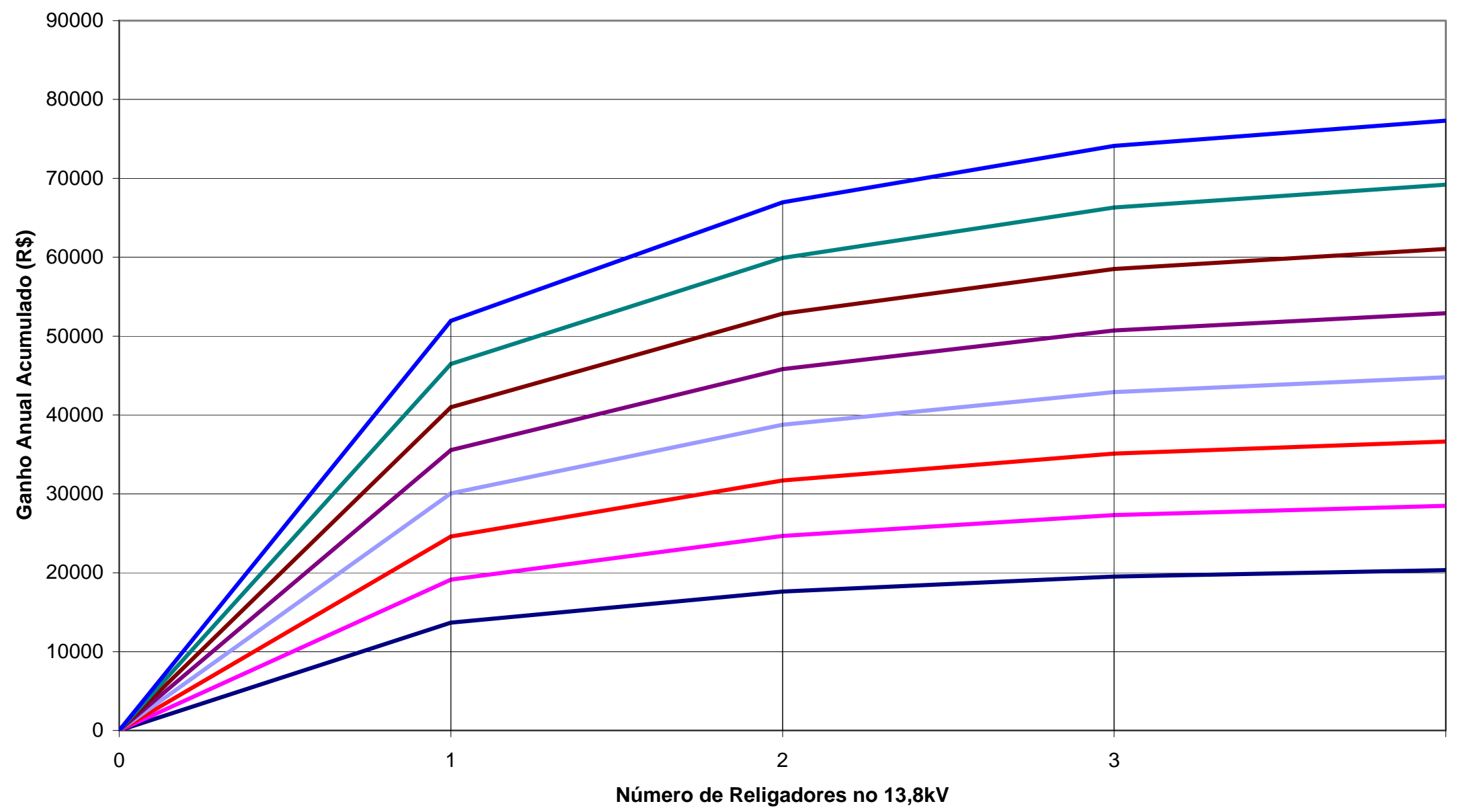

- Taxa de Falha $=1$ Taxa de Falha $=1,4-$ Taxa de Falha $=1,8-$ Taxa de Falha $=2,2$ Taxa de Falha $=2,6$

- Taxa de Falha $=3$ Taxa de Falha $=3,4$ Taxa de Falha $=3,8$

FIGURA 5.10 - Ganho acumulado das alternativas no primeiro ano 


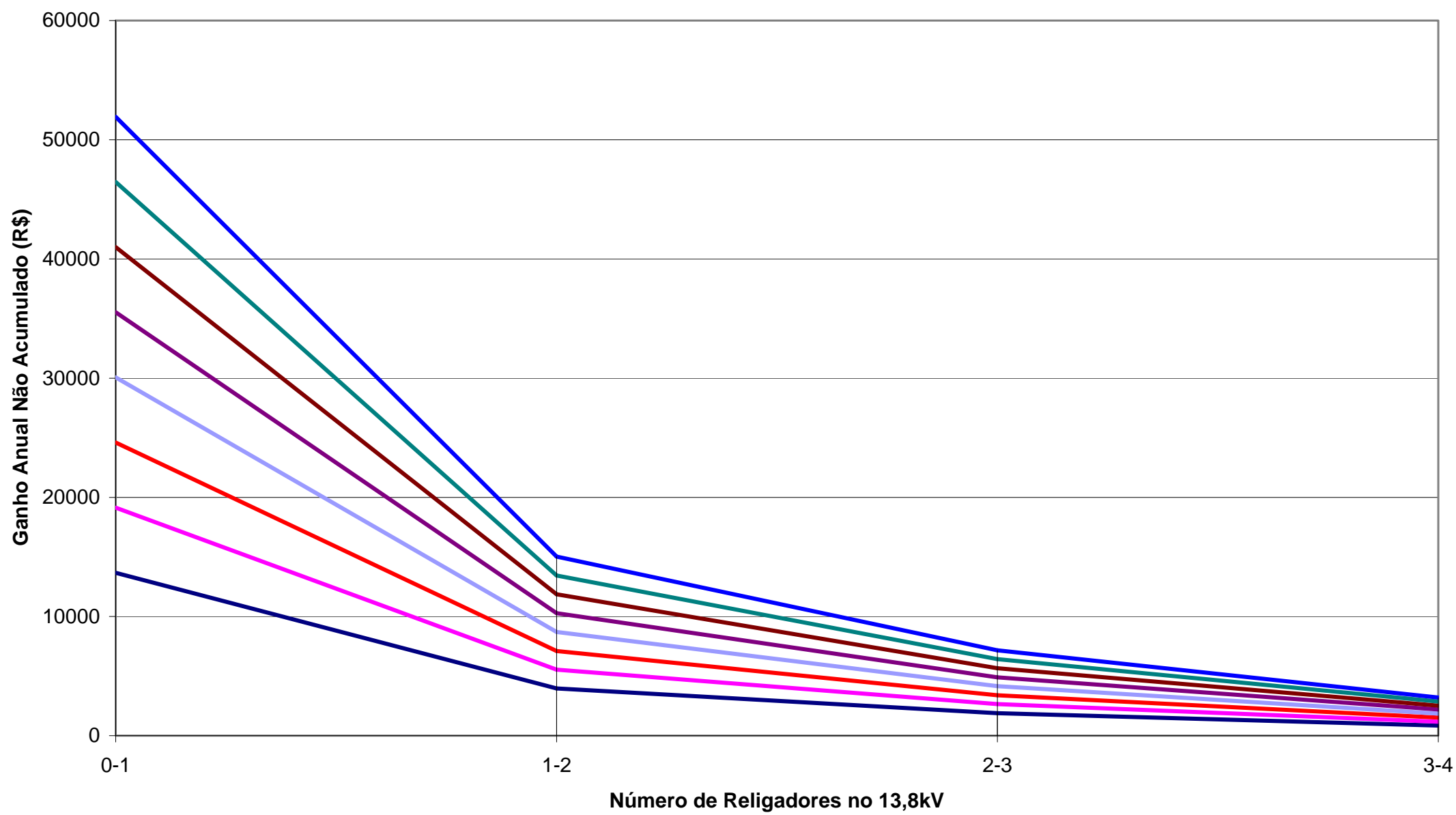

Taxa de Falha $=1$ Taxa de Falha $=1,4$ Taxa de Falha $=1,8$ Taxa de Falha $=2,2$ Taxa de Falha $=2,6$

-Taxa de Falha $=3$ Taxa de Falha $=3,4$-Taxa de Falha $=3,8$

FIGURA 5.11 - Ganho anual não acumulado (incremental) das alternativas no primeiro ano 
Através da análise dos resultados apresentados nas tabelas 5.16 e 5.17 e dos gráficos das figuras 5.10 e 5.11, em especial dos resultados derivados de análise dos ganhos incrementais e dos tempos de retornos de investimentos incrementais pode-se observar que, para taxas de falhas mais próximas a estimada da região em estudo (3,4 def./km/ano) a alternativa de implementação de 2 religadores "NF" no circuito mostra-se como a melhor alternativa de custo/benefício. Esta alternativa corresponde a alternativa RA-04 exposta no capítulo 4 deste trabalho.

Nota-se que, se optando por instalar o $3^{\circ}$ religador no circuito, o ganho incremental proporcionado, considerando taxa de crescimento de carga de 5\% ao ano, só permite um retorno dos $\mathrm{R} \$ 30.000,00$ investidos em aproximadamente 9 anos. Tendo em vista as possíveis futuras melhorias da manutenção dos circuitos da região, que poderiam acarretar uma queda da taxa de falhas, conclui-se que o ganho na instalação deste religador poderá ser inferior ao estimado, resultando em um período de retorno de investimento muito longo.

Desta maneira, conclui-se que: devem instalados dois religadores "NF" no fim dos blocos 6 e 17 do circuito X2 (figura 5.12), para otimizar o desempenho desse circuito na ocorrência de defeitos.

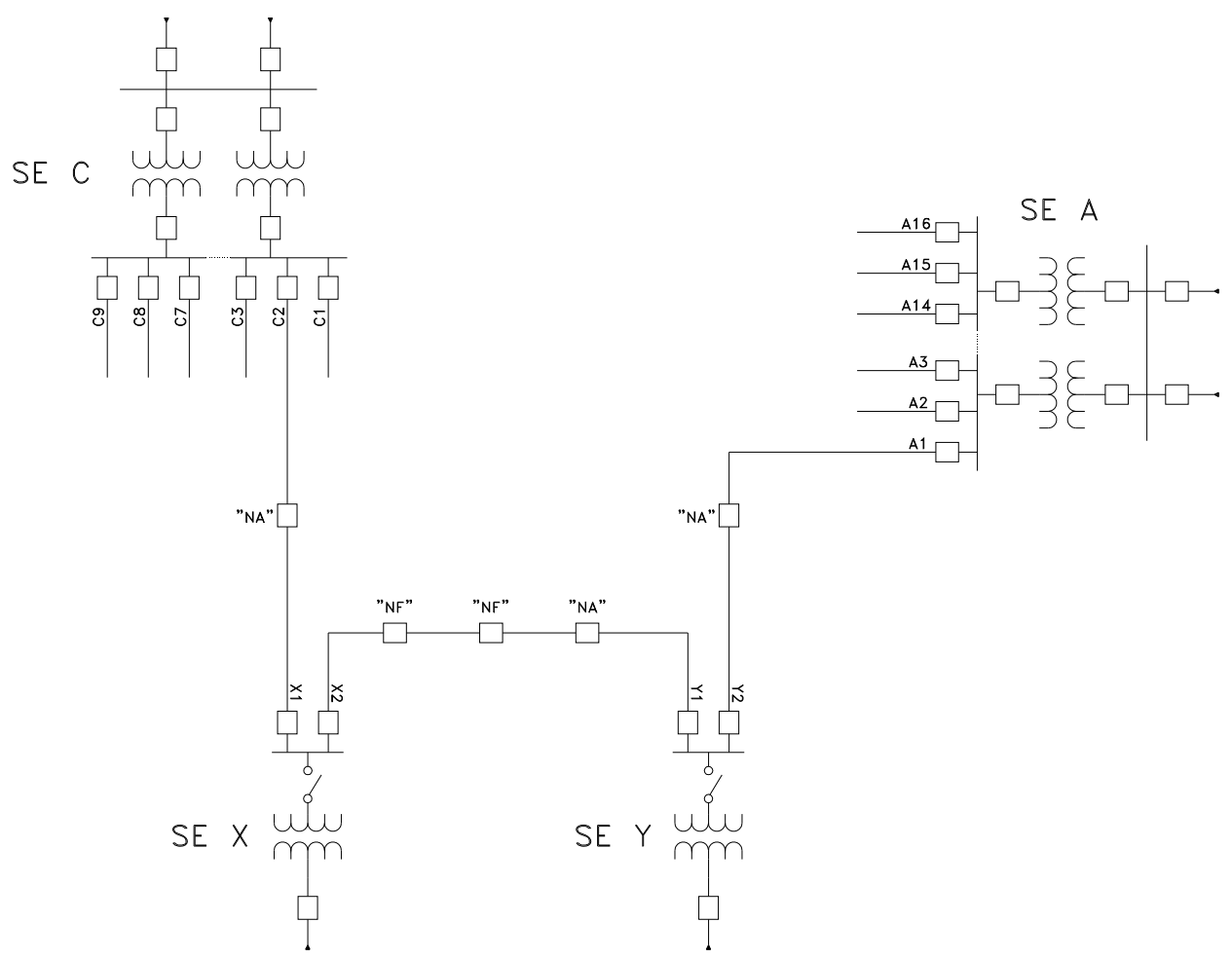

FIGURA 5.12 - Diagrama unifilar da alternativa escolhida para alocação dos religadores 


\section{CONCLUSÃO}

O modelo proposto para Planejamento de Sistemas de Distribuição utilizando recursos de automação representa uma inovação face ao processo convencional, na medida que introduz uma dimensão adicional na avaliação das alternativas de aumento da oferta de energia em um sistema de distribuição.

Essa nova dimensão consiste na integração de instrumentos para otimização da reserva de capacidade de suportar contingências no processo de planejamento, bem como na consideração dos diferentes níveis de sensibilidade da carga em face de interrupção de fornecimento.

A metodologia proposta prevê o estabelecimento de "conjuntos" de automação que incluem equipamentos de chaveamento e lógicas de operação que podem ser instalados na rede, constituindo alternativas de reforços para o sistema.

A avaliação das alternativas é fundamentada não só no custo dos equipamentos mas também nos diferentes custos da energia não distribuída, associados aos diferentes tipos de consumidores afetados, resultantes das interrupções.

A pesquisa desenvolvida nesta dissertação oferece uma importante contribuição para o planejamento de sistemas de distribuição, por meio de alternativa ao critério convencional "N-1", que não raro acarreta sobre-investimentos alocando capacidades de reserva pontuais não otimizadas, além de tratar todas as cargas com o mesmo nível de sensibilidade.

A aplicação da metodologia num estudo de caso ilustrou a efetividade da proposta. 


\section{PROSSEGUIMENTO DOS ESTUDOS}

Durante o desenvolvimento desta pesquisa foram identificados alguns temas que, por estarem a margem do foco deste trabalho, não foram pesquisados com profundidade, mas que merecem atenção em estudos posteriores. Dentre esses, estão o desenvolvimento de:

- instrumentos de apoio à alocação dos recursos de automação, considerando a existência de infra-estrutura de comunicação;

- ferramentas para avaliação das instalações para supervisão das operações de medição e telecomando, que poderia onerar a aplicação de recursos de automação no planejamento, como a necessidade de digitalizar subestações e coordenar a proteção;

- análise de riscos associados à adoção dos recursos de automação ao invés de ampliar as instalações estruturais do sistema;

- métodos de otimização do planejamento de aumento da oferta de energia em sistemas distribuição, utilizando técnicas como: algoritmos genéticos e programação dinâmica, quando há a alternativa da utilização de recursos de automação;

- metodologia para avaliação da sensibilidade da carga, em função do uso final. 


\section{BIBLIOGRAFIA}

[1] ANEEL. PRODIST - Módulo2 - Planejamento da Expansão do Sistema de Distribuição, Rev. 1, Brasília, SRD, 2006, 26 p.

[2] KHATOR, S. K. e LEUNG, L. C. Power Distribution Planning: A Review of Models and Issues, IEEE Transactions on Power Systems, Vol. 12, No. 3, Agosto 1997;

[3] FANNING, R. Distribution vision 2010: planning for automation, Power Systems Conference and Exposition, 2004. IEEE PES, Vol. 3, p.1692-1693, Outubro 2004;

[4] GARDNER, E. Distribution automation today: separating tools from toys, Rural Electric Power Conference IEEE, Kansas City - EUA, p. B2/1-B2/16, Abril 1993;

[5] Dolezilek, D. J., Power System Automation, Schweitzer Engineering Laboratories 2000, Pullman, Washington. [Online] http://www.selinc.com/techpprs/6091.pdf

[6] ROTH, P. D., Communications architeture in modern distribution systems, CIRED2001, Jun. 2001;

[7] ZIMMERMAN, K. e COLLUM, M., Implementing distribution automation and protection, Schweitzer Engineering Laboratories 2003, Pullman, Washington. [Online] http://www.selinc.com/techpprs/6151.pdf;

[8] HART, D. G. et al., Automated solutions for distribution feeders, IEEE Computer Applications in Power, 2000;

[9] HUBER, R., Advanced distribution automation: a strategy for improved reliability, The Line, Abr. 2005; 
[10] GOMES P., SCHILLING M. Th., Custo de Interrupção: Conceituação, metodologia de avaliação, valores existentes e aplicações, XIV SNPTEE, Belém-PA, 1997.

[11] MAgAlhÃES C. H. N., GOUVÊA M. R., SilVA F. A. T., TAHAN C. M. V., ARAÚJO FILHO L. G. C., Avaliação do custo social de interrupção do fornecimento de energia elétrica do lado da demanda no estado de São Paulo, XVI SNPTEE, Campinas-SP, Outubro 2001.

[12] TOLLEFSON, G. et al., A Canadian customer survey to assess power system reliability worth, IEEE Trans. on Power Systems, Fev. 1994;

[13] MASSAUD, A. G. et al., Electricity restriction costs, IEE Proceedings Generation, Transmission and Distribution, Vol. 141, №4, 1994, página(s): 299-304;

[14] BILLINTON, R., Economic cost of non-supply, IEEE Power Engineering Society Winter Meeting, vol.2, 2002, página(s): .959-962.

[15] SAMDAL, K. et al., Customers' interruption costs - what's the problem ?, CIRED, Maio 2003;

[16] BERTAZZI, A., LO SCHIAVO, L., FUMAGALLI, E., O custo das faltas de energia para o consumidor, Eletricidade Moderna (tradução de artigo originalmente publicado no CIRED 2005), Agosto 2006;

[17] SOUTHERLIN, S. R., New distribution automation switchgear and its contribution to overhead distribution reliability, CIRED 97, Jun. 1997;

[18] LIU, H. et al., New triple single reclosers improve distribution reliability, IEEE Rural Electric Power Conference, 2001, página(s) D2/1-D2/6. 
[19] $\mathrm{CHO} J \mathrm{R}, \mathrm{N}$. e HA, B., The results of the field test in distribution automation system for Korea utility, IEEE Power System Technology, 1998.

[20] JACKSON, R. E. e WALTON, C. M., A case study of extensive MV automation in London, CIRED, Maio 2003;

[21] CHEN, R. L. e SABIR, S., The benefits of implementing distribution automation in open eletricity market, Canadian Conference on Electrical and Computer Engineering, 2001;

[22] LETHONEN, M. e KUPARI, S., A method for cost benefit analysis of distribution automation, IEEE International Conference on Energy Management and Power Delivery, Vol.1, 1995, página(s): 49-54.

[23] ANEEL. Resolução N505, Brasília, Nov 2001, 14 p.

[24] HE Y., SODER L., ALLAN R. N., Distribution Automation: Impact of Communication System on Reliability of Automatic Control, IEEE Porto Power Tech Conference, Porto - Portugal, Setembro, 2001.

[25] SPERANDIO M., COELHO J., RAMOS R., Prospecção de Sistemas de Distribuição de Energia Elétrica Automatizados, Uma Visão Estratégica, VI SIMPASE - Simpósio de Automação e Sistemas Elétricos, São Paulo - SP, Agosto,2005.

[26] GARDIMAN V. L. G., PIRES NETO F. M., RUFINI R., Sistema de Telecomando e Monitoramento de Religadoras Automáticas da Rede de MT Via Comunicação Celular - STMRA, IVCIERTEC - Seminário Internacional sobre Automação de Redes de Distribuição de Energia Elétrica e Centros de Controle, São Paulo - SP, Setembro, 2002.

[27] PIMENTEL P. R. DE S., BALDISSIN NETO A., CÉSAR L. S., FRAMIL R. R., Revolução na Distribuição (Uso da tecnologia Power Line Carrier na 
Automação dos Sistemas Elétricos), VI SIMPASE - Simpósio de Automação e Sistemas Elétricos, São Paulo - SP, Agosto,2005.

[28] RODRIGUES J.R.M., Primeira Subestação em Funcionamento com IEC 61850, VI SIMPASE - Simpósio de Automação e Sistemas Elétricos, São Paulo - SP, Agosto,2005.

[29] BILLINTON, R., JONNAVITHULA, S., Optimal Switching Device Placement in Radial Distribution Systems, IEEE Transactions on Power Systems, Vol. 11, No 3, 1996. Página(s): 1646-1651.

[30] CELLI, G., PILO, F. Optimal Sectionalizing Switches Allocation in Distribution Networks, IEEE Transactions on Power Systems, Vol. 14, No 3, 1999. Página(s): 1167-1172.

[31] KAGAN N., OliVEIRA, C. C. B., SCHMidT, H. P., KAGAN, H. Métodos de Otimização Aplicados a Sistemas Elétricos de Potência, 1. ed. São Paulo: Edição dos Autores, 2005. v. 1. 200 p.

[32] KAGAN N. Planejamento de Sistemas de Distribuição de Energia Elétrica Material de disciplina ministrada no curso de pós-graduação do Departamento da Engenharia de Energia e Automação da Escola Politécnica da USP, São Paulo - SP, 2005 


\section{ANEXO A}

Enumeração dos blocos de carga dos alimentadores envolvidos 
A1

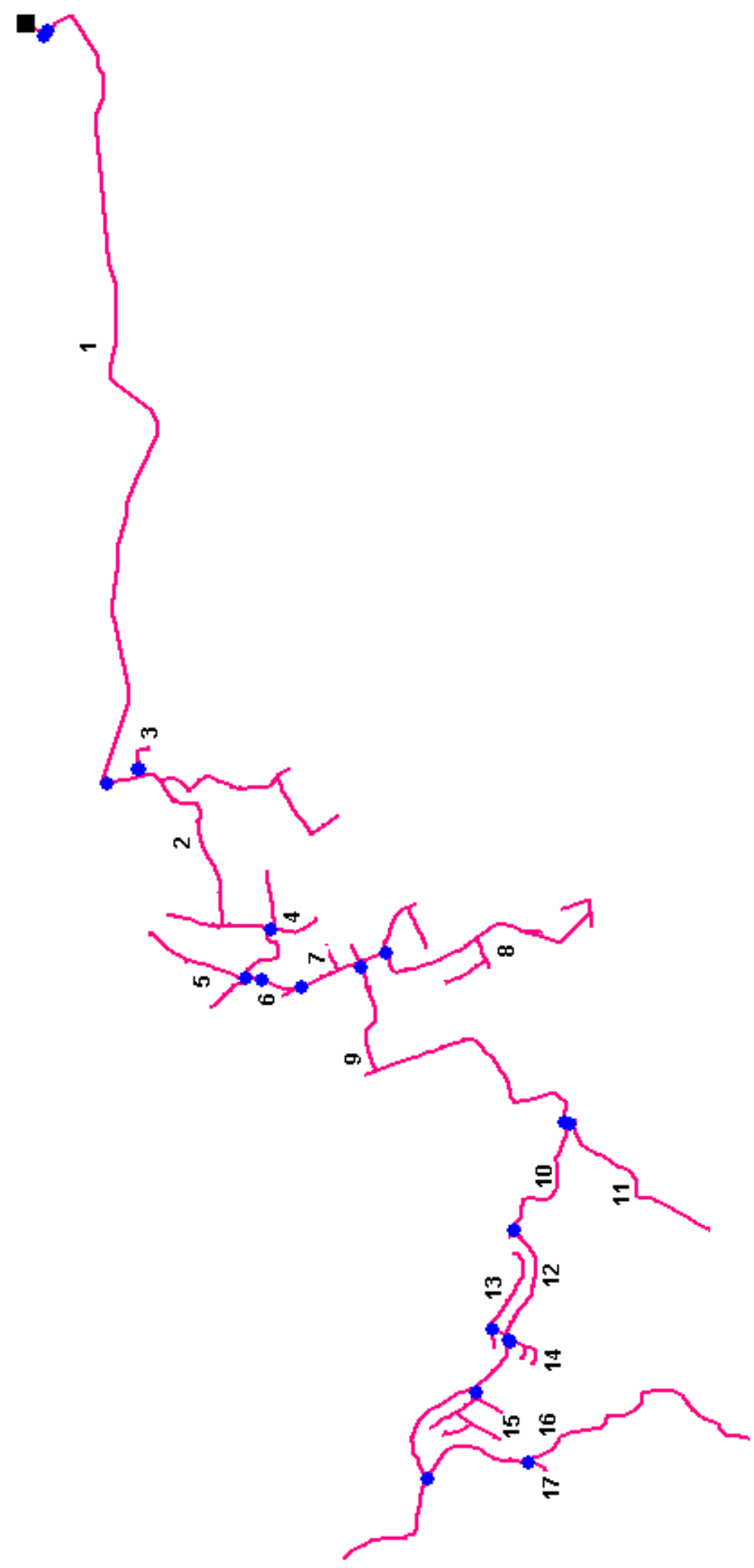


A2

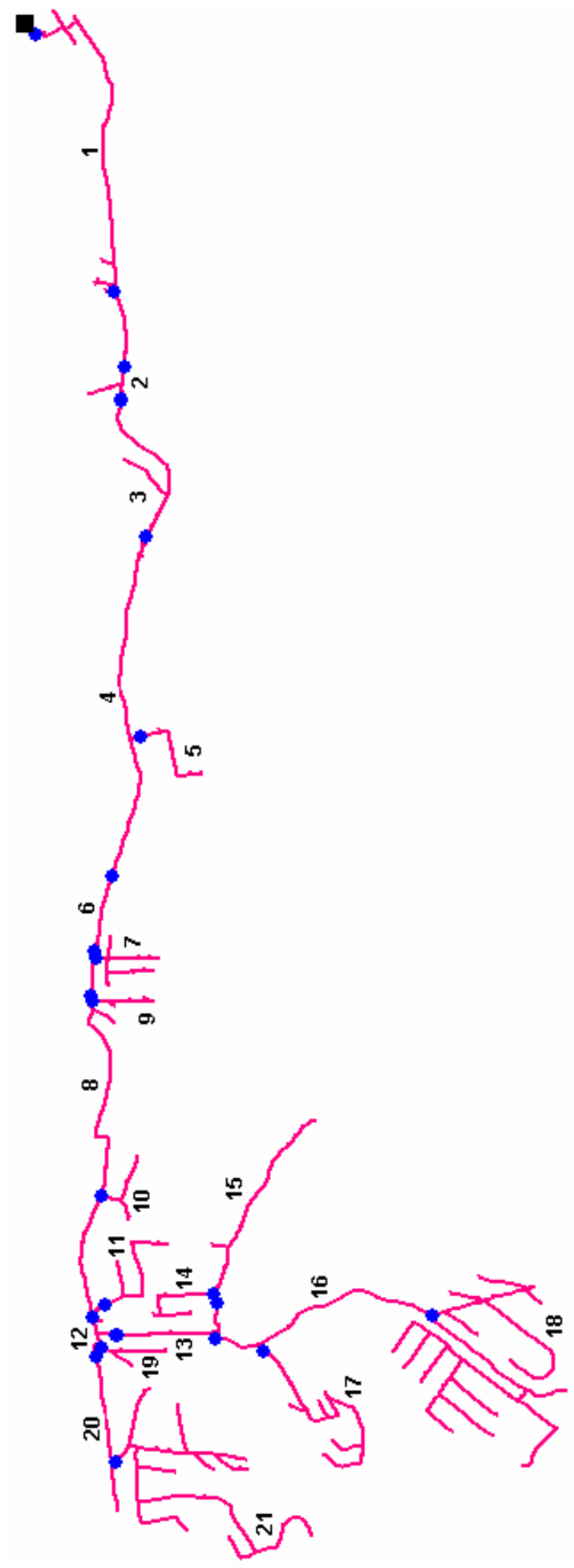


B1

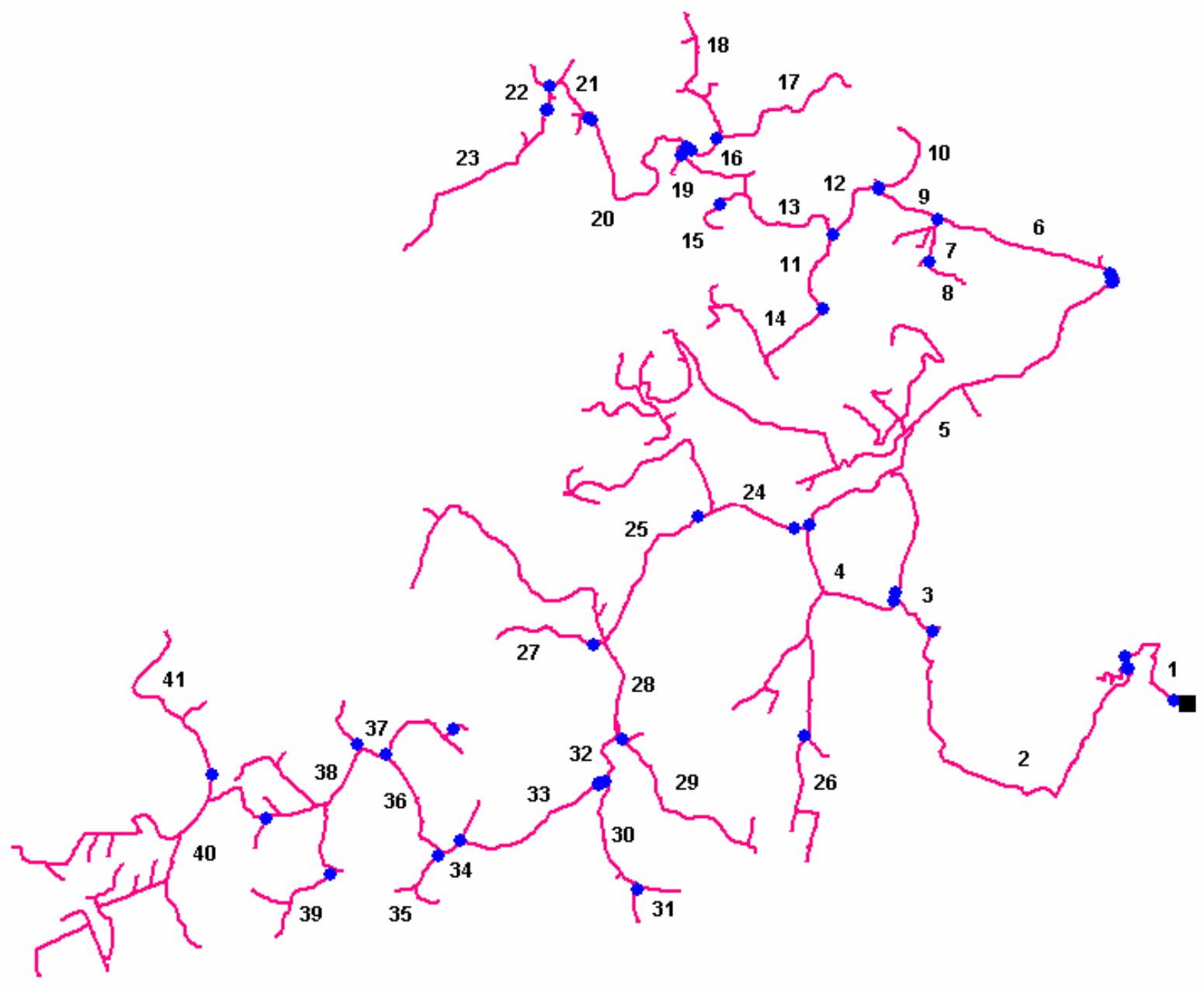


C1

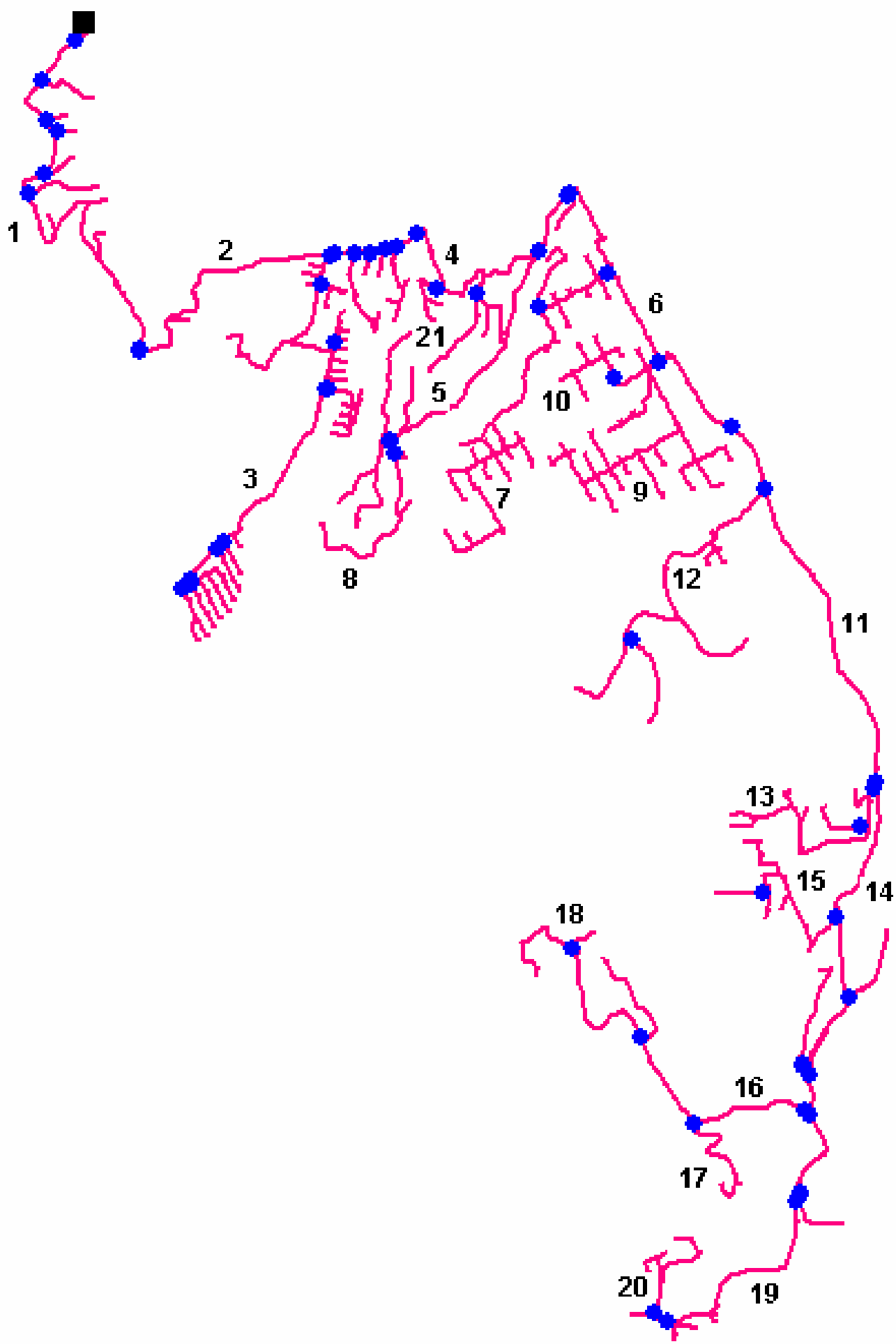




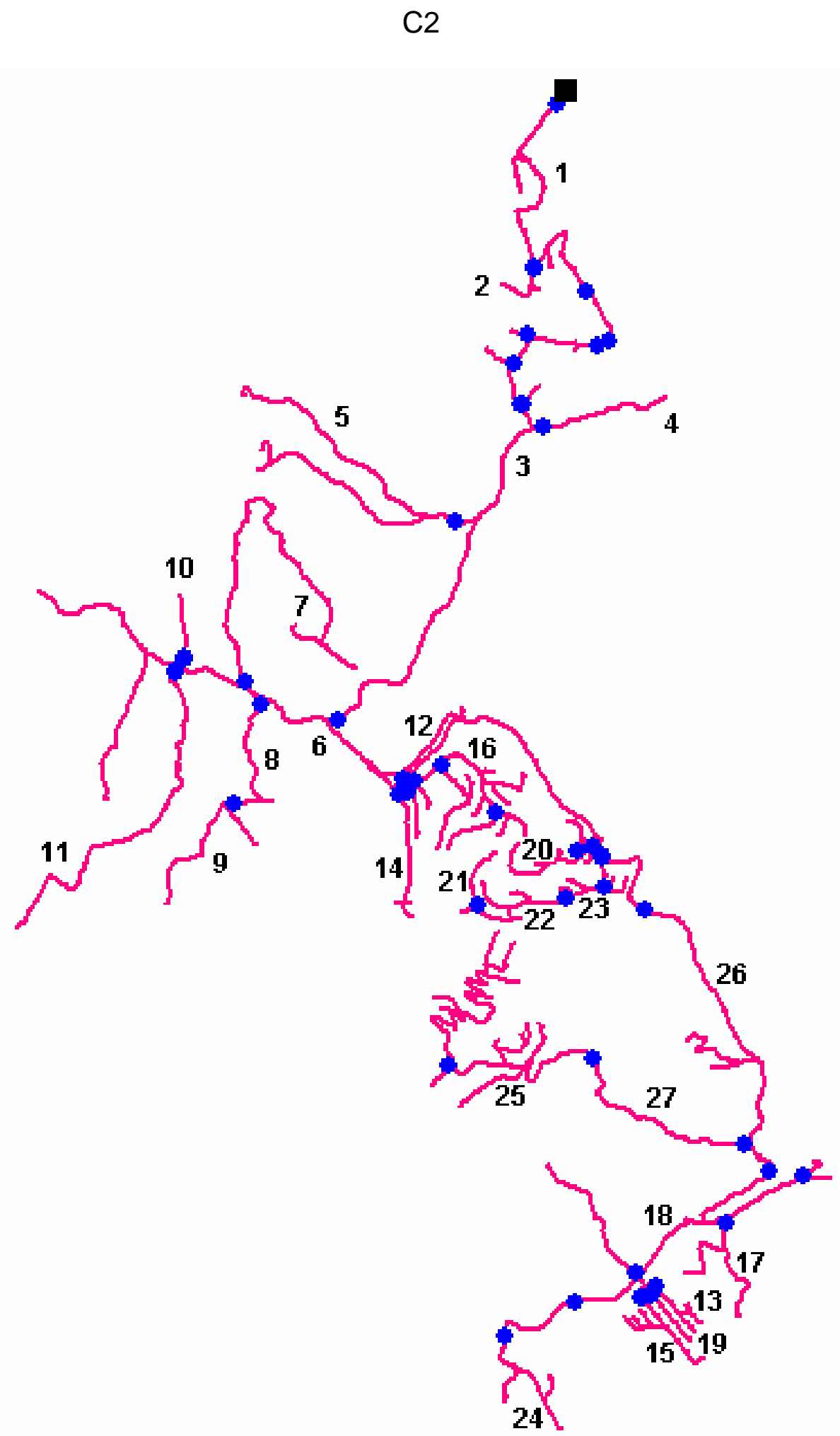




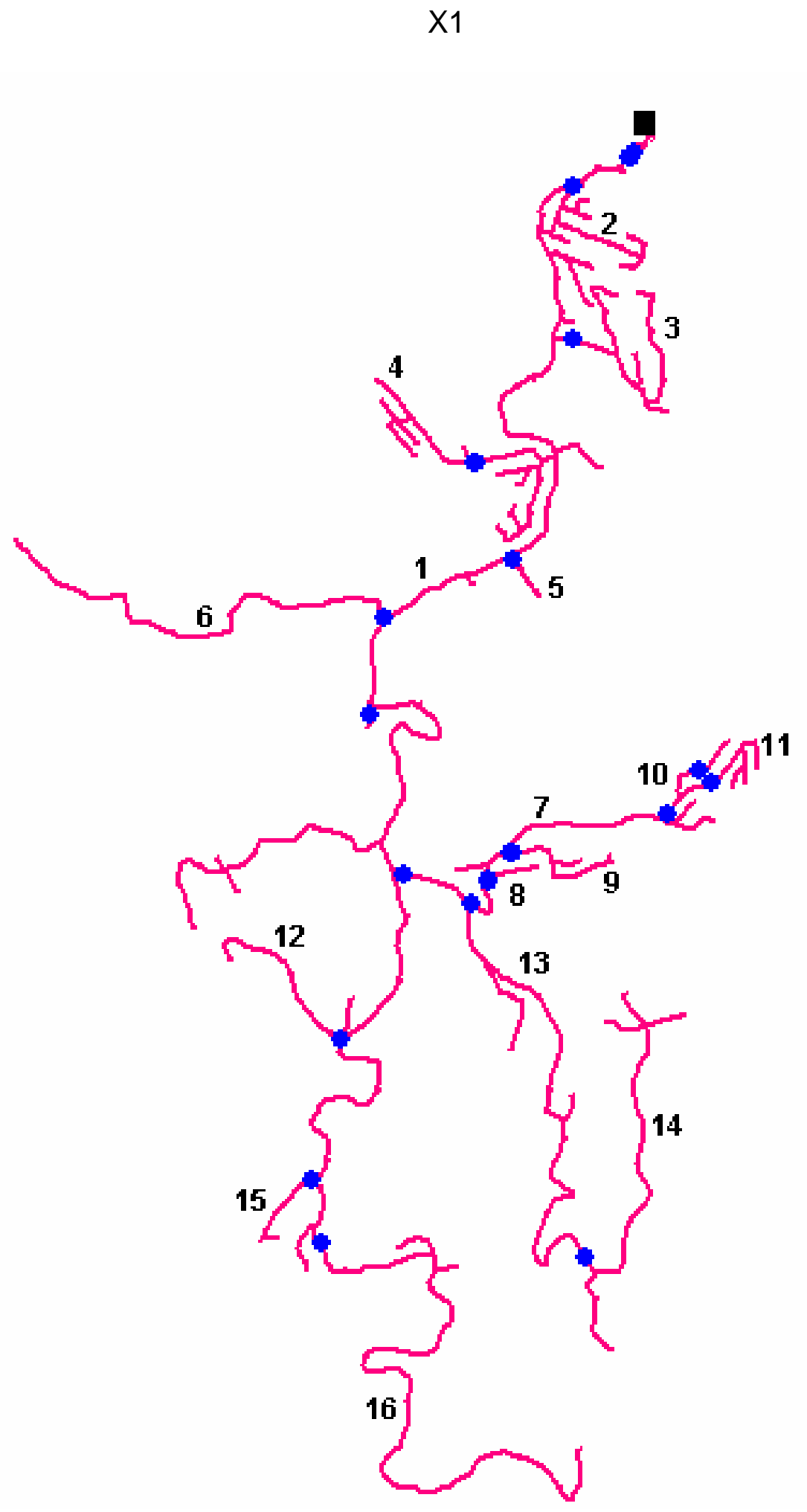




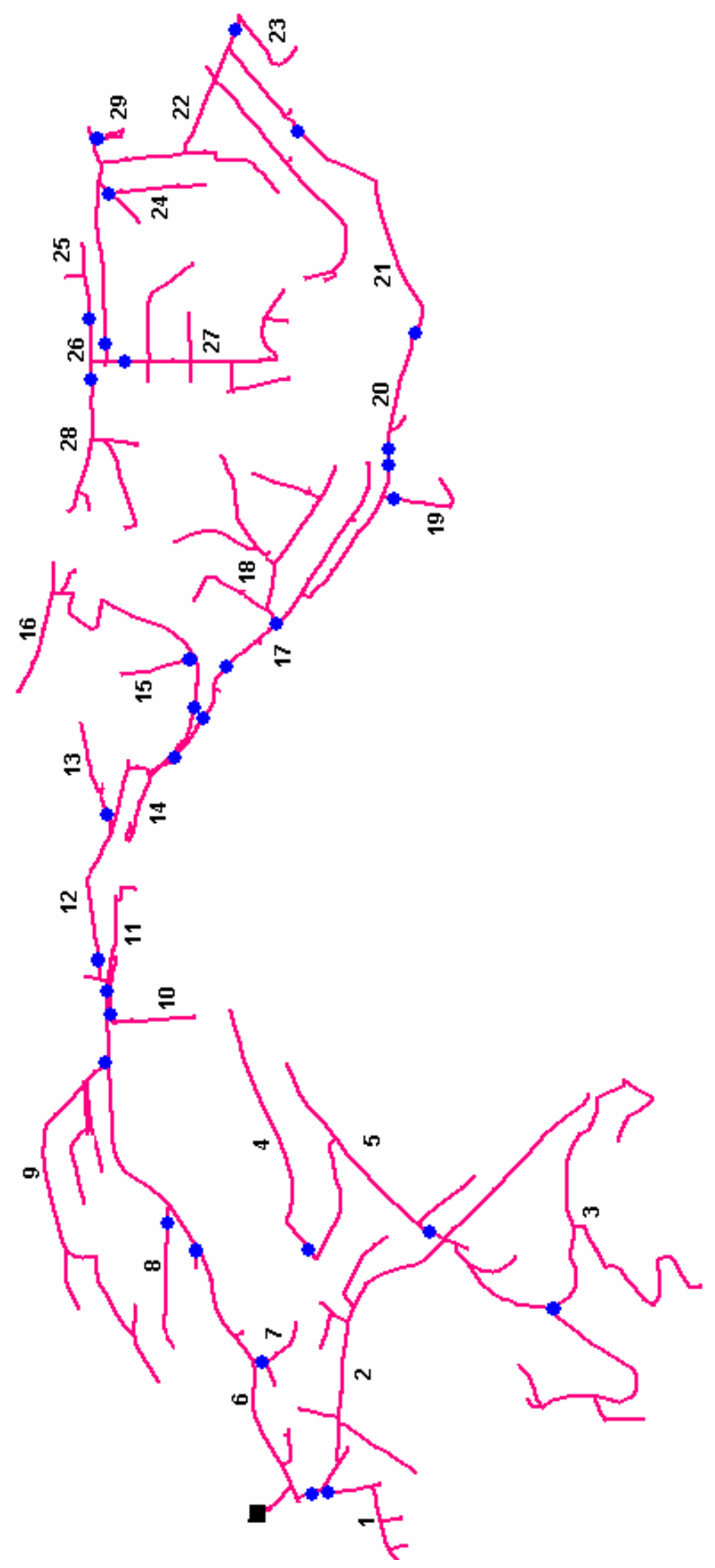


Y1

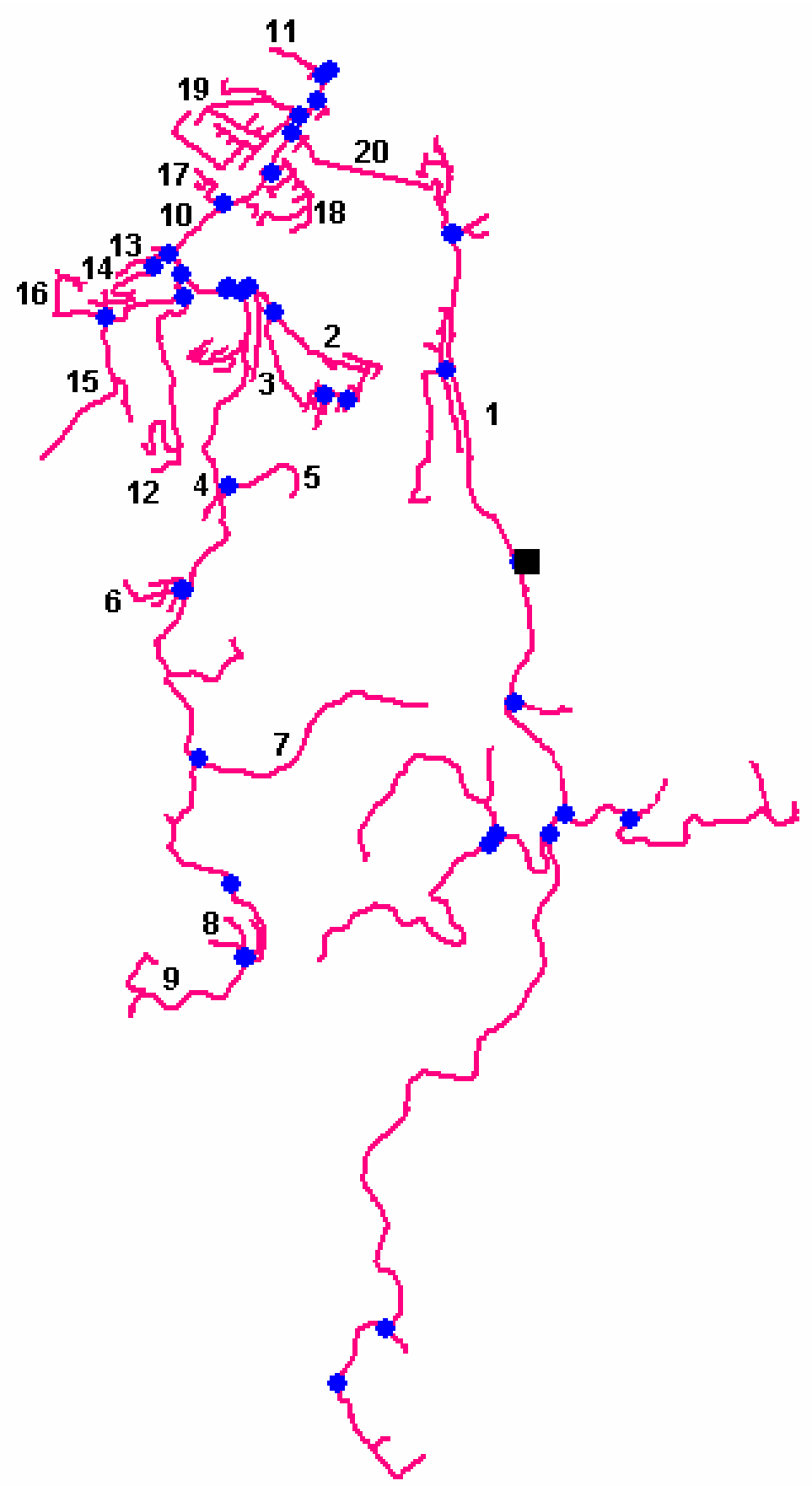




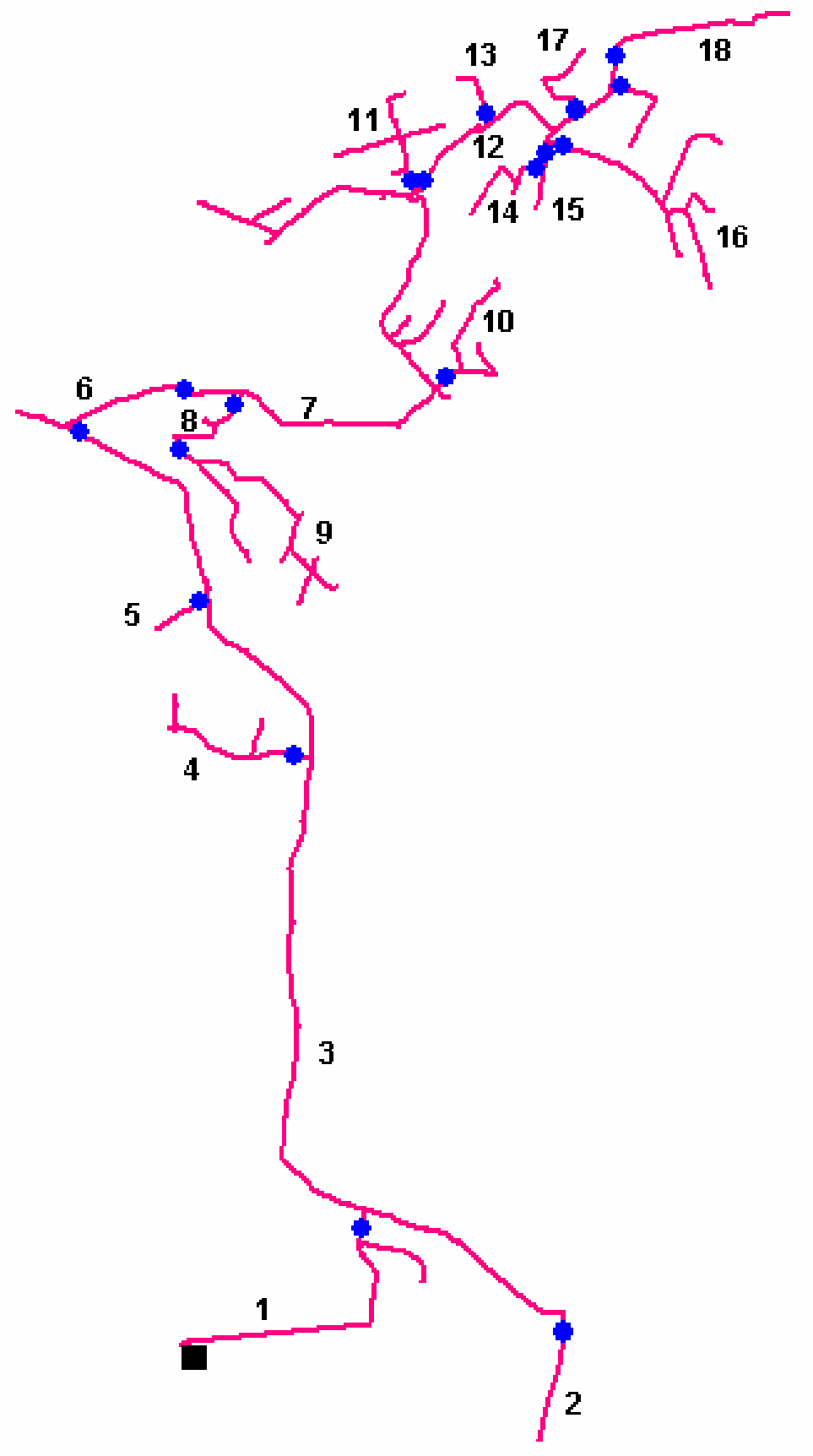

